\title{
Temporalsemantische Dynamisierungen: Zur Korrelation von Regression und Progression
}

\subsection{Welt und Subjekt: Die regressiv-progressive Verschränkungsstruktur in Ottos Die Lehnspflichtigen}

\section{Hintergründe: Orientierungslinien zur Erfassung von Regression und Progression}

Die Forschung zu unserem Gegenstandsfeld spricht immer wieder von einer »Auflösung der Romantik « (Schmidt 1853: 434) oder von einer >Fortwirkung der Romantik< (vgl. Kluckhohn 1928), von >Metamorphosen der Romantik< (vgl. Hauser 1953) und von einer >Romantik im Vormärzく (vgl. Dedner/Hoftstaetter 1992). Derartige Zuschreibungen laufen auf eine zentrale Annahme hinaus: »Die Romantik wird fortgesetzt und gleichzeitig verwandelt, umgedeutet." (Hauser 1953: 257). ${ }^{1}$ Klar sollte sein, dass ein Epochenwechsel prozessual und nicht durch abrupte Verschiebungen verläuft. Und lassen wir dabei auch den aus literaturhistoriografischer Sicht berechtigten Einwand außer Acht, dass diese Problematik bei Abnahme einer Dominanz des einen Systems und Dominanzzunahme eines anderen in der Geschichte der Literatur wohl immer mehr oder minder deutlich auszumachen ist, so hat sich unsere Auseinandersetzung doch der Frage zu stellen, wie dies konkret bei der Zwischenphase aussieht, wie sich zugleich goethezeitlichromantische Elemente und nichtgoethezeitlich/postromantische Elemente in Texten wiederfinden lassen, diese sich gegenseitig beeinflussen und auf welche Weise durch sie Bedeutung aufgebaut wird. Denn klar sollte bis hierher auch geworden sein, dass Überlagerungen dieser Art ein zeitreflexives Moment erzeugen: Traditionell-epigonale und neuartige Elemente halten sich anscheinend die Waage

${ }^{1}$ Vgl. dazu ausführlicher Martini (1991: 358). 
(vgl. Erhart 2008: 135), ziehen aber Effekte nach sich, die in Textwelten entsprechenden Niederschlag finden - die Aktivierung des Zeiterlebens, das >Zeitwissen<, ein »Leiden an der Gegenwart« (ebd.: 142), das »Gefühl der Leere« (Hess 1997: 22) - und die mittels Bändigung, Beherrschung und Reorganisation von Zeit behoben werden wollen. Dabei gilt zu beachten, dass beileibe nicht alle Texte tatsächlich Zeichenarsenale der Goethezeit (im Allgemeinen) oder der Romantik (im Besonderen) abrufen, weitaus mehr Texte allerdings durchaus die Orientierung an der Vergangenheit als bedeutungstragendes Element einsetzen.

Stets liefen unsere Überlegungen darauf hinaus, das Verhältnis von Welt und Figur einzubeziehen, sei es bei der Betrachtung der Entwicklungsstufen des Subjekts, sei es bei den Ausführungen zur Temporalsemantik, bei der Differenzierung von Formen der Reduktion und der Erfassung der >Tendenz zur Mitte< oder auch bei der Bestimmung der zeitreflexiven Funktionalisierung von Liebe. Wenn man sich angesichts dieser Lage fragt, wie das Verhältnis zwischen beiden Strukturmengen in unserem Zeitabschnitt spezifiziert werden könnte, stößt man unweigerlich auf die Begriffe >Weltschmerz $<$ und >Zerrissenheit $<-$ die die eigentliche Problematik zwar nur anzudeuten vermögen und dennoch von zentraler Bedeutung sind. Denn: Eine Krise der Gegenwart impliziert ein Leiden an der Welt und hat >Zerrissenheit< als Teil der Personen-Konzeption zur Folge. An prominenter Stelle etwa spricht Sengle mit Blick auf die Biedermeierzeit von »dämonische[r] Zerrissenheit und sentimentale[m] Weltschmerz« (Sengle 1971: 2): »Die Melancholie ist zunächst überall rein empirisch festzustellen, bei Rückert und Raimund, so gut wie bei Heine, Grabbe und Büchner, und nicht nur bei den Dichtern persönlich, sondern auch bei den Gestalten, die sie darstellen.« (Ebd.) Allein bleibt dabei der letzte Zusatz eine unbegründete Mutmaßung Sengles. Zwar deutet er eine entsprechende Blickrichtung auf Texte (wie Immermanns Die Epigonen) an, führt diese aber stets auf die Perspektive des jeweiligen Autors zurück. Sengle spricht über die Verfasser, nicht über Texte, nicht über die in ihnen modellierten Welten und Figuren. So ist auch sein Kapitel zum »Weltschmerz in der Tragödie « von einem deutlichen Hang zur Autorpsychologisierung geprägt und darin folgerichtig von »Weltschmerzpoeten« (Sengle 1972: 350) die Rede. Die Dramen bringen, so Sengle, »ganz deutlich zum Ausdruck, was die Verfasser [...] damals oft fühlten und dachten, ohne es sich einzugestehen« (ebd.). Wir sollten doch in Reaktion auf derartige Äußerungen meinen, dass die Literaturwissenschaft gut daran tut, sich mit ihrem eigenen Gegenstand zu beschäftigen, und sich nicht dazu verleiten lassen sollte, pseudopsychologische Diagnosen zu erstellen zumal diese für ihren Gegenstand nur bedingt von Relevanz sind. Dieser Einsicht folgend sind die Termini, um die es sich auch bei Sengle dreht, in der neueren Forschung durch die Arbeit an konkreten Texterscheinungen aufgearbeitet sowie 
auf ihre Variabilität und Komplexität hin geprüft worden (vgl. Begemann 1990; Rinsum/Rinsum 1992: 41 ff.; Lukas 1998a: 391 u. Landshuter 2007: 92-96).

Zielführend an dieser Stelle ist die Annahme, dass sich insgesamt nicht nur die Relationierung von Subjekt und Welt erahnen lässt, die für unseren Kontext wohl ausschlaggebend ist, sondern damit verbunden auch eine Negativ-Wertung in Form einer für das Subjekt unbefriedigenden Zustandswahrnehmung, die gleichfalls im Hinblick auf das Literatursystem nicht gänzlich unbegründet ist. Weltschmerz und Zerrissenheit - das wären dann Resultate eines Ungleichgewichts zwischen der Erwartung des Subjekts einerseits und den sich bietenden Möglichkeiten, der Potenzialität von >Welt< andererseits - und dies mit psychopathologischer Konsequenz. Entsprechende Effekte sind das Auftreten zunehmend neurotischer Figuren (vgl. Lukas 1996 u. Wünsch 1997), vornehmlich aber - und grundlegender - das Nachdenken über Zeit und Zeitlichkeit auf Figuren- und Textebene. Und genau dem wäre hier nachzugehen.

Nun lässt sich angesichts der bisherigen Ergebnisse weiter annehmen, dass Darstellung und Wahrnehmung der Relationierung zwischen Personen-Konzept und Welt zeitreflexiv fundiert ist, und ferner, dass die mit dem Modell der Initiationsgeschichte verbundenen Vorstellungen literarisch nur noch provisorisch aufrechterhalten werden, wenn sie nicht gar gänzlich aufgegebenen werden und das Modell zur Normalisierung von Subjekten funktionalisiert ${ }^{2}$ und damit einem anderen Zweck zugeführt wird als noch in der Goethezeit. Das Erzählmodell ist in eine instabile Lage geraten. Wir möchten den Blick daher im Folgenden ausweiten und auf die Modellierung von >Welten< insgesamt lenken: vorzugsweise auf die Dynamisierung der Leitdifferenz Alt vs. Jung/Neu, die wir um die Begriffe >Progression< und >Regression< erweitern.

Wenn im Folgenden der Komplex miteinander verkoppelter Strukturen - der $>$ Regression $<$ und der >Progression $<-$ als epochenspezifische Merkmalsmenge zu bestimmen versucht und zu diesem Zweck differenzierend aufgefächert wird, so geschieht dies unter Berücksichtigung der folgenden Orientierungslinien:

(1) Hypothese ist, dass Texte zwei Strukturmengen - daher auch in einfacher Anführung: >Regression $<$ und >Progression $<-$ aufbauen, die mit der Leitdifferenz Alt vs. Jung/Neu im Zusammenhang stehen. Diese Strukturen implizieren zusätzlich - dies ein weiterer Gesichtspunkt - Transformationsmuster, die

\footnotetext{
${ }^{2}$ Zum Anteil der Normalität an der Bifurkation Romantik vs. Zwischenphase vgl. grundsätz-
} lich Link 2002. 
die Richtung vorsehen, entstehende Konflikte mit Hilfe einer Neumodellierung von Vergangenheit (>Regression<) oder aber der Tilgung möglichst aller Merkmale von $>$ Vergangenheit $<$ zu harmonisieren ( $>$ Progression $<$ ).

(2) Wichtig ist dabei der Konflikt, den wir auf ein zeitreflexives Strukturcluster bestehend aus >Regression< und >Progression< zurückbeziehen. Wenn $>$ Regression< - als Wunsch oder Vollzug - eines der zentralen Themen ist (vgl. Lukas 2001: 67), dann gilt es zu untersuchen, wie Texte - die eben $>$ Regression< nicht umstandslos als wünschenswert ausstellen - mit ihr umgehen und welche Rolle dabei progressiven Strukturen zukommt. Die Orientierung an der > Vergangenheit< wird gemäß unserem Basiskonzept zugleich als dominant und problematisch semantisiert, die fiktionsinterne Kontextualisierung mit gegenläufigen Tendenzen konfrontiert und damit Zeitreflexion evoziert. $>$ Regression< und >Progression< sind reziprok korreliert und bedingen sich gegenseitig.

(3) Semiotisiert werden diese Strukturen in Komponenten der dargestellten Welt, insbesondere in Figuren, sie lassen sich aber ebenfalls auf der Textoberfächenstruktur - im Erzählen - nachweisen (vgl. Decker 2005b; Lukas 2001). Für Textwelten ist die korrelative Verschränkung von anthropologischindividueller Ontogenese und historisch-kultureller Phylogenese bedeutsam, für Strukturen des discours die Integration lyrischer Textsegmente und die narrative Retrospektive.

(4) Zeitreflexive Texte kombinieren Zeitmodelle der Zirkularität und der Linearität oder denken deren Kombination zumindest an. Wenn sie die eigens modellierte Vergangenheit in der Zukunft zu reinstallieren anzeigen, verfahren sie zirkulär - sie betten dies aber ein in ein fortschreitendes, linear-temporales und progressiv-modernisierendes Modell von Zeit: Dargestellte Welten (unseres Textkorpus) sind stets Veränderungen (unter anderem sozialer, kultureller, wirtschaftlicher, technologischer Art) unterworfen und präsupponieren geschichtlichen Fortschritt, denen sie sich nicht entziehen können, und machen demgegenüber bestimmte (und markierte) Teilmengen geltend, die vergangene Zustände wiederherzustellen oder zu bewahren anstreben. 


\section{Regression und Progression in Ottos Die Lehnspflichtigen}

Nehmen wir ein Beispiel zur Hand, um die Grundzüge der genannten Linien exemplarisch aufzuzeigen. Luise Ottos Die Lehnspflichtigen ist ein Text, ${ }^{3}$ der beides instruktiv veranschaulicht: das wichtige Verhältnis von $>$ Welt $<$ und $>$ Person< wie auch die strukturelle Verzahnung von >Regression< und >Progression $<$. Eine Grafschaft im (fiktiven) westfälischen Schwarzwald steht im Zeichen der Auflehnung der Bauern gegen ihre Obrigkeit. Helene aufseiten der Grafschaft und August aufseiten der Untertanen versuchen zu vermitteln, besinnen sich auf ihre Liebe und werden im Eifer des Gefechts unwissentlich von Helenes Vater erschossen. Am Ende vollzieht die dargestellte Welt einen moderat-liberalen Systemwechsel.

Zwei Probleme sind ausschlaggebend: zum einen die zwecks Fortführung des gräflichen Geschlechts arrangierte Heirat Helenes mit einem Verwandten, die die Eltern ohne ein Mitspracherecht der Tochter ansetzen und die in Konflikt zu geraten droht mit ihrer Liebesbeziehung zu August; zum anderen die soziale Spannung zwischen dem Grafen und der Bevölkerung, die zunächst verbalkommunikativ gelöst werden soll, dann jedoch schließlich in einen gewaltsamen Konflikt umschlägt, bevor der Graf letztlich doch Zugeständnisse gegenüber dem Landvolk macht. Die Grundordnung des Textes ist demnach in zwei Hinsichten durch unsere Leitdifferenz geprägt: Die eine Seite möchte Altes bewahren, die andere das alte Reglement durch ein neues ersetzen; die eine Seite tendiert zur endogamen Eheschließung (zwecks Bewahrung des >alten< Adelsgeschlechts), die andere hingegen strebt eine Ständegrenzen übergreifende Liebe an und versucht damit einen familienunabhängigen und von der Tradition losgelösten Weg einzuschlagen.

Temporal situiert ist das Geschehen im Frühling, und diese Situierung selbst ist natürlich insofern bedeutungstragend, als die im Jahreszyklus als >Neubeginn semantisierte Jahreszeit hier zugleich auch den >Neubeginn von Welt< indiziert, »denn es sollte Frühling werden, Frühling sein und bleiben überall im deutschen Lande« (Otto 1982 [1849]: 251). Semantisch spezifiziert wird daneben ebenfalls die historische Situierung - zusätzlich zur Nennung der Jahreszahl $>1848<$ im Titel und damit ihrer unmittelbaren Anlehnung an die alltägliche Lebenswirklichkeit der zeitgenössischen Leserschaft - durch die Bezeichnung einer >neuen und großen Zeit< und dadurch in der Wahrnehmung der Figuren als >dysfunktionale< Zeit des sozialkulturellen Umbruchs scharf von der funktionalen Vergangenheit

\footnotetext{
${ }^{3}$ Der Text erschien unter dem Titel Die Lehnspflichtigen. Westfälische Dorfgeschichte aus dem Jahre 1848 zuerst in den Ausgaben 26, 27 u. 28 der Frauen-Zeitung (1849).
} 
abgesetzt. Und dieser Brennpunkt der dargestellten Gegenwart erscheint semantisch übersättigt. August zu Helene: »Alles, was dieser großen Zeit nicht mehr gemäß ist, was sich ihr dennoch entgegenstemmt, ohne sich ihren mächtigen Umgestaltungen fügen $\mathrm{zu}$ wollen, das wird von ihr zermalmt und vernichtet.« (Ebd.: 258) Und weiter:

Wir sind nicht ungerecht - die Vorrechte, durch die er [der Graf] uns so drückt, sie sind nicht sein Unrecht, sie sind das Unrecht vergangener, barbarischer Zeiten - aber diese gehen jetzt mit eins zu Ende, und wer die neue Zeit, die Zeit des Menschenrechts am ehesten anerkennt, der wird der Größte sein unter den Großen dadurch, daß er durch ein großes Wort das Unrecht der vergangenen Zeiten sühnt und auf seine Vorrechte verzichtet zugunsten des allgemeinen Menschenrechts, des Rechtes derer, deren Unterdrücker er so lange war. (Ebd.: 259 f.)

Deutlich wird die Gegenwartsproblematik gemäß unserer Grundachse 1 - Heterogenität -, und zwar hinsichtlich unterschiedlicher und gegenläufiger (gesellschaftlicher) Tendenzen, die die Handlungsgegenwart bestimmen: die Tendenz nämlich zur Änderung gegebener sozialer Verhältnisse auf der einen und die Tendenz zur Restauration von Bestehendem auf der anderen Seite (»es bleibt alles, wie es gewesen «; ebd.: 266). Deutlich wird auch, dass diese Tendenzen sich in einem Zeitmodell bündeln, das eine konkrete Grenzziehung vornimmt zwischen der textinternen Vergangenheit (korreliert akzeptierte Ungleichheit) und der Gegenwart (korreliert nicht akzeptierte Ungleichheit, >Unrecht $<$ ), und aufgrund ebendieses Kontinuitätsbruchs die Zukunft abkapselt und nunmehr als einen $>$ Möglichkeitsraum< ausstellt. Kurz: Die Gegenwartsrealität begreift die Zukunft eben nicht mehr - wie bis dahin geschehen - anstandslos als Fortsetzung der Vergangenheit. Doch nicht nur, dass sich die Textwelt durch die Anwesenheit beider Lager konstituiert; diese stehen zudem in massivem Konflikt zueinander. Sie streben nämlich in dem einen Fall an, das andere Teilsystem zu stürzen, in dem anderen, die Weltordnung zu konsolidieren. Die Welt, wie sie hier dargestellt wird, steht mit ihren »Bewegungen der Gegenwart « (ebd.: 252), wie es an einer prägnanten Stelle heißt, auf der Kippe.

Der Text präsentiert eine doppelläufige Ereignisstruktur: Erzählt werden die Geschichte eines Liebespaares und die Geschichte einer revolutionären Auflehnung. Beide Ebenen sind miteinander verschränkt: Handlungen der Figuren haben Auswirkung auf das Problem der dargestellten Welt, und andersherum haben entsprechende Entwicklungen von >Welt< Auswirkung auf einzelne Figuren im Zentrum des Geschehens. Auf beiden Ebenen verschlüsselt der Text weitere zeitreflexive Informationen: Zum einen wird eine Revolution jüngster Vergangenheit - die Februarrevolution - in Frankreich erwähnt, die bereits einen Systemwechsel 
von einer aristokratischen Monarchie hin zu einer republikanischen Staatsform zur Folge hatte. In Deutschland steht eine dementsprechende Konfrontation zu Erzählbeginn unmittelbar bevor - und semantisiert die Gegenwart als Umbruchsphase: Die Erzählinstanz spricht von einer bevorstehenden »schlimme[n] Zeit « (ebd.: 253), Helene von einer »furchtbaren Zeit« (ebd.: 262). Das selegierte Geschehen steht demzufolge stellvertretend für einen tiefgreifenden Wandel der dargestellten Welt insgesamt; es ist nicht als singulär-partikulares und alles in allem folgenloses Geschehen zu werten. Ferner übertreten die Volksvertreter mit Ausbruch der Revolution nicht nur topografisch die Grenze zu ihnen unerlaubten Räumen, sie tun dies zudem gewaltsam und verbrennen unter anderem »alte Gemälde« (ebd.: 267) und zerstören damit zeitkonservierende Artefakte und mithin Vergangenheitsrepräsentationen einer bis dahin hegemonialen Sozialklasse. Am Ende bleibt der Zustand der dargestellten Welt ambig: Einerseits vermag es die Hegemonialklasse, sich zunächst zu behaupten (»als Militär gegen die Bauern anrückte, zerstreuten sich diese bald«; ebd.: 269), andererseits gibt der Graf den Forderungen bald darauf nach. >Zukunft< an dieser Stelle ist als Zustand semantisiert, dessen Unsicherheit über die Textgrenze hinaus Bestand hat.

Auf Individualebene sind in zeitreflexiver Hinsicht zum anderen drei Aspekte bemerkenswert: die schon über das erzählte Geschehen in die Vergangenheit hinausreichende Verbindung zwischen den Hauptfiguren, das verbindende Artefakt einer goldenen Uhr und schließlich die Tötung der beiden Protagonisten. In der Uhr findet sich die Vergegenständlichung von Zeit, sie kann als konkretes Indiz auf die Dominantsetzung des Zeitthemas gelesen werden, insbesondere auch in der Hinsicht, dass die Hauptfiguren mit einem Zeitmesser korreliert werden: Die beiden Figuren werden in zeitreflexiver Hinsicht explizit relevant gesetzt. Helene und August sind innerhalb ihrer Räume besonders markiert und markant klassifiziert, indem sie als Grenzgänger fungieren; sie verbindet ihre Liebe und gegenseitiges Vertrauen, das seinen Ausdruck findet in der Übergabe der goldenen Uhr als Zeichen einer >goldenen < (= wünschenswerten) Zukunft, und sie bilden somit metonymisch eine versöhnliche, in der Gegenwart initiierte Einigung der beiden feindlichen Lager ab. So erleben sie inmitten des Zusammenbruchs ihres Umfeldes einen Moment der Vereinigung und sozialen Gleichstellung:

Er konnte nichts antworten, er preßte sie heftig in seine Arme, und sie litt es, ja sie schmiegte sich selber innig an ihn und bot ihm den Mund zum Kusse - In diesem furchtbaren Moment, wo für sie eine Welt aus ihren Fugen gegangen zu sein schien, da stürzten all die alten jämmerlichen kleinen Vorurteile mit den Türmen des Schlosses zusammen in ihr erbärmliches Nichts - da wußte sie nichts mehr von einer hohen Gräfin und einem armen Bauernsohn - da waren sie beide mehr als dies: Menschen [...]. (Ebd.: 268) 
Dass dieses Ziel allerdings ein nur temporäres und nicht realisierbares darstellt, zeigt sich in der Tilgung der Figuren am Ende gleichsam als Marker einer entschiedenen Negativierung von >Zukunft<. Denn gleichwohl auf der einen Ebene >Zukunft< zugunsten der einen Tendenz umgesetzt wird, ist sie auf der anderen Ebene - die der Individuen - gekappt. Resultat auch in dieser Hinsicht ist Zukunftsoffenheit.

Es deutet sich bereits mit diesen Beobachtungen an: Der Text ist alles andere als einfach gestaltet. Er ist zwar ebenfalls als Narration einer Initiationsgeschichte zu lesen und in dieser Hinsicht nicht uninteressant, da die Entwicklung der Heldin von einer imaginativ-fiktiven Konzeptionierung eines Wandels hin zur Realisierung und aktiven Teilnahme am realiter vollzogenen Wandel ebenfalls das kunstreflexive Potenzial von Die Lehnspflichtigen impliziert. Die Novelle weist aber darüber hinaus. Ihre zeitreflexive Vielschichtigkeit zeigt sich im komplexen Zusammenspiel von >Regression< und >Progression<, die grob in den folgenden Ausgangspunkten festgehalten werden kann:

(1) >Regression< und >Progression < sind in der Figuration verankert und zeigen reziproke Dynamiken innerhalb der Textwelt an, die jeweils >Alt< oder $>N e u<z u$ realisieren anstreben, kategorial aber von der semantischen Textschicht, auf der unsere Leitdifferenz gelagert ist, zu unterscheiden sind. Sie manifestieren sich nicht als temporale Phänomene im engeren Sinne - zum Beispiel in Form von Teilwelten, in denen Zeit unterschiedlich verläuft -, sondern in denkgeschichtlichen, sozialen, kulturellen und anderen Problemstellungen, die textintern akut sind, auf die Vergangenheit zurückweisen und für die Zukunft unterschiedliche Modelle vorsehen. Sie weisen auf Textregulationen hin, die die Konsistenz der dargestellten Welt zum Ziel haben, folglich also der Aufhebung der Leitdifferenz dienen. Im gegebenen Fall vermag es die progressive Tendenz, sich im Endzustand durchzusetzen, da die regressive Tendenz in Person des Grafen zwar dominant ist, im Kontext der zur Verfügung stehenden Handlungsmöglichkeiten aber die falschen wählt. >Alt< ist präsent, dominant und wird im Endzustand modifiziert und an >neu< angeglichen. Demnach wird die Leitdifferenz in der Ereignisstruktur des Textes sin Bewegung gesetzt $<$, dynamisiert, und in einem konsistenten (aber unsicheren) Modell entladen.

(2) Die fokussierten Handlungsträger (Helene, August) versinnbildlichen die Ausgeglichenheit zwischen Vergangenheitsorientierung und der Bereitschaft einer (ideologischen) Neuausrichtung für die Zukunft. Sie stellen diejenigen Figuren dar, die den Konflikt diplomatisch zu lösen anstreben, die innerhalb der semantischen Räume, denen sie angehören, andersartig agieren und 
in ihrer persönlich-amourösen Verbindung ihrer gemeinsamen Vergangenheit - wie auch der >eigenen Zeit<, in der sie leben - bewusst werden und zugleich ein zukunftsweisendes und harmonisches Konzept verkörpern. Wir finden hierin unsere >Tendenz zur Mitte< wieder. Die Tilgung dieser >figürlichen Mitte< zeigt an: >Alt< ist korreliert mit dem Tod von >Jung< und stellt damit nicht allein eine als antiquiert wahrgenommene Belastung für das Sozialsystem dar, eine indirekte existenzielle Bedrohung des Großteils der Bevölkerung, sondern ebenso eine direkte Bedrohung für die Kindergeneration, die ein versöhnliches Ende hätte gewährleisten können. Eine >Mitte< ist im Endzustand absent; der Konsistenz des Zukunftsmodells läuft damit zuwider, dass auch nach Neuaufstellung des Sozialsystems keine Verbindung zwischen den semantischen Räumen >Adel $<$ und $>$ Volk $<$ besteht, die Neuordnung von >Welt $<$ demnach eine nur oberflächlich-harmonische, trügerische, potenziell vorläufige ist. Zukunftsoffenheit und -negativierung können auch beschrieben werden als gekapptes Metaereignis - als eine nur angedeutete, nur resignative Umgestaltung der dargestellten Welt.

(3) Folglich verschiebt der Text den Fokus von einer Zentrierung der Individualhandlung hin zur Problematisierung des Zustands seiner Welt. Er tut dies, indem er Zustände der Textwelt aufbaut, die offensichtlich das Subjekt bedrohen oder es in seinem Handeln verunsichern und lebensbedrohliche oder mindestens einschneidende Konsequenzen haben - das Subjekt findet sich in seiner (soziokulturellen) Umgebung zunehmend nicht mehr zurecht.

Dieses Kapitel nimmt drei Teilbereiche in Blick und verhandelt zunächst den Aufbau von >Welten< und ihre signifikant zeitreflexiven Strukturierungen (3.2), geht dann zur Koppelung von progressiven mit regressiven Tendenzen über (3.3) und wendet sich abschließend zeitreflexiv auffälligen Phänomenen der Zeitbehandlung und damit bestimmten discours-Formationen zu (3.4).

\subsection{Welten}

Wenn die Rede von >Welt< ist, so sprechen wir - ohne die Debatte unter anderem um die Begriffe >fiktive Welt<, >literarische Wirklichkeit< oder >Diegese< wiedergeben oder gar auszuwerten zu können (vgl. Zipfel 2001 u. Schmid 2014 [2003/2005]: 31-44) - von einem durch einen gegebenen narrativen Text semiotisch präsentierten Gesamtzusammenhang aller Signifikate: einem fiktiven Universum. Ein durch einen Text modelliertes Universum konstituiert sich 
(1) durch implizit präsupponierte oder explizit thematisierte Einheiten räumlicher, zeitlicher und kausaler beziehungsweise konsekutiver Relationen, ist (2) von Figuren (und weiteren Entitäten) bewohnt und umfasst den Rahmen eines Geschehens, liegt (3) notwendigerweise im und mit dem Text unvollständig vor und ist (4) durch ideologische Diskursformationen reguliert, insofern es über eigene Systeme von Normen und Werten verfügt, die das Denken, Handeln, Fühlen und Kommunizieren regulieren. ${ }^{4}$ Nun soll es im Folgenden nicht darum gehen, herauszustellen, dass Texte temporale Teilwelten sowie Metatilgungen und Metaereignisse darstellen, sondern darum, ihre konkrete Verfasstheit und Implikationen zu erfassen - denn erst hierüber lassen sich Aussagen bezüglich unserer Leitthese generieren.

Wir haben schon anhand der bislang behandelten Beispiele Phänomene herausarbeiten können, die auf die Beschaffenheit von >Welten< und die Problematik im Zusammenspiel von >Welt $<$ und $>$ Zeit $<$ hindeuten, etwa anhand von Hauffs Das Bild des Kaisers. Betrachtet man die Welt dieses Textes, so ist die Funktionalität ihrer topografischen und temporalsemantischen Ausprägung sinnfällig. Den Makrokosmos bildet, wie gesagt, die über das Textende hinausreichende Gegenüberstellung von Nord- und Süddeutschland, den Mikrokosmos und Schauplatz des eigentlichen Geschehens formieren die Baden-Württembergischen Burgen von Willi und Thierberg, deren semantische Zuschreibungen wir bereits dargelegt haben (vgl. Abschn. 2.2). Der Text macht kein Metaereignis geltend, nimmt keine Verschiebung der dargestellten Ordnung vor, er präsentiert hingegen einen kaschiert-harmonischen Endzustand und erzählt eine (im goethezeitlichen Sinne) dysfunktionale Initiationsgeschichte. Weiterführend bedeutsam ist nun und hierin ähnelt Hauffs Text zunächst dem von Otto - die Verstrickung des Liebespaares in politisch motivierte Ideologiekonflikte, vor deren Hintergrund sich die eigentliche Geschichte abspielt und von denen die Existenz der Figuren abhängt. Während diese Konflikte auf globaler Ebene über das Ende hinaus Bestand haben, wird die Konstellation durch >Entradikalisierung < (beziehungsweise: Relativierung) der Extrempositionen Thierbergs und Roberts entschärft. Demgegenüber stellen aber wiederum Texte wie Ottos Die Lehnspflichtigen die Polysemie des Endzustands sehr viel deutlicher aus, als dies in subtiler Form Hauff tut. Hier ersetzt eine Neuordnung die alte, das Liebespaar scheitert und wird durch Tod getilgt - vorherrschend ist ein nichtharmonischer Endzustand. Wir haben uns daher auf ein recht vielschichtiges Feld im Umgang mit $>$ Welt $<$ und

\footnotetext{
${ }^{4}$ Folglich können sogenannte Storyworlds aufgefasst werden als »intersubjective communicative constructs based on a given narrative representation« (Thon 2016: 54).
} 
>Zeit< einzustellen, das wohl in erster Linie auf die Heterogenität und Dynamik des Literatursystems selbst zurückzuführen ist.

In jedem Fall, so können wir aber sagen, ist es mit Blick auf unser Textkorpus legitim zu konstatieren, dass ein wesentliches Merkmal in der segmentierenden Gestaltung von Welten liegt, genauer: dass das Verhältnis von >Vergangenheit<, $>$ Gegenwart $<$ und >Zukunft< selbst, das heißt, der jeweilig modellierte Paradigmenwechsel ${ }^{5}$, als auch die Wahrnehmung, Wertung und Verhandlung dieses Wechsels vonseiten der Figuren als wichtig erachtet wird. Dahingehend lassen sich folgende Leitfragen zur Rekonstruktion dieses Teilbereichs formulieren:

- Komplex der Merkmale und Regularitäten. Welche Merkmale lassen sich in temporal-diegetischen Segmenten (= temporalen Teilwelten) bestimmen? Wie sind literarische Welten in temporaler (und temporalsemantischer) Hinsicht aufgebaut?

- Dichotomiekomplex >Statik vs. Dynamik<. Welche Dynamisierungsvorgänge werden dargestellt? Und wie verhalten sich dazu statische Strukturen der Leitdifferenz? Welche Verschiebungen innerhalb von Weltgefügen lassen sich ausmachen und wie finden diese statt?

- Komplex der Resultativität. Welche Konsequenzen ergeben sich aus der Dynamisierung der diegetischen Grundordnung? Inwiefern kann von der >Zeit als Störung< oder von einer >Störung der Zeit< gesprochen werden? Hier ergeben sich Aussagemöglichkeiten sowohl über das Verhältnis von Gegenwart und Vergangenheit als auch über das Zukunftssegment.

Einsteigen wollen wir in diesem Teil mit der Charakterisierung von Teilwelten, bevor wir das zentrale Strukturmodell bestehend aus >Regression< und >Progression< in > Welten $<$ vertiefen und die Koppelung von Linearität und Zirkularität als teilphasenübergreifende Invarianz zu bestimmen versuchen.

\footnotetext{
${ }^{5}$ An dieser Stelle geht es um modellierte Kulturen und damit um Paradigmenwechsel innerhalb dieser Weltmodelle. Dass damit indessen auch eine potenzielle Beschreibbarkeit des außerliterarischen Kulturverständnisses gegeben ist, erläutert grundsätzlich Kuhn (2001). Vgl. in verkürzter Form auch Nies (2011).
} 


\section{Bewegungen der Gegenwart::Temporale Teilweltenmodelle, die Semantisierung von Zeit als 'Störung und die Konfrontation mit der Vergangenheit}

In Ottos Text ist die Rede von >Bewegungen der Gegenwart<: Im Rahmen des Geschehens wird etwas verhandelt, das zwar tradiert vorliegt, das allerdings auch nicht mehr umstandslos hingenommen wird und von Bestand sein kann. Eingeräumt wird damit die Potenzialität mehrerer Zukunftsoptionen, der Erwartungshorizont wird erweitert, mehrere Zukünfte sind denkbar. Die Zwischenphase, so lässt sich generell sagen, neigt in ihrer zeitreflexiven Ausrichtung zu einer Konfligierung von >alter $<$ und >neuer $<$ Zeit einschließlich ihrer jeweiligen Semantiken, die eine dichotomische Anordnung und inhaltlich klare Segmentierung im Rahmen eines Phasenmodells nahelegt. Zugleich überlagert aber das Literatursystem die Semantiken der Einzelphasen im Gegenwartssegment: Die Vergangenheit ist präsent, wird jedoch als Belastung wahrgenommen und als ebensolche gestaltet. Genau dies hat naturgemäß auch Einfluss auf das Zukunftsmodell - die Zukunft ist nicht oder kaum planbar, nicht vorhersehbar -, jedoch rückt $>$ Zukunft $<$ dadurch als $>$ Raum< verschiedener Alternativen überhaupt erst ins Licht der Betrachtung. Die Folge ist eine Kluft zwischen Zukunftskonzept und Zukunftsmodell. Sowohl Überlagerungserscheinungen als auch das Problem der Zukunftsgestaltung sorgen für >Zeitstörungen<, Schwierigkeiten also im Umgang mit $>$ Zeit< auf den Ebenen des Erzählens und des Erzählten.

Interessant erscheint dabei, wie Teilweltenmodelle konkret semiotisiert und semantisiert sind, insbesondere natürlich dann, wenn wir von regressiven und progressiven Strukturen ausgehen, die >Vergangenheit< nicht nur repräsentieren können, sondern sie in dem einen Fall zu reinstallieren oder zu konsolidieren anstreben und in dem anderen von ihr losgelöste, neue Konzepte in Anschlag bringen. Es geht also über die bisherigen Bestimmungsversuche hinaus um das Verhältnis von Gegenwartsinstanzen zur Vergangenheit - um wiederum zu ersehen, welche Dynamiken sich daraus ergeben: Die eine Instanz tendiert zur Wiederherstellung oder Verfestigung der als >Alt $<$ semantisierten Strukturen, eine andere Instanz zur Auflösung dieser Strukturen und zur Etablierung neuer.

In Anbetracht von alledem sei erinnert: Wir konzentrieren uns nicht ausschließlich auf Formen historischen Erzählens - dem die Rückwendung in die Vergangenheit und damit auch konkrete Vergangenheitsentwürfe eigen sind und dessen statistisch-repräsentative Häufigkeit natürlich auch unser Vorhaben plausibilisiert -, sondern eben auch auf solche Texte, die nicht dem historischen Erzählen zuzuordnen sind und dennoch dem Segment >Vergangenheit< einen hohen Stellenwert in ihrer Bedeutungskonstitution zuschreiben. 
So eben im Fall von Die Lehnspflichtigen. Anzunehmen ist hier ein System temporaler Teilwelten, nicht allein bestehend aus Vergangenheit, Gegenwart und Zukunft, sondern auch hinsichtlich des Funktionierens der dargestellten Welt als Kultur zweier Ordnungen (A und B). Ordnung A ist aristokratisch reguliert und nimmt die soziale Separation zwischen Ober- und Unterschicht vor, wobei wiederum der Oberschicht justiziable Befugnisse obliegen und sie ökonomisch von der Unterschicht profitiert. Die Festlegung dieser Ordnung reicht weit in die Vergangenheit zurück. Ordnung B ergibt sich am Ende des Textes, wird lediglich angedeutet und in ihrer Resultativität nicht näher beleuchtet. Allerdings findet mit ihr eine Verschiebung der Verhältnisse statt: Der Adel gibt die ihm in der Vergangenheit zuerkannten Privilegien auf und gesteht den Bauern und der Dorfbevölkerung gewisse Freiheiten und Unabhängigkeit zu.

Das Modell temporaler Teilwelten, das der Text entwirft, könnte wie folgt visualisiert werden:

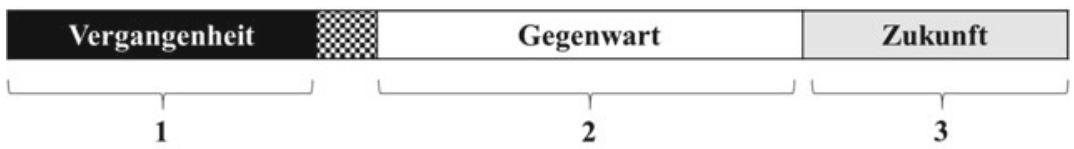

Abbildung 3.1 Das einfache Zeitmodell in Ottos Die Lehnspflichtigen

Auf den ersten Blick ist dieses Modell denkbar einfach in einer dreiteiligen Form aufgebaut. In der Gegenwart >passiert< etwas auf beiden erzählten Ebenen (der der Individuen und der des Kollektivs), das eine Separation der dargestellten Welt in temporale Segmente initiiert und die Zukunft in den Status eines Verhandlungsraums versetzt. Wir wollen hierbei zum Zwecke der Differenzierung von anderen zeitreflexiven Modellierungsformen von einem einfachen Zeitmodell sprechen (siehe Abb. 3.1). Dieses ist in seiner theoretischen Erscheinung allein dadurch markiert und als Ausprägung der Zwischenphase bedeutsam, als es die oben genannten, allgemeinen Merkmale erzählter Welten aufweist und vorzugsweise dreiteilig konstituiert ist.

Dass jedoch auch Texte, die dieses einfache Modell realisieren, nicht >einfach< im Sinne von >simpel< oder >banal< aufgestellt sind, lässt sich ebenfalls an Die Lehnspflichtigen aufzeigen. Denn zu ergänzen wäre, dass der Text den Bruch zwischen den Segmenten 1 und 2 auf beiden Ebenen zeitlich vor der erzählten Gegenwart ansetzt, mit der Folge, dass 1 und 2 sich überlappen: Ein 
Merkmal von >Gegenwart< findet sich bereits in der dem Text vorgelagerten Vergangenheit, ein (eminentes) Merkmal von >Vergangenheit< findet sich (noch) in der Gegenwart: Virulent fungiert zum einen der gewaltsame Ordnungswechsel in Frankreich, der für Deutschland die Bedrohung einer »schlimme[n] Zeit« (ebd.: 253) korreliert. Dieses Ereignis scheint Novitäts- und Sensationscharakter aufzuweisen, da - so macht der Text deutlich - sogar die ansonsten eher unbehelligte Helene davon weiß. Mehr noch: Es hat fundamentale Folgen für den vom Text selegierten Weltausschnitt und wirkt auf das kulturelle Selbstbewusstsein des Kollektivs ein. Ferner, so hatten wir schon angedeutet, ist es die Errettung Helenes durch August, die beide Figuren zusammenführt. Und diese Zusammenführung damit ist die Potenzialität der Grenzüberschreitung und -verschiebung impliziert - liegt im nur angedeuteten Jugenderlebnis (Rettung vor dem Ertrinken) und wird in der Befreiung Helenes vor den »verwildert aussehende[n] Männer[n]« (ebd.: 252) wiederholt. Die goldene Uhr ist als Signifikant dieser Verbindung zu deuten, sie wird zum »Pfande des Bundes« (ebd.: 263): »SSie dient auch der Zeit, wie Sie [August], aber immer im gleichmäßigen Schritt, lassen Sie sie eine Warnung für sich und eine Erinnerung sein, daß diese wunderbare Zeit mich zu Ihrer gemacht hat « (ebd.: 262); und: » Ich habe diese Uhr seit dem Tage getragen, wo Sie mich aus dem Wasser zogen, mein Vater gab sie mir damals, mir eine Freude zu machen - und weil sie so lange mit mir gelebt, hat sie Wert - sonst keinen.« (Ebd.: 263)

Es resultiert daraus eine temporale Grauzone, die sich um das Jugenderlebnis und den andernorts vorgegriffenen revolutionären Ordnungswechsel anordnet. Beides liegt von der diegetischen Gegenwart aus besehen in der Vergangenheit, strahlt aber in die Gegenwart hinein, insofern es für die Ereignisse in Segment 2 maßgeblichen Einfluss hat. An beiden Geschehensmomenten wird die Beendigung eines Zeitabschnitts markiert - eines geschichtlichen Abschnitts (Systemwechsel) und eines Lebensabschnitts (Adoleszenz).

Die konkrete Gestaltung des einfachen Zeitmodells in Die Lehnspflichtigen wäre dementsprechend folgendermaßen aufzufächern (vgl. Abb. 3.2):

Die Zustandswechsel von a bis $c$ beziehen sich auf die Ebene der Individualhandlung und dort auf die zentrierten Figuren Helene und August. Angesichts dieser Überführungen kann der Verlauf der Geschichte dieser Figuren als gescheitert angesehen werden. Da sie aber vom Text als positive Helden markiert werden, ist ihre Tilgung am Ende zudem einem nicht wünschenswerten Endzustand der dargestellten Welt äquivalent. Der Ordnungswechsel von A nach B erscheint daher als nur eingeschränkt angestrebter. Einerseits begrüßt der Text die Reformierung des antiquierten Sozialreglements, andererseits erfolgt sie unter Verzicht 


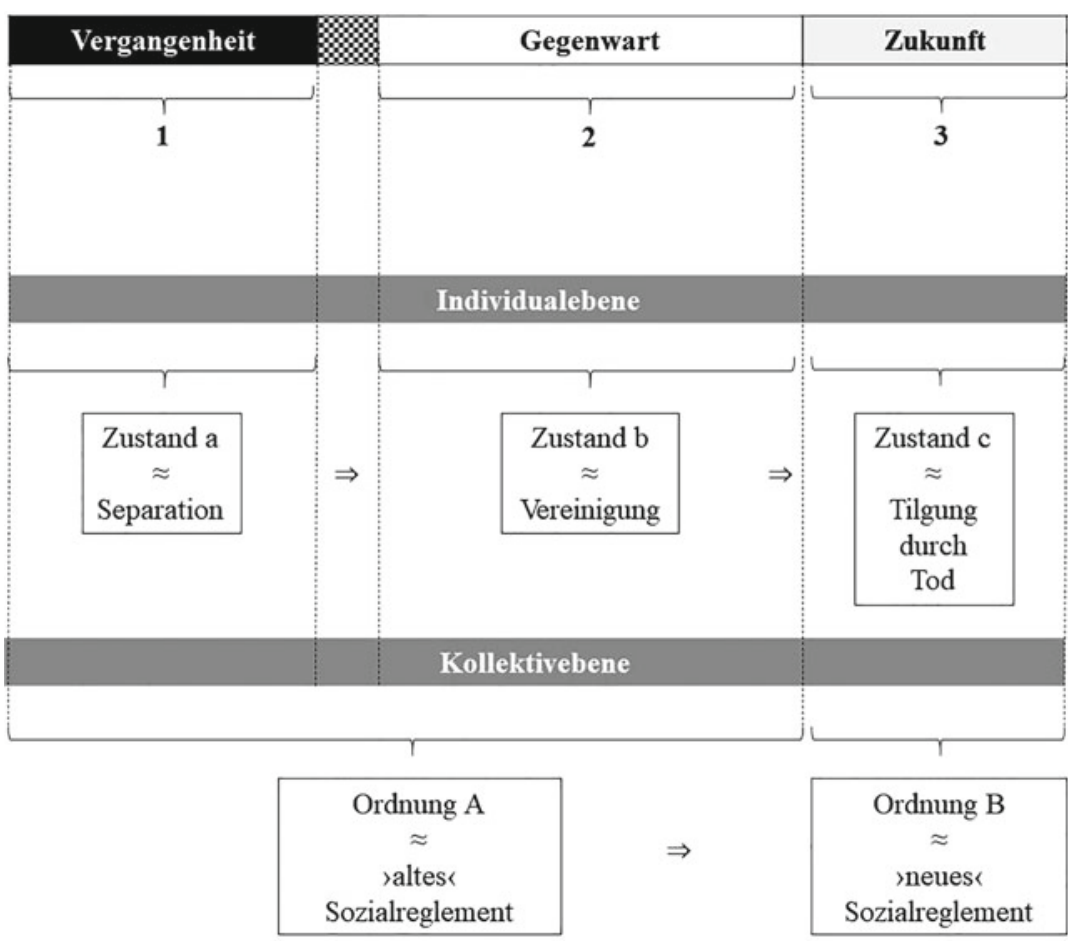

Abbildung 3.2 Das einfache Zeitmodell in Ottos Die Lehnspflichtigen (ergänzt)

auf individuelle Zukunftsträger allenfalls resignativ, nicht aber als gefeierter Systemwechsel.

Auch hierin findet sich eine bereits bekannte Regularität des Literatursystems bezüglich der Modellierung von >Zukunft< wieder: die Relativierung des Endzustands; nun allerdings nicht mit Blick auf den Initianden, sondern in einer Variante, die die gesamte dargestellte Welt betrifft. Man könnte auch sagen: Eine wünschenswerte Ordnung wird am Ende zwar umgesetzt, aber nur zum Preis der Aufgabe der Helden. Dies unterstreicht von dieser Warte aus zum einen die Verbindlichkeit dieser Regularität, es macht aber zum anderen auch auf die Notwendigkeit einer Öffnung der Betrachtungsweise auf das Textkorpus insgesamt aufmerksam. 
Belassen wir es vorerst bei diesen vorläufigen Beobachtungen an unserem Beispiel und wenden uns weiteren Formen des Aufbaus temporaler Teilwelten zu. Im Gegensatz zu jenen, im Hinblick auf die Vergangenheit einphasig gestalteten Textsystemen wie in Die Lehnspflichtigen sind nämlich auch solche anzunehmen, die > Vergangenheit< mehrphasig realisieren. Einphasige Vergangenheitssegmente finden sich neben unserem Beispiel unter anderem in Der tote Gast, Das Unvermeidliche, Der Brudermord, Geschwisterliebe, Zu spät!, Die gute alte Zeit und Der Condor. Mögen auch diese Texte im Einzelfall diskutabel sein, so müssen sie doch deutlich von Werken unterschieden werden wie Madelon oder Die Romantiker von Paris, Die schwarze Spinne, Die Narrenburg, Brigitta, Die Judenbuche und Der Hochwald, die sehr viel umfassendere Anordnungen schaffen und damit in Abgrenzungen zu ersteren komplexe temporale Teilwelten entwerfen. Wir wollen annehmen, dass beide Modellierungsformen zwar phänomenologisch zu unterscheiden sind, sie aber in ihrer Funktionalisierung zur Reflexion von Zeit auf Ähnliches hinauslaufen, nämlich darauf, die bereits vielfach erwähnte Konfrontation der Gegenwart mit der Vergangenheit zur Geltung zu bringen. Lediglich die Semiotisierung auf der Textoberfläche und die Semantisierung auf einem niedrigen Abstraktionsniveau sind unterschiedlich.

Die genannten Texte im letzteren Fall haben nun gemein, dass sie >Vergangenheit< mehrphasig staffeln und auf diese Weise quantitativ eine größere Menge von Zeitpunkten und -abschnitten explizieren, die in der Vergangenheit liegen, damit aber >Zeit< auch qualitativ ausdifferenzieren. Dies entspricht einem grundsätzlich anderen Aufbau temporaler Teilwelten als im ersten Modelltyp und hat Folgen für die Verhältnismäßigkeit von >Vergangenheit< und >Gegenwart $<$. Denn Texte dieser Art präsupponieren nicht nur eine der erzählten Gegenwart vorausgehende Vergangenheit, sondern stellen sie direkt oder indirekt auf der Textoberfläche aus und machen sie damit explizit. Teilweise geht die Konstitution des Vergangenheitssegments - wie auch die Auseinandersetzung der Figuren mit ihr - gar so weit, dass die Gegenwart hinsichtlich der Geschehensdichte auf ein Minimum reduziert wird: In Die Mappe meines Urgroßvaters etwa finden ein Umbau des Hauses und ein Umzug der Figuren statt. Viel entscheidender dagegen sind offenbar die Rezeption der Mappe und damit die Geschichte des Urgroßvaters, nicht aber die eigene. Auch in Kurz' Liebeszauber erscheint die dargestellte Gegenwart >entnarrativiert<, besteht aus zermürbenden Lateinaufgaben des Protagonisten, wohingegen die Vergangenheit eine hohe Ereignisdichte aufweist. $\mathrm{Zu}$ nennen wären auch Gotthelfs Die schwarze Spinne und Stifters Die Narrenburg.

Der Unterschied zwischen beiden Modellen liegt neben dem pragmatischdarstellerischen und dem diegetisch-ontologischen Aspekt ebenfalls in der Semantisierung von Vergangenheit. Denn mit der Einphasigkeit von Vergangenheit in 
dem einen Fall geht der Entwurf eines einzigen semantisch-temporalen $>$ Raumes< einher, im anderen mit der Mehrphasigkeit der Entwurf mehrerer $>$ Räume<, durch den der abstrakt-semantische Gesamtraum >Vergangenheit< binnendifferenziert wird. Daher auch die hier gewählte Bezeichnung: Im letzteren Fall ist >Vergangenheit< in dieser Hinsicht komplex-mehrschichtig semantisiert.

Bevor wir im Verlauf des Kapitels weitere Texte für Teilphänomene dieses Bereichs einbinden, möchten wir als prominentes und recht anschauliches Gegenbeispiel zu Ottos Text Stifters Der Hochwald anführen und zeigen, inwiefern Semiotisierung und Semantisierung anders verlaufen als im ersten Fall. Zentrales Thema ist bekanntlich auch hier ein zweifaches: die erste Liebe und damit der Übergang vom Jugendalter zum Erwachsenenalter einerseits und die Bedrohung der dargestellten Kultur durch den Krieg mit einer anderen, fremden Kultur andererseits. ${ }^{6}$ Darüber baut der Text zwei Problemfelder auf, die er miteinander verknüpft und auffächert. Erstens das Problem der Ablösung von der Herkunftsfamilie - bereits bekannt als Modifikationsaspekt der Initiationsgeschichte. Nun allerdings wird ein möglicher Entwicklungsgang - wie ihn das Literatursystem der Goethezeit noch als notwendig erachtet hatte - gänzlich unterdrückt und allenfalls als verflossene Option angedacht. Folglich ist das Problem hier aus einem Blickwinkel zu untersuchen, der sich im vorherigen Kapitel schon angedeutet hatte, und zwar in Hinsicht auf seine Verhandlung im Rahmen der dargestellten Welt insgesamt. Zweitens nimmt der Text eine Parallelisierung von individueller und gesellschaftlicher Geschichte vor, indem er den (erneuten) Ausbruch von (bereits vergangenen) Leidenschaften bei einer der Protagonistinnen in Entsprechung zur Präsenz des Kriegsgeschehens im Handlungsraum setzt.

Das erstgenannte Problem basiert auf der Opposition aus geschwisterlicher Liebe, die als erotisch-homosexuelle Liebe umgedeutet wird, und außerfamiliärer, heterosexueller Liebe. Die Kollision erzeugt eine inkonsistente Situation, die zugunsten einer einseitigen geschwisterlichen Liebe aufgelöst wird, und zwar bezeichnenderweise durch Kriegshandlungen - mit der Folge allerdings, dass die Familie >ausstirbt<. Das zweite Problem gibt Aufschluss über beides: die Paradoxie der dargestellten Anthropologie und die Unsicherheit der dargestellten Gegenwartsepoche. Erotische Leidenschaft mit exogamer Ausrichtung bewertet der Text einerseits negativ - sie führt zu tiefgreifenden Konflikten und gefährdet die Figuren -, zugleich wird vom Erzähler aber klargemacht, dass mit ihrer Vermeidung und Tilgung >etwas< verloren geht - am Ende sind die Figuren verstorben und der Raum zerstört -, und diese implizite Notwendigkeit zum eigenen

\footnotetext{
${ }^{6}$ Eine überzeugende Analyse vor dem Hintergrund des >Normenkonfliktes zwischen Natur und Kultur< findet sich bei Wünsch (1996). Die Aussagen dort dienen hier als Grundlage.
} 
Fortbestand und zur Gestaltung von $>$ Zukunft $<$ kann ex negativo als positive Wertung gelten. Die Erzählsituation, die dem Text als narratoriale Rahmung dient, komplettiert über die literarische Anthropologie hinausgehend die Koppelung von $>$ Regression< und >Progression<. Der Text weist eine retrospektive Vergangenheitszugewandtheit auf, zugleich wird diese insofern als > verloren $<$ gekennzeichnet, als exogam-leidenschaftliche Liebe als potenziell progressives Strukturelement im Innenleben einer der betroffenen Figuren bis zum Lebensende zwar Bestand hat, nicht aber gelebt werden kann und somit resultatlos bleibt. Die Konsequenz ist vielmehr die Semantik einer negativierten Zukunft, man könnte sogar von einer partiellen Negativierung von >Zukunft< auf der Individualebene sprechen.

Bezeichnenderweise bettet der Text dies nun in ein komplexes temporales Teilweltenmodell ein und koppelt damit anthropologische Problemstellungen mit Zeitreflexion. Eine erste Komponente dieses Modells ergibt sich aus einer Betrachtung der Protagonistin Clarissa. Vom Erzähler nicht selegiert (beziehungsweise im Figurengespräch nur teilweise rekonstruiert), aber dennoch präsupponiert sind Kindheit und - vor allem - eine bei Erzähleinsatz verflossene Liebesbeziehung zwischen Clarissa und Ronald. Im letzten Kapitel »Waldruine« wird Zeit stark gerafft; die Schwestern altern von Jungfrauen zu achtzigjährigen Greisinnen und sterben. Daraus wiederum folgt eine mit Blick auf die Figur Clarissa dreiphasige Zeiteinteilung: (nichtselektierte) Vergangenheit, (erzählte) Gegenwart und (geraffte) Zukunft.

Überlagert wird diese Teilkomponente allerdings von einem übergeordneten Zeitmodell. Der Text begnügt sich nicht damit, die Geschichte des Geschwisterpaares zu erzählen, sondern situiert diese in einer diachronen Ordnung, die betont vergangene und zukünftige Zustände der dargestellten Welt einbezieht. Festzumachen ist dies einerseits an der diegetischen Erzählinstanz, einem namenlosen Jüngling: Zwar wird mit ihm und seinen Schilderungen zunächst lediglich die Erzählgegenwart als Zeitpunkt bestimmt, er setzt sich aber mit seiner retrospektiv-erzählerischen Rückwendung zur Vergangenheit des Handlungsraums in Beziehung - die »zerfallene Ritterburg « (Stifter 1980b [1842/1844]: 215) - und repräsentiert damit gleichfalls die Zukunft des von ihm Erzählten. Andererseits offenbart sich eine dem erzählten Geschehen vorgelagerte Vergangenheit in den Erzählungen Gregors am Waldsee, die mehrere hundert Jahre bis in die Zeit Karl des Großen zurückreicht und durch Heidentum und mystisch-makabre Zauberei geprägt ist (Abb. 3.3).

Die Ordnungen $A$ und $B$ lassen sich aus den Binnenerzählungen des alten Gregor rekonstruieren: Zum einen die Zeit eines heidnischen Königs und des verzauberten Sees, zum anderen die Jugend Gregors. Ordnung $C$, die an sich einer Unordnung oder einem Umbruch äquivalent ist, formiert das Hauptgeschehen, 


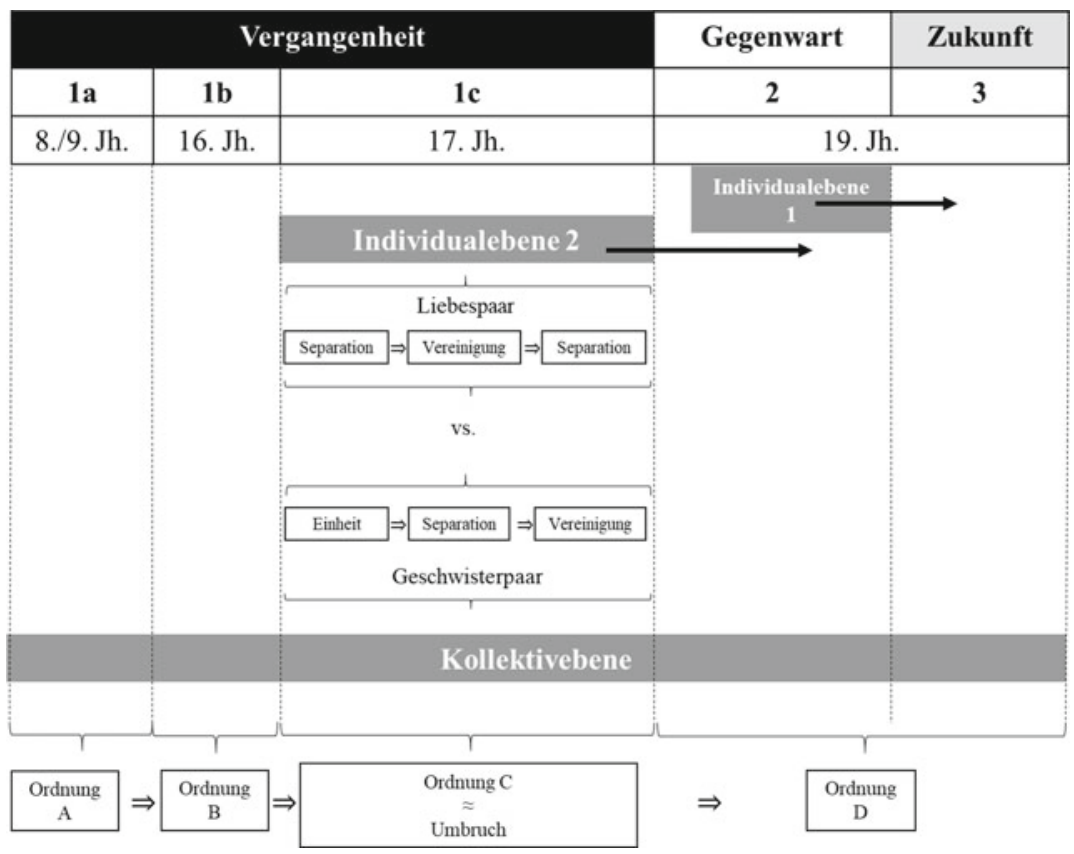

Abbildung 3.3 Das komplexe Zeitmodell in Stifters Der Hochwald

Ordnung $D$ entspricht zum einen der Zeit des Rahmenerzählers, die - wie auch die vorherigen Segmente - durch eine Retrospektive in die Vergangenheit geprägt ist, zum anderen der Zukunft der dargestellten Welt.

Es lassen sich drei Signifikanzen benennen: Erstens überwiegt rein quantitativ der Anteil von Elementen, die sich der Vergangenheit zuordnen $(1 a, b, c)$; so ist auch das von der Erzählung zentrierte Hauptgeschehen temporal im Vergangenheitssegment situiert (1c). Und nicht nur das: Auch orientiert sich ein Großteil der Figuren an der Vergangenheit. Gregor, indem er Kulturgeschichtliches nachliefert, Clarissa und Ronald (auf der Individualebene 2), die ihre Liebe zu erneuern anstreben, der Rahmenerzähler (auf Individualebene 1) durch seine narrative Rekonstruktion des vergangenen Geschehens. Zweitens aber sind Teile der Vergangenheit und die Gegenwart partiell mit Zukunftssemantiken versehen; zum einen, wenn die Auswirkungen des Geschehens für die Schwestern in stark geraffter Form präsentiert werden und damit den zeitlichen Fortlauf nach den 
einschneidenden Ereignissen darlegen, des Weiteren insofern, als die Erzählgegenwart einen topografischen Raum in einem gegenüber dem erzählten Geschehen zukünftigen Zustand erfasst. Drittens gestaltet sich >Zukunft< - und damit $O r d-$ nung $D$ - ambig, gleichermaßen als Zeit der Absenz menschlichen Lebens und der Renaturierung wie auch als fortschreitender Kultivierungsprozess - wobei ersteres im Fokus steht und letzteres sich an der Handlungs- und Erzählperipherie abspielt.

Auf Basis der gegebenen Vergleichsfolie, die wir zwischen unseren Beispieltexten (im Hinblick auf die Problematik und die Modellierung von $>$ Zukunft $<$ ) ausmachen können, lässt sich ein regulatives Merkmal benennen, das den Wesenszug des im Literatursystem bedeutsamen Verhältnisses zwischen >Welt< und >Subjekt< maßgeblich beeinflusst und das von Bedeutung zu sein scheint für die Spezifik der vorliegenden Zeitreflexion:

Vergangenheit versammelt - bei unterschiedlicher segmentaler Ausdifferenziertheit - gegenwartsdeterminierende Textelemente.

Zwei Anmerkungen dazu: >Welten $<$ unseres Korpus weisen zum einen nicht nur eine dezidierte temporale Segmentierung in Vergangenheit, Gegenwart und Zukunft auf (wie im Basiskonzept illustriert), sondern setzen bestimmte Funktionsmuster dominant, die >Vergangenheit< als Menge aller ihr zugeordneten Elemente in ihrer Relation zu >Gegenwart< zugeschrieben werden. So kommt es zur Überlagerung von >Gegenwart< und >Vergangenheit<. Denn Vergangenheitselemente - seien es Familientraditionen, Institutionen, überlieferte Werte und Normen einer mentalen Kultur, alte Liebschaften, Fehltritte oder -entscheidungen - nehmen maßgeblichen Einfluss auf die Handlung beziehungsweise sind materiell und personell in der Gegenwart existent, zugleich aber als >unzeitgemäß<, >überholt<, >alt<, >antiquiert< semantisiert und damit temporalsemantisch alteritär gekennzeichnet. Die Akzentverschiebung von einer neutralen Zuschreibung wie >von zeitlich langem Bestand hin zu den genannten Attribuierungen und damit die Dominantsetzung dieser Elemente resultiert zum anderen nicht allein aus der Tatsache, dass sie vorhanden sind, sondern dass sie vonseiten verschiedener Textinstanzen auf bestimmte Weise evaluiert werden.

Verhandelt werden - angesichts der ersten Feststellung - demnach neben individuell-anthropologischen Problemen grundsätzlich auch solche der Gestaltung von >Welten<, der Funktionsweisen und der Konstitution des Erzählens wie auch der Stellung ästhetischer Kommunikation im Rahmen kultureller Selbstproduktion - allgemeine Probleme also, die das Literatursystem in diegetischen Zeitmodellen verankert und zeitreflexiv auflöst. Leitet dies einerseits über zum Kapitel 
zur Selbstreferenzialität, so ist an dieser Stelle anderseits ein Rückkopplungseffekt auffällig, der sich im Verhältnis von Figur und Diegese niederschlägt:

Das Problem der Vorrangstellung des Systems gegenüber den Handlungsträgern.

Auch hierzu zwei Anmerkungen: Figuren ist es erstens offensichtlich kaum oder gar nicht möglich, ihre Welt zu gestalten, ihr Leben nach eigenen Vorstellungen auszurichten, geschweige denn, bestehende Systeme zu reformieren. Im Gegenteil sind sie äußeren Umständen ausgesetzt, die ihr Leben beeinflussen, mit subjektexternen - teils sogar deutlich als ich-dyston markierten - Normen und Werten konfrontiert, denen sie sich zu beugen haben, und Bedingungen unterworfen, die ihr Leben erschweren. Figurenhandlungen sind heteronom determiniert. Entweder haben sie sich der >Tendenz zur Mitte< anzupassen oder aber sie scheitern. Dabei ist dieses Verhältnis zwischen Figur und $>$ Welt $<$ zweitens aber nicht unhinterfragtes Faktum, zumal >Welten $<-$ wie im Kapitel zur temporalsemantischen Anlage des Literatursystems erörtert (vgl. Abschn. 2.2) - selbst inkonsistent sind, unausgewogen im Aufbau, oft dem Zusammenbruch nahe, wie ja ebenfalls Ottos Text deutlich vor Augen führt. Für das Personen-Konzept hat das den Einbezug neurotischer Grundzüge der Figur zur Folge: psychische Störungen unterschiedlicher Erscheinungsform, die infolge bestimmter Erfahrungen mit tiefgreifend psychisch-mentaler Belastung zustande kommen und durch andauernde Fehlgewohnheiten ausgebildet werden, den Betroffenen zwar bekannt sein können, aber unverständlich bleiben, und sich symbolisch ausdrücken (vgl. Brockhaus 2001: 400 f.).

Für den Umgang mit literarischen Welten bedeutet dieses Missverhältnis die Gefahr eines Kollapses - teilweise in Form von Metaereignissen, teilweise auch durch die angestrebte, teils radikale Auflösung von Inkonsistenzen durch Tilgung von Teilräumen. Es bedeutet angesichts unseres Basiskonzepts - das ja die Disjunktheit der Segmente >Vergangenheit<, >Gegenwart< und >Zukunft< vorsieht - , dass zur weiteren Behandlung des Komplexes von >Welt $<$ und >Subjekt $<$ eine wichtige Ebenenunterscheidung notwendig ist, um die Separiertheit der Segmente einerseits und ihre Überlagerung andererseits nachvollziehen zu können:

Auf Ebene der Ontologie der Diegese sind gleichermaßen temporalsemantisch >alte und >neuartige Elemente vorhanden. Auf Ebene der Figurenwahrnehmung und/oder der Textideologie (oder: der figürlichen und narratorialen Perspektive) werden erstere oder letztere alteritär und inkompatibel gesetzt - daraus resultiert: Die Störung von Zeit, die einer Krise äquivalent ist. 
Signifikant ist - kultursemiotisch gesprochen - die Kluft zwischen der dargestellten sozialen Kultur und der mentalen Kultur: Das, was im sozialen Bereich praktiziert wird und besteht, ist nicht mehr gänzlich in Einklang zu bringen mit dem, was über >Kultur $<$ gedacht wird. Die mentale >Kultur $<$ des Literatursystems stellt sich zersplittert dar und stiftet mit Blick auf die dargestellte Realität Inkonsistenzen. Mit Blick auf Ottos Text gesprochen: Rein ontologisch betrachtet ist das Vorhandensein verschiedener Sozialgruppen und Ideologien nicht notwendigerweise auch problembehaftet. Allein die divergierenden Annahmen über die soziokulturelle Realität haben ein Nachdenken über >Vergangenheit< und >Gegenwart< zur Folge und belegen die >Zukunft< mit dem Status eines Feldes mehrerer (und auszuhandelnder) Optionen. >Gegenwart $<$ und >Vergangenheit< werden miteinander konfrontiert, >Zukunft< wird zum unvorhersehbaren Möglichkeitsraum.

Dies alles hat insofern weitere Auswirkungen, als Figuren die Konfrontation von >Zeiten < wahrnehmen, kommunizieren und bewerten und daraus Rückschlüsse auf das eigene Dasein ziehen, auf das eigene Verhalten, ihr Denken, Handeln und Fühlen in Bezug auf die unmittelbare Lebenswirklichkeit, aber auch mit Blick auf die Zukunft. Im letzten Kapitel war diesbezüglich von >Zeitkonflikten< die Rede, die für das Individuum - vornehmlich den Initianden - als daseinsentscheidend angenommen werden müssen. Erforderlich zur potenziell erfolgreichen Zukunftsgestaltung, so eine signifikante Proposition, die benannt werden konnte, ist die Auseinandersetzung mit verschiedenartigen Problemen der Vergangenheit unerlässlich.

Doch diese Regularität, so lässt sich hier nun fortführen, gilt wie für Initianden wie für ganze Weltsysteme. Immer wieder spielt die Vergangenheit eine Rolle für das Geschehen und die narrative Präsentation dieses Geschehens; immer wieder ist das Geschehen deutlich an jene gebunden und kann sich nicht losgelöst von ihr entwickeln. Oder die gegenwärtige Realität wird als unstet wahrgenommen und skeptisch betrachtet, da sich in ihr Maßgaben des Denkens und Handelns derart verändert haben, dass Figuren nicht mehr zurechtkommen. So ließe sich die Aktivierung des Zeiterlebens, die wir als optionale Textstrategie zur Markierung von Zeitreflexion benannt hatten, nicht allein bei Initianden, sondern bei allen möglichen Figuren der dargestellten Welt konstatieren. Das wohl anschaulichste Beispiel stellt dahingehend Mundts Roman Moderne Lebenswirren dar, worin massiv - und zwar von nahezu allen Protagonisten - über Zeit und das Verhältnis von >Welt< und >Person< resümiert und debattiert wird. Salzschreiber Seeliger spricht von einer Krankheit, die er »Zeitpolyp« (Mundt 1834: 11) nennt; die von ihm angebetete Esperance spricht von einer $>$ Zeit der Reformen $<$. Andere Figuren entwickeln Deutungsmuster (Mundus) oder debattieren über regressive 
und progressive Prinzipien politischen Handelns (Zodiacus). Der Text kennzeichnet die von ihm dargestellte Gegenwart zu Beginn der 1830er-Jahre - dies die Konsequenz dieser Störung - als >Zeitalter der Reflexion< (vgl. ebd.: 55, 65 f., 71 u. 207).

Offensichtlich ist dem Literatursystem in seiner Gestaltung von >Welten aber nicht allein daran gelegen, solche temporalsemantischen Inkonsistenzen (= >Zeitstörungen $<$ ) darzustellen, sondern zusätzlich daran, diese im Endzustand in Konsistenzen zu überführen. Und genau darin wird ein drängendes Problem angestoßen, das sich in gegenläufigen >Bewegungen<von Textinstanzen niederschlägt, denn Lösungsstrategien stehen nur bedingt zur Verfügung. Zwar ist Texten die Konfrontation mit der > Vergangenheit< als eine in Anschlag gebrachte Problemlösungsstrategie inhärent, verbunden mit der Aufgabe: >Setze dich mit Problemen der Vergangenheit so auseinander, dass ihre Kenntnis und mögliche Lösungen kompatibel mit deinen eigenen Vorstellungen/Wünschen/Plänen/Maximen sind. Dann steht einer positiven Zukunft nichts im Wege.< Die vom Literatursystem präferierten jungen Figuren streben häufig in die Zukunft, werden darin jedoch gehemmt, indem sie mit Elementen der Vergangenheit konfrontiert werden. Oder sie trauern von vornherein vergangenen Zuständen nach und versuchen diese wiederherzustellen, ohne sich über in der Regel fatale Konsequenzen, die daraus entstehen, im Klaren zu sein. Von ihnen sind Normen - zum Beispiel die Norm des unbedingten Erhalts der Familie - habitualisiert, die sich auf zwischenmenschlicher Ebene als schädigend herausstellen. Die Aussicht einer zufriedenstellenden und erwünschten Zukunft solcher Figuren kollidiert in dem einen wie in dem anderen Fall mit der Vorrangstellung des Systems gegenüber seinen Handlungsträgern, die sich in der Regel ein- und unterzuordnen haben. Beispiele dafür hatten wir bereits angeführt: Man denke an Stifters Der Hagestolz und Der Hochwald, aber auch an Laubes Das Glück oder Hauffs Das Bild des Kaisers sowie an Das Schloß Dürande und Geschwisterliebe. Das Problem der diegetischen >Reibung < zwischen konstatierter Inkonsistenz und unmöglicher oder kaschierter oder offen möglicher Transformation der Textwelt in eine konsistente $>$ Welt $<$ ist daher als hochrangiges Problem des Literatursystems einzuordnen. Und da es sich um temporalsemantische Strukturen handelt, die dieses Problem zur Geltung bringen, sollte es ebenfalls Thema unserer Auseinandersetzung sein.

Angesichts der dargelegten Beobachtungen wäre ein weiteres zentrales Merkmal der Zwischenphase abzuleiten und explizit zu machen. Die Dominanz von > Vergangenheit< impliziert eine regressive Stoßrichtung von Texten in der Konfliktlösung, die dem linear-chronologischen, unidirektionalen Zeitkonzept der dargestellten Welt wie auch der Orientierung mancher Figuren entgegensteht: 
Texte der Zwischenphase koppeln progressive mit regressiven Strukturen.

Alle diese propositionalen (hier kursiv hervorgehobenen) Teilmengen im Verbund sind es, die neben dem postromantischen Lebenslaufmodell eine zweite reflexive Zeitstruktur generieren, auf deren Explikation es in diesem Kapitel ankommt.

\section{Regression und Progression in konfligierender Anordnung: Vier Dimensionen}

Angekommen wären wir damit bei den zentralen Strukturanordnungen selbst. >Zeitstörungen $<$, wie sie die Zwischenphase geltend macht, können als Dynamisierungsvorgänge der dargestellten Welt begriffen werden. Dieser Annahme liegt zweierlei zugrunde: Zum einen unterliegt Gegebenes in seiner semantischen Strukturanlage (konzipierten oder tatsächlich vollzogenen) Verschiebungen, >Bewegungen also auf paradigmatischer Textebene. Zum anderen gibt es solche Teilstrukturen, die tendenziell $>$ Bewegungen $<$ anstoßen (= progressiv), und wiederum solche, die diese zu verhindern suchen beziehungsweise im gegebenen Konfliktzustand >Gegenbewegungen $<$ vornehmen (= regressiv). >Regression< und $>$ Progression< sind reziprok, gegenläufig und in zeitreflexiven narrativen Texten variantenreich ausgebildet. Im gegebenen Beispiel Die Lehnspflichtigen übernehmen diese Funktionen der Adel in seinem konsolidierenden und das Volk mit seinem revolutionären Handeln. Getragen werden Dynamisierungen dieser Art durch Individuen und Institutionen dargestellter Welten, die ihre Merkmale formieren und Regulationen geltend machen: Dominante Institutionen werden als $>$ alte $<$ gestaltet und ihr Niedergang potenziell nahegelegt und angesteuert. Andere Institutionen erscheinen hingegen nicht ausgeprägt und tragfähig genug, um erstere gänzlich abzulösen. In Ottos Text wird der Adel zwar zur Lockerung des sozialen Regelsystems bewegt, ohne allerdings, dass er seine Position gänzlich einbüßen müsste. Im Gegenteil: Er verfügt über das Textende hinaus über die eigentliche Staatsgewalt und ist darin eben nicht abgelöst.

Verschiedene Varianten der Dichotomie Regression vs. Progression setzen denn fortschrittlich-modernisierende oder restaurativ-traditionsorientierte >Bewegungen $<$ unterschiedlicher Art in Gang. ${ }^{7}$ Sie formieren Konglomerate aus figürlichen

\footnotetext{
${ }^{7}$ An dieser Stelle muss auf eine ähnliche Merkmalskoppelung in der Romantik hingewiesen werden. Kremer/Kilcher konstatieren, dass »die tiefgreifenden Veränderungen im Zuge der Französischen Revolution« (2015: 23) eine >Öffnung des Zukunftshorizontes< bewirken, und die Romanik parallel dazu durch ein »Moment der Offenheit « (ebd.) gekennzeichnet sei. Exemplarisch genannt wird Friedrich Schlegel, der ein Modell liefere, »das das Verhältnis von
} 
und räumlichen Temporalsemantiken verschiedener Klassifikation, wie sie im Kapitel zum modifizierten Initiationsmodell genannt worden sind. Statistisch häufig anzutreffen sind dabei die folgenden Umfelder:

(1) die politisch-soziale Dimension

(2) die anthropologische Dimension

(3) die sozialökonomische Dimension

(4) die ästhetisch-kunstreflexive Dimension

Grundsätzlich wichtig ist, dass sich diese Dimensionen komplementär verhalten und so auch komplex-vielschichtige Anordnungen aus mehreren Bereichen in Texten vorzufinden sind. So ist es etwa mit Blick auf die modifizierte Initiationsgeschichte nicht ohne Belang, dass neue Lebenslaufmodelle (die die Zwischenphase markieren) gegenüber alten Modellen (als Applikationen der Goethezeit) oftmals regressiv semantisiert sind; Figuren also, die innerhalb der dargestellten Welt als neuartig markierte Modelle repräsentieren, >Zukunft< als Re-Installation von >Vergangenheit $<$ anstreben, wohingegen andere Figuren in der Zukunft einen Neuzustand zu etablieren versuchen. Eine derartige Konstellation wird beispielsweise in Geschwisterliebe, Das Schloß Dürande, Addrich im Moos als höchstproblematisch verhandelt. Auffallend oft finden sich Verknüpfungen von politischer und anthropologischer Dimension, von politischer und ästhetischkunstreflexiver oder auch von ökonomischer und anthropologischer Dimension. Wir wollen dies anhand unserer Textkorpora überblickshaft erläutern.

(1) Beginnen wir mit der politisch-sozialen Dimension. Wie bereits in Das Bild des Kaisers und Der Hochwald illustriert - teilphasenübergreifend zu beobachten unter anderem auch in Addrich im Moos, Madelon oder Die Romantiker in Paris, Der Familienschild und Imagina Unruh -, handelt es sich (im weitesten Sinne) um Aushandlungen politischer Systemwechsel, die teils mit möglichen Umstellungen des Sozialsystems einhergehen können. ${ }^{8}$ Teilweise sind diese angelehnt an

Früh- und Spätromantik als eines von revolutionärer Öffnung hin zu restaurativer Schließung bestimmt « (ebd.: 24). Die Folgerung: »Der Gegensatz von Liberalisierung und Restauration bezeichnet die komplexe Beziehung von früher und später Romantik.« (Ebd.: 27) Ein Ansatzpunkt zwecks Differenzierung zwischen Romantik und Zwischenphase könnte angesichts dessen sein: Bei der Romantik haben wir es mit einer dominant diachronen Anordnung des Verhältnisses von Öffnung und Schließung zu tun, bei der Zwischenphase mit einer synchronen Gegenüberstellung. Während also das Verhältnis von Früh- und Spätromantik durch Entdifferenzierung zu kennzeichnen wäre (vgl. ebd.: 24), besteht das signifikante Merkmal der Zwischenphase (gerade im Reflexionszielpunkt >Zukunft $<$ ) in der Differenzierung.

${ }^{8}$ Bezüglich des Zusammenhangs von politisch-sozialer Dimension und der Koppelung von Regression und Progression vgl. auch die These Hannah Arendts: »Die Tatsache, dass das 
die politische Ereignisgeschichte der außerliterarischen Wirklichkeit - wie Ottos Text deutlich macht und zusätzlich durch den Untertitel untermauert -, an anderer Stelle sind sie in die Vergangenheit verlagert (zum Beispiel: Die Judenbuche) und greifen gar historische Ereignisse auf (wie den Dreißigjährigen Krieg in Der Hochwald). In allen diesen Fällen ist Welt Verhandlungsgegenstand in dem Sinne, als politische Kräfte gegeneinander wirken, dieses Gegeneinanderwirken sich oftmals in gewaltsamen Konflikten entlädt und die Weltordnung dadurch auf den Prüfstand stellt - und über ihre Zukunft entscheidet.

Mit Blick auf Die Lehnspflichtigen kann ergänzt werden: Der Graf ist als >alt< und >der Vergangenheit zugehörig < semantisiert, er ist aber zusätzlich in seinem Handeln regressiv. Er repräsentiert das Bestreben eines eminenten Teilsystems der dargestellten Welt, einen Vergangenheitsraum zu konsolidieren, der bis in die Gegenwart hinein existiert und über die Gegenwart hinaus bis in die Zukunft hinein existieren soll, jedoch nunmehr bedroht ist. Vertreter des Gegenraums wiederum weisen das wesentliche temporale Merkmal der politischsozialen Progressivität auf, das abgleitet wird aus der Erkenntnis eines sozialen Unrechts. Eine Dynamik entsteht folglich einerseits durch Approximation und Transgression einer politisch motivierten, sozialen Grenze, andererseits durch die Verhandlung von Optionen möglicher Welten in der Zukunft, deren Denkbarkeit durch die progressive Tendenz überhaupt erst eingeräumt werden: Es geht um eine soziopolitisch fundierte Vergangenheit, die in die Gegenwart hineinragt, beklagt und behoben werden soll zugunsten einer aus einer Teilperspektive des Textes besseren Gestaltung der Gesellschaftsordnung in der Zukunft.

Vergleichbar damit ist Das Bild des Kaisers. Allerdings ist das Raster der politischen Positionen hier differenzierter, ebenso wie die Grundopposition auf mehrere Instanzen verteilt ist: Sogar Binnenräume der jeweiligen Relata geraten zu potenziellen Austragungsorten (siehe Abb. 2.4 u. 2.5, Abschn. 2.2). Aber auch hier werden Aktion (Robert) und Reaktion (Thierberg) politisch verankert, folglich Progression (Robert) und Regression (Thierberg) in einer politischen Dimension aufgerufen, gleichwohl sich die hergestellte Konsistenz des Teilraums (Schwabenland) in der Annäherung der beiden Extrempositionen natürlich vornehmlich in der Paarbildung von Anna und Robert niederschlägt.

Die politische Dimension kann folglich individuell oder institutionell konstituiert sein, angebunden ist sie stets an politische Ideologien oder mentale Konzepte politischer Systemordnungen. In Mundts Moderne Lebenswirren beispielsweise

Wort >Revolution< ursprünglich Restauration bedeutete, ist mehr als nur eine semantische Kuriosität. Selbst die Revolutionen des 18. Jahrhunderts lassen sich nicht begreifen ohne die Erkenntnis, dass Revolutionen erstmals ausbrachen, als die Restauration ihr Ziel war, und dass der Inhalt dieser Restauration die Freiheit war.« (2018: 13) 
finden sich oppositionell angeordnete Korrelationen von Politik an ein bestimmtes Konzept von Zeit:

Ich verkenne eben so wenig die Grundwahrheiten, die der Absolutismus in sich hat, als ich die ewigen Grundwahrheiten verkennen möchte und je verkannt habe, an welchen der Liberalismus in dieser Zeit seine Berechtigung hat. Man thut Unrecht, beide abzuweisen; man muß sie gegen einander auszugleichen verstehen. Und diese Kunst der Ausgleichung ist die höchste Politik, die enthält zugleich die einzige Wahrheit! (Mundt 1834: 187)

Herr von Zodiacus, der Sprecher dieser Zeilen, fährt fort und plädiert - man erinnert sich an unser Theorem - für eine >Mitte< zwischen den Gegensätzen:

Und diese Mitte ist das Prinzip der Gegenwart. Ist denn nicht diese Gegenwart dieser Herzpunkt zwischen Vergangenheit und Zukunft, in dem sich beide mit ihren Strahlen berühren, zu dem sie hinströmen, von dem sie ausströmen? Die Gegenwart ist das segelfertige Schiff, das zwischen den beiden, gleich mächtigen Strömen der Vergangenheit und Zukunft hinsteuert. (Ebd.: 188)

Ohne zunächst auf die textspezifische Realisierung dieses Komplexes einzugehen, wird doch allein hierdurch schon deutlich, inwiefern offensichtlich politisch fundierte Modelle zeitreflexiv funktionalisiert sein können: indem sie regressiven oder progressiven >Strömungen` zugeordnet werden, welche beide im Gegenwartssegment ihre Berechtigung haben.

(2) Der Hochwald setzt einen anderen Akzent. Auch hier bedroht der gewaltsam ausgetragene, politisch-soziale Systemwechsel das Figurenpersonal auf Individualebene. Und auch hier wird dieser Wechsel vollzogen - allerdings zuungunsten der Individuen. Allerdings dienen nicht die politischen Teilsysteme ( $>$ Schweden $<$ und $>$ Deutschland $<$ ) als Träger von $>$ Progression $<$ und $>$ Regression $<$, sondern vielmehr übernimmt dies das Geschwisterpaar.

Die anthropologische Dimension ist in unserem Zusammenhang also deshalb zentral, da sie alle anderen Varianten mehr oder weniger prägend überdeckt. Figuren denken, agieren und kommunizieren entweder gemäß einer im textinternen Kontext antiquierten, vornehmlich >goethezeitlich < markierten Anthropologie, die keinen Bestand hat, oder gemäß einer zwar zeitgemäßen, aber deshalb nicht weniger problematischen Anthropologie. Und ebendies unterstreicht den zentralen Status der Grundachse >Anthropologie<: Menschsein in der Literatur der Zwischenphase ist vor allem deshalb problematisch, da es an gegenläufige Modelle gekoppelt ist, die in Bezug auf ein und dieselben Sachverhalte 
(zum Beispiel: >Liebe $<$ ) einander widersprechende aktionale Umgangs- und mentale Verarbeitungsweisen vorsehen. Bemerkenswerterweise stehen nun auch diese Modellierungen im Zeichen von >Progression $<$ und $>$ Regression $<$ : So ist Clarissa in Der Hochwald als Figur semantisiert, die mit ihrer Liebe zu Ronald zwar > von der Vergangenheit eingeholt $<$ wird, jedoch mental in Richtung >Zukunft< orientiert ist. Zu ersehen ist dies an der Maßnahme des Textes, Ronald durch Tod zu tilgen und damit die Paarbeziehung als unmöglich zu gestalten, mit der Folge, dass der Teilraum am Ende (der Erzählgegenwart) als >Raum ohne Lebende< vorgeführt wird. Ex post wird damit die Botschaft vermittelt, dass mit der heterosexuellen Verbindung Nachkommenschaft anzunehmen gewesen wäre, die im tatsächlichen Zukunftsmodell indessen bezeichnenderweise fehlt. > Regression< kann sich durchsetzen, hat aber einen zukunftsnegierenden Effekt. Die Schlussfolgerung in nuce: Von >Regression< und >Progression< in anthropologischer Dimension kann demnach dann die Rede sein, wenn Werte und Normen, individuelle Verhaltens-, Rede- und Denkweisen in die jüngste oder ältere Vergangenheit beziehungsweise auf die Neugestaltung der in Aussicht stehenden Zukunft ausgerichtet sind.

(3) Wirtschaftliche Belange sind einerseits für dasjenige Subjekt von Bedeutung, das eine bürgerliche Existenz mit eigenem Gelderwerb anstrebt und in verschiedener Hinsicht den eigenen Weg in die >Mitte< der Gesellschaft zu finden sucht. Aber nicht alle Figuren, die uns in der Literatur der Zwischenphase begegnen, sind >Bürgerliche< wie sie etwa im bürgerlichen Trauerspiel des 18 . Jahrhunderts anzutreffen sind oder wie sie später im Literatursystem des Realismus auftauchen. Das Spektrum dargestellter Gesellschaftssysteme ist vielmehr ein breit gefächertes und reicht von Unterschichten und Erwerbslosen bis hin zum Adel. Andererseits gewinnen wirtschaftliche Belange - mit Blick auf unsere Textkorpora zunehmend in den 1830er- und 1840er-Jahren - an Bedeutung für dargestellte Welten insgesamt. Denn nicht selten befindet sich der Wirtschaftssektor dieser >Welten< ebenfalls in einem zumindest merklichen, wenn nicht gar konfliktreichen Umbruch, besonders ausgeprägt etwa in Mügges $Z u$ Spät! oder in Immermanns Die Epigonen. Die Dimension ist auf Engste verzahnt mit gesellschaftlichen und politischen Teilbereichen, auf Basis derer sie in Texten überhaupt erst ersichtlich wird. Eines der zentralen Themen in Die Epigonen ist der Konflikt zwischen Adel und Bürgertum, genauer: zwischen dem Herzog und Hermanns Oheim, die jeweils mit unterschiedlichen wirtschaftlichen Vorgehensweisen agieren. Während Ersterer feudalistisch aufgestellt ist, steht das Handeln des anderen im Zeichen der beginnenden Industriellen Revolution. Mit der Tilgung beider Seiten und mit dem Endzustand des Normalsubjekts Hermann tendiert der Text schließlich zu einem Mittelweg. Zu Spät! wurde bereits behandelt hinsichtlich 
der Entwicklung der Paarfindungsprozesse und der als wünschenswert ausgestellten Verbindung zwischen Georg und Victoria, die sich auf eine bürgerlich-soziale Mitte zubewegen. Dabei wurde als wesentlich benannt, dass die Paarfindung ein zwar ebenfalls verhandeltes, aber nachrangiges Problem darstellt und vielmehr vom Thema >Geld< überlagert wird: Die dargestellte Welt ist durch einen deutlichen sozialen »Contrast « (Mügge 1846b: 174) zwischen Bürgertum und Adel gekennzeichnet und durch eine ebenso deutliche Dynamik, die mit Wirtschaftlichkeit korrespondiert und Auswirkung auf monetäre Kapazitäten hat. Gleich zu Beginn wird (Zieh-) Vater Hartberg als »reicher Fabrikant« (ebd.: 159) vorgestellt, der als der »erste Industrielle des Landes« (ebd.) gelten darf. Nach Abreise Georgs geraten die Geschäfte in eine wirtschaftliche Krise und unterliegen hohen Verlusten: Die »Geschäfte unseres Hauses sind in der letzten Zeit sehr verwickelt worden « (ebd.: 199). In Verhandlung des um das Vermögen Hartbergs konkurrierenden Adelshauses Tamnau wird Georg mitgeteilt: »Die Zeiten sind zu böse, um auf einen guten Verkauf der Gebäude zu rechnen « (ebd.: 209). In wirtschaftlicher Hinsicht unterliegt die dargestellte Welt also starken Schwankungen, die eine Dominanz des Geldthemas nach sich ziehen: bezüglich des wirtschaftlichen Standpunktes, mit existenzieller Bedeutung (vgl. ebd.: 215 u. 238) und mit Bezug auf die Vergangenheit (vgl. ebd.: 172). Erkennbar werden in diesem Zusammenhang Tendenzen regressiven und progressiven Handelns, die der Text in eine ausgewogene >Mitte< überführt: Am Ende sind alle Parteien in wirtschaftlicher Hinsicht gerettet - das Adelspaar zumindest vorläufig, das bürgerliche Paar wahrscheinlich nachhaltig. > Regressivität< liegt aufseiten des Adels, der sich für Veränderungen nicht bereit zeigt, sondern im Gegenteil Grenzgänger wie die bürgerliche Agnes - die in ihrer Ehe mit Tamnau dessen Verhaltensweisen annimmt - assimiliert und insgesamt nach außen hin mittels strikter Abgrenzung funktioniert. Wenn mit der Industriellen Revolution eine Neuerung auf globaler Ebene hingenommen werden muss, so liegt das Bestreben des Adels auf der Konsolidierung zumindest der hierarchisch strukturierten Sozialordnung, die aufgrund eines Vermögensdefizits und des drohenden Reputationsverlustes zwischenzeitlich auf der Kippe steht. >Regressivität $<$ ist mit der Unterdrückung von Neuerung gleichbedeutend, hier klar gekennzeichnet durch die versuchte Übernahme und Auslöschung des bürgerlichen Wirtschaftszweiges nach Hartbergs Tod. Das Bürgertum seinerseits ist nicht nur sozial ausdifferenziert (arbeitende Stände, Kaufleute, Gewerbetreibende, teilweise Bedürftige; vgl. ebd.: 174), sondern erscheint verbunden mit produktiven Werten (wie vorzugsweise Leistungsbereitschaft, Rechtsgefühl und Sittlichkeit) und ist mit einer Charaktereigenschaft versehen, die garantiert, über den Selbsterhalt hinaus eine glückliche 
Zukunft zu gestalten. >Progressivität< also ist äquivalent zur Durchsetzungskraft eines dezidiert bürgerlichen Glücks.

(4) Schließlich liegt mit der ästhetisch-kunstreflexiven Dimension ein Strukturkomplex auf Figuren- und Textebene vor, der ebenfalls vergangenheitsorientierte gegen zukunftsorientierte Tendenzen aufstellt und insbesondere als Anlage des Merkmals der Entromantisierung gelesen werden kann. Daher ist es als Spezialfall der regressiv-progressiven Koppelung zu interpretieren und wird im nachfolgenden Kapitel gesondert betrachtet. Einstweilen sei vorausgeschickt: Auch hinsichtlich diverser Formen von >Kunst $<$ - seien es Artefakte oder Künstlerfiguren - sind solche Größen zu beobachten, die tradierte, aber überkommene Poetiken repräsentieren, und wiederum solche, die davon losgelöste, neue Spielarten formieren und in Konkurrenz zu ersteren treten. Auszumachen sind Texte dieser Art bereits in den frühen 1820er-Jahren (Der tote Gast), dann bis in die 1840er-Jahre hinein (Imagina Unruh), gleichwohl dort dann in erster Linie andere, eher >prärealistische< Problemstellungen akut werden. Kernzeitraum derart entromantisierend-verfahrender Texte sind indessen die 1830er-Jahre (zum Beispiel mit Cordelia; vgl. Brössel 2016).

Drei Beispiele: Die Entzauberung von Welt in Der tote Gast basiert auf der bewusst-intendierten und funktionalisierten Fiktionalisierung von Gegebenem. Notwendig in der Personen-Konzeption ist das Bewusstsein einer nichtfantastischen Konstitution von >Welt $<$ : Hauptmann Waldrich erkennt den Status einer Sage als imaginierter Mythos und erzählt sie unter Einbindung einer real existenten Figur zum Zweck der eigenen Partnerwahl neu. Der Text nimmt so eine Trennung vor zwischen einer aus einer Teilperspektive mit starkem Vergangenheitsbezug als fantastisch wahrgenommenen Welt und ihrer Umdeutung durch eine andere Teilperspektive zum Zweck der Zukunftsneugestaltung.

Vischers Cordelia bündelt die Kollision ästhetischer Konzepte in seinen Figuren, die er in ein triadisches Raster bestehend aus >Klassik<, >Romantik $<$ und >Biedermeier $<$ einbettet - wobei wichtig ist zu betonen, dass es sich hierbei um textfunktional eingebundene Topoi handelt, und nicht um literaturästhetische Merkmale (etwa der Weimarer Klassik), die anzitiert werden. Wilhelm tritt als Vertreter der >Klassik $<$, Christoph - und mehr noch Friederich - als Vertreter der >Romantik< auf, während Theobald zwischen beiden Positionen zu vermitteln sucht und Cordelia selbst als Nachkomme einer Italienerin und eines Deutschen und als Ziehtochter des >romantischen< Friederich ebenfalls eine Zwischenstellung bezieht. Mit Hilfe dieser Figuren werden poetologische Standpunkte verhandelt, in Kunstwerken verschiedenster Art werden immer wieder Probleme der Realität verarbeitet. Die zwischenzeitlich als wünschenswert wahrgenommene Verbindung zwischen Theobald und Cordelia wird jäh unterbunden 
durch den leidenschaftlich-affektiv handelnden, unberechenbaren Wilhelm, der Cordelia tötet und sich im Wahn selbst richtet. Friederich stirbt aus Gram, Theobald und Christoph fristen forthin ein resigniertes Dasein. Zukunftsträchtig gelten kann das als neuwertig ausgegebene Kunstkonzept figuriert im temporär realisierten Paar; dessen Progressivität wird aber als >gestört $<$ - auf Textebene also: alteritär - konzipiert, und zwar insofern, als der Konflikt vom Text mit der Goethezeit - insbesondere mit der Klassik - als nachhaltig destruktiv gestaltet wird. Erzeugt wird auch hier ein selbstreflexiv-metatextuelles Moment: Das Literatursystem trachtet nach einer zukunftsgewandten Neukonzeption, die es allerdings bedingt durch die rückwärtsgewandte Belastung durch die Goethezeit nicht zu realisieren imstande ist.

Auch in Imagina Unruh ist die kunstreflexive Dimension mit dezidiert anthropologischen Problemstellungen korreliert: Imagina ist die modifizierte $>$ Romantikerin ‘, die in ihrer gesellschaftlichen Umwelt als Fremdkörper agiert. Mit ihrer fundamental retrospektiven Denk- und Handlungsart wird sie vonseiten der Gesellschaftsvertreter mit gegenwärtigen, politischen Unruhen in Verbindung gebracht und bleibt meistenteils unverstanden. In einer inkonsistenten Welt - bestehend aus ordnungskonsolidierenden und ordnungsrevidierenden Gruppierungen -, deren Zukunftsbild ungewiss ist, hat Kunst allenfalls einen selbstbezüglichen Bestand, ist ihrerseits jedoch nur eingeschränkt zukunftsweisend.

\section{Theoretische Fassung und phasenspezifische Ausbildung}

Zurück zur theoretischen Erfassung der Konfligierung und semantischen Koppelung von >Regression< und >Progression<. Mit einfachen Anführungen werden diese Abstrakta deshalb versehen, weil sie in Texten vielfältig realisiert vorliegen - es handelt sich bei ihnen um Paradigmen, die das Literatursystem aufbaut, um Zeit zu reflektieren und im Zusammenhang damit den eigenen Status im Abgleich mit der Goethezeit und mit Blick auf ein nachfolgendes Literatursystem zu justieren. Eine statistisch belegbare Relevanz ergibt sich allein aus dem Grund, da sie relativ häufig aufgerufen werden. Doch das Literatursystem betreibt ebenso in qualitativer Hinsicht einen enorm hohen Aufwand, sie nicht nur zu installieren, sondern zugleich auch textkonstitutiv einzusetzen. Man könnte auch sagen: Der Zwischenphase geht es im weitesten Sinne immer auch um die Gegenüberstellung von >Neufindung $<$ und >Bewahrung $<$.

Die genannten Varianten weisen gemeinsame Merkmale auf und formieren damit epochenspezifische Kennzeichen. Grundsätzlich ließe sich das folgende Schema aufstellen (Abb. 3.4): 


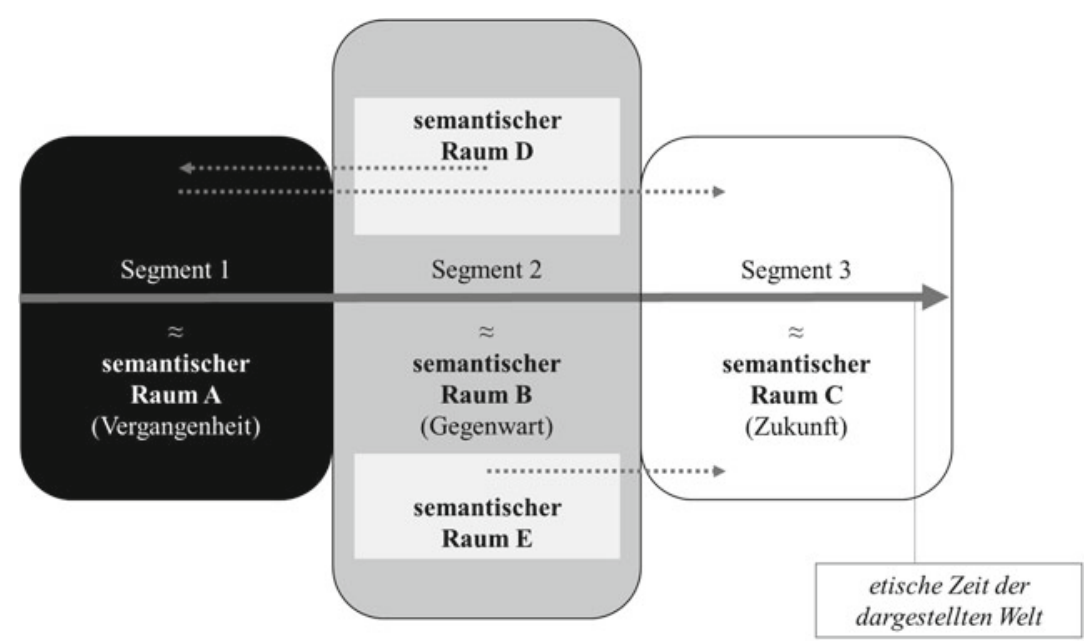

Abbildung 3.4 Schema zum Zusammenhang des segmentalen Zeitmodells und den temporaldeiktisch unterschiedlich ausgerichteten Strukturmengen $>$ Regression $<$ und $>$ Progression $<$

Die Zwischenphase installiert die Zeitsegmente 1 bis 3, nimmt demnach also ein linearverlaufendes, unidirektionales geschichtliches Modell bestehend aus Vergangenheit, Gegenwart und Zukunft an, kennzeichnet diese Segmente zugleich aber als semantische Räume, deren zeitlich bedingte Abfolge als Brüche inszeniert werden und deren Disjunktheitsmerkmal zeitliche Diskontinuität erzeugt. Segment 1 wird gemäß einfachem oder komplexem Modell einphasig oder mehrphasig semiotisiert. Verbunden wird diese Anlage zusätzlich mit der Installation der semantischen Räume $D$ und $E$, wobei $D$ regressive Teilstrukturen versammelt und Eprogressive und beide binnendifferente Teilräume des semantischen Raums $B$ darstellen. D und E laufen dem Gesamtmodell bestehend aus A, B und C insofern zuwider, als sie durch die Ausrichtungen an der Vergangenheit und der Zukunft die Gegenwart mit regressiven beziehungsweise progressiven Merkmalen anreichern, und zwar - dies ist als Epochenspezifikum zu werten - in hochgradig konfligierender Anordnung.

In Texten mit einer solchen Struktur obliegt es den Protagonisten nicht allein, sich mit der Vergangenheit auseinanderzusetzen. Vielmehr stellt diese Konfrontation wohl nur eine Teiloperation eines größeren zeitreflexiven Zusammenhangs dar, in dessen Zuge Werte und Normen, Institutionen, (künstlerische 
und nichtkünstlerische) Artefakte, zwischenmenschliche Bindungen und Verpflichtungen wie sie tradiert, kulturell geformt und habitualisiert vorliegen, auf ihre Gültigkeit und Tragfähigkeit hin geprüft und für das zukünftige Dasein und Zusammenleben gegebenenfalls zusätzlich einer Revision unterzogen werden. >Welten< insgesamt befinden sich im Widerstreit gegenläufiger Tendenzen, seien sie anthropologisch fundiert, sozialgeschichtlich, sozialökonomisch, politisch oder poetologisch-programmatisch.

Das Literatursystem geht in seinen Phasen unterschiedlich mit dieser Dynamisierungsanlage um. Textkorpus A zeichnet sich durch eine Absenz des Komplexes aus. Ausnahmen bilden freilich die Texte Heinrich Zschokkes - Addrich im Moos etwa, dessen hauptsächliche Problemverhandlung sich um revolutionäre Volksaufstände von schweizerischen Dörflern gegen Städter dreht. Umso rascher nimmt seit der zweiten Hälfte der 1820er- und vor allem in den 1830er-Jahren die breitgefächerte Verhandlung der Gegenüberstellung von >Regression< und >Progression< zu - und dies autorengenerationsübergreifend bei Tieck, Hauff, Hebbel, Immermann, Vischer, Mundt und Büchner. Tatsächlich offenbart sich Korpus B - und damit diejenige Phase, der wir eine Krise goethezeitlichen Erzählens diagnostiziert haben - als Kaleidoskop unterschiedlicher Realisierungsformen, auf der alle Dimensionen gleichrangig nebeneinander versammelt sind. Rückzuschließen wäre also, dass das Zeitproblem bestehend aus fortschrittlicher > Vorwärtsgewandtheit<, aktueller Unschlüssigkeit und traditionalistischer >Rückwärtsgewandtheit< hier am größten ist. Resultate dieses Krisenherdes sind zumeist radikaler Natur - es sei denn, Figuren bewegen sich in die anzustrebende >Mitte<. Dies gelingt teilweise (Das Bild des Kaisers) - aber nicht immer (Jud Süß) - bei Hauff und eingeschränkt bei Mundt (Moderne Lebenswirren entgegen Madelon) sowie bei Tieck (Waldeinsamkeit), bei Laube (Das Glück) und Mügge (Zu spät!), nicht aber bei Hebbel, Immermann, Vischer und Büchner. In Korpus C wiederum dominiert die anthropologische Dimension, die zwar teilweise mit anderen der genannten Dimensionen verkoppelt ist, jene aber gegenüber Korpus B deutlich in den Hintergrund drängt. Gleiches gilt für die Radikalisierung des Endzustands, der nun in der Regel durch (scheinbare) Harmonie, in dem Fall durch Relativierung gekennzeichnet wird. Repräsentativ steht dafür das Werk Stifters, dessen Der Hagestolz, Die Narrenburg und Der Hochwald bereits Erwähnung fanden. Gleiches gilt für Bergkristall und Die Mappe meines Urgroßvaters. In Bergkristall sind es wirtschaftliche Belange, durch die sich die entgegenstehenden Dörfer unterscheiden. Die Versöhnung wird aber nicht etwa durch eine Zusammenlegung ertragsbringender Ressourcen erreicht, sondern durch die Rettung verirrter Kinder, die die Nachkommenschaft eines grenzgängerischen Paares repräsentieren. Die titelgebende Mappe in der anderen Erzählung Stifters wiederum macht 
ebenfalls auf den zentralen Kulminationspunkt aufmerksam, ist es doch die phylogenetische Entwicklung der Familie im Kleinen und der Gesellschaft im Großen, die dem Bedürfnis des Rahmenerzählers nach Retrospektive und Überlieferung entgegensteht, und deren latente Konfrontation zur Entfremdung innerhalb der Familie führt (vgl. Adam 1993: 140 f.). Auch andere Texte zeigen diese Tendenz auf, etwa Dronkes Kriminalnovelle Das Unvermeidliche (Anthropologie und Jurisprudenz), ${ }^{9}$ Schückings und Drostes Der Familienschild (Anthropologie und Sozialgeschichte), Tiecks Waldeinsamkeit (Anthropologie und Ästhetik), Hebbels Die Kuh (Anthropologie und Ökonomie). Die Ausnahme hier bildet Ottos Die Lehnspflichtigen, der zwar idealtypisch für die Ausformung des Komplexes steht, zugleich aber an Texte der 30er-Jahre erinnert und im Kontext der 40er-Jahre etwas aus dem Rahmen fällt.

\section{Zur Überlagerung zirkulärer und linearer Zeit bei Tieck, Zschokke und Stifter}

Der Umstand, dass zwei Strukturmengen vorliegen, die kollidieren und einen kardinalen Verhandlungskomplex darstellen, steht, so wurde deutlich, im Zusammenhang mit dem Umgang mit Zeit in dargestellten Welten unseres Literatursystems. Und dieser Zusammenhang ist wichtig: Uns geht es nicht um die Verarbeitung außerliterarischer Diskurse (hervorgebracht beispielsweise durch die politische Ereignisgeschichte), ebenso wenig, wie um das Nachspüren philosophischer Theoreme (etwa derjenigen Hegels) ${ }^{10}$-, sondern um einen Sonderfall der Zeitsemiose. Neben der Frage also, in welchen Konkretisationen die Semantiken der Regression und Progression auftreten, ist der Frage nach ihrer Korrelation mit Konzepten und der Modellierung von Zeit nachzugehen. Sie lässt sich vorläufig wie folgt beantworten:

\footnotetext{
${ }^{9}$ Dronke hat im Übrigen neben seinen literarischen Texten eine auch in zeitreflexiver Hinsicht bemerkenswerte Studie über die Stadt Berlin vorgelegt (vgl. Ernst Dronke: Berlin. Mit einer Einführung von Hans Christoph Buch. Berlin 2019 u. Zischler [2020]).

${ }^{10}$ Diesem Vorhaben hat sich beispielsweise eine Dissertation im Rahmen des DFGgeförderten Schwerpunktprogramms »Ästhetische Eigenzeiten. Zeit und Darstellung in der polychronen Moderne « zugewandt. Der Teilbereich, dem die Dissertation zu Stifter zugeordnet ist und der von Sabine Schneider (Zürich) verantwortet wurde, war Teil der ersten Förderphase und trug die Überschrift: »Entschleunigung. Moderne Zeiterfahrung und poetische Eigenzeit in der Prosaliteratur des 19. Jahrhunderts (Stifter, Raabe)«. Vgl. die Homepage zum Projekt: aesthetische-eigenzeiten.de/projekt/entschleunigung/beschreibung/; aufgerufen am 22.12.2020.
} 
Die Semantiken der Regression und Progression werden semiotisch auf die Koppelung linearer und zirkulärer Zeitmodelle/-konzeptionen projiziert.

Unberührt bleibt dieser Befund von der Tatsache, dass teleologisch-lineare und zyklisch-zirkuläre Zeitkonzeptionen in geschichtsphilosophischen Zusammenhängen bereits im 18. Jahrhundert gefunden werden können, etwa in Giambattista Vicos Grundzügen einer neuen Wissenschaft über die gemeinsame Natur der Völker (1725/30), dessen Ricorso-Modell beide Vorstellungen von Zeit zu vereinen versucht. Vielmehr ist davon auszugehen, dass die Modellierungsform der Verzahnung und gegenseitigen Beeinflussung von zyklischen und linearen Strukturen für die Zwischenphase signifikant ist und im Rahmen zeitreflexiven Erzählens eine große Rolle spielt.

Konstatiert worden ist dies an anderer Stelle etwa am exemplarischen Fall der späten Texte Ludwig Tiecks: Er »thematisiert beide Zeit-Modelle, das der Teleologie wie das der Zirkularität in Lebenslaufmodellen wie in Dichtungskonzepten « (Hagestedt 1996: 186). In Auseinandersetzung mit Der junge Tischlermeister ist davon die Rede, dass das Subjekt dem »leeren alltäglichen Kreislauf « (ebd.) zu entfliehen anstrebt sowie von einer »Forderung der Iteration des Jünglingsalters « (ebd.) durch die Figuren und vom entgegenstehenden, linear verlaufenden und »unaufhaltsame[n] und unumkehrbare[n] Alterungsprozeß« (ebd.). Ein gutes Beispiel ist auch Der fünfzehnte November. Konstitution und Entwicklung(-sstagnation) des Subjekts, eingeschriebene Zahlenordnungen gebunden an Zeiträume und Daten, die Anniversität und individuelle und globale Ereignisse zeigen an, dass der Text Linearität und Zirkularität koppelt, um dadurch die »zerstörte Einheit der Welt« (ebd.: 190) zum Ausdruck zu bringen. Man kann sagen: Dieses zweidimensionale Modell nimmt im Denken am Ausgang der Goethezeit einen zentralen Platz ein, schließlich wird mit ihm die Möglichkeit eingeräumt, das teleologische Konzept von Geschichte (des Einzelnen und der Kultur) zu revidieren, denn »wenn eine einmalige Iteration möglich ist, dann ist vielleicht auch eine mehrmalige möglich« (ebd.: 192).

Wir wollen weiterführend argumentieren: Erstens handelt es sich beim angesprochenen Sachverhalt um ein teilphasenübergreifendes Phänomen - es findet sich in den Korpora A, B und C; in A lediglich vereinzelt, häufig dann in B und C. Zweitens steht es im Zusammenhang mit Zeitreflexion. Wie aus unterschiedlichen Blickwinkeln angesprochen, fungiert Zeitreflexion als strukturell-semantischer Träger literarischen Wandels. Das heißt, über die Auseinandersetzung mit Zeit und über Konflikte literarischer Welten rückt ein poetologisches Problem in den Fokus: die Loslösung von der Goethezeit und die Neufindung eines unbekannten, aber intendiert anderen Systemzustands. Die Relation Linearität korr. Zirkularität 
ist ein Fingerzeig auf das Hadern zwischen diesen beiden Orientierungspunkten und zeitreflexiv prägend.

Das Problem ist auch in Die Lehnspflichtigen zentral-fundamental. Wenn die zyklisch wiederkehrende Jahreszeit des Frühlings mit der Möglichkeit einer Neuordnung von >Welt< in Beziehung steht und zugleich das Liebespaar erneut zusammentrifft und ihre Verbindung symbolisch mit einer goldenen Uhr greifbar macht, so wird zunächst die deutliche Semantisierung von zirkulärer Zeit als Träger der beiden Problemfelder offenbar. Die Verhandlung der dargestellten Ordnung in der unmittelbaren Vergangenheit und stärker noch in der Gegenwart, wie auch die potenzielle Vereinigung der beiden Hauptfiguren in der Zukunft, indizieren wiederum ebenso deutlich ein lineares Zeitverständnis, das der Textwelt inhärent ist. Bemerkenswert ist das Ende: Mit der Tilgung seiner Hauptfiguren, die als Hoffnungsträger einer versöhnlichen Lösung hätten fungieren können, ist eine Zwischenlösung für das soziale Problem verknüpft. Denn nach dem gewaltsamen Konflikt der Erzählgegenwart kehrt die Ordnung in einen Zustand der modifizierten Vergangenheit zurück. Die Grafschaft behält die Vorherrschaft, gleichwohl sie einige Obrigkeitsrechte abtritt. Auf Sozialebene verfährt der Text also zirkulär. Linearität und Zirkularität sind dieser Ordnung am Ende gleichermaßen eingeschrieben.

Nehmen wir drei weitere Texte der Korpora A, B und C in die Hand und schließen bei Tieck an. Seine Novelle Waldeinsamkeit weist die "Aufeinanderprojektion zyklischer und linearer Strukturen « (ebd.: 187) auf, die der Text auf mehreren Ebenen verankert und so Zeitreflexion evoziert. Waldeinsamkeit ist als entromantisierender Text zu lesen, insofern er werkimmanent reflexiv die eigene Position als späte und dezidiert postromantische Schrift thematisiert: Der titelgebende Neologismus $>$ Waldeinsamkeit< referiert intertextuell auf ein repräsentatives, da für die Romantik stilbildendes Kunstmärchen Tiecks - Der blonde Eckbert (1797) -, in dem >Waldeinsamkeit< als topografisch-semantischer Brennpunkt der zentralen Problematik einer »Indifferenz von Wahrnehmung und Halluzination [gestaltet wird], die letztlich die [...] Ununterscheidbarkeit von Realität und Traum und die Unfestigkeit der Figur fortschreibt« (Kremer 2016: 507). Vor diesem Hintergrund wird ein Bezug dadurch aufgebaut, dass der spätere Text >Waldeinsamkeit< zum einen als romantisches Zeichen thematisiert, das im kulturellen Wissen der Handlungsgegenwart inventarisiert erscheint und zugleich mehrheitlich als antiquiert und nicht zeitgemäß gewertet wird, und er den Ausdruck zum anderen synthetisierend-topografisch umsetzt und auf diese Weise inszeniert. Denn im Handlungsverlauf wird der Held Ferdinand durch Intriganten entführt und als Gefangener in einem »kleine[n] rätselhafte[n] Haus mitten in einem dichten Walde« (Tieck 1986 [1841]: 881) gehalten: »[U]nd so erstaunt der 
junge Gefangene noch immer war, so mußte er doch lächeln, als ihm jetzt jenes kleine Gedicht von der Waldeinsamkeit einfiel« (ebd.; Hervorhebung im Original). Das Zeichen >Waldeinsamkeit< steht folglich metonymisch für ein ganzes Zeichenarsenal, das seinerseits stellvertretend für die Romantik genutzt wird und bereits in zyklische Strukturen innerhalb eines Gedichtes eingebettet ist (Abb. 3.5):

\section{Abbildung 3.5}

Zirkularität in Tiecks

Waldeinsamkeit

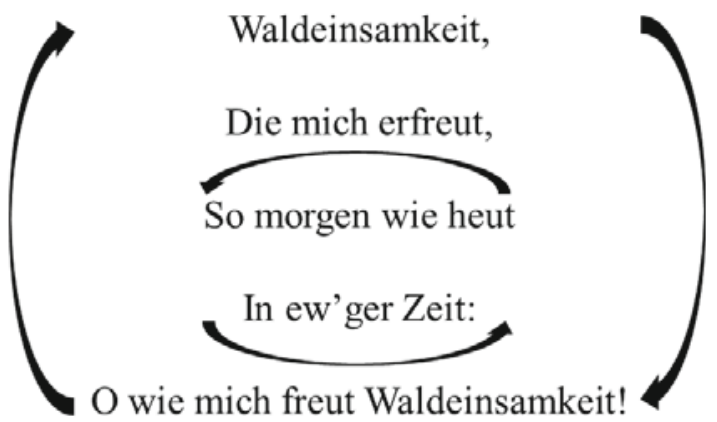

Angezeigt wird in diesem Teilausschnitt, den der Text aus dem Ursprungstext übernimmt, Zirkularität erstens formal, indem »Waldeinsamkeit« den Text einleitet wie auch abschließt, zweitens in der Proposition »morgen wie heut«, einer täglichen Iteration äquivalent, die zugleich drittens gegen die Chronologie angeordnet ist und zeitenthoben ad infinitum wiederholt wird.

Zirkulär funktioniert der Text Waldeinsamkeit also erstens, indem er einen werkimmanent intertextuellen Bogen spannt und Vergangenes iterativ aufgreift - und diese Referenz zugleich das Paradigma der Zirkularität unterstreicht und anreichert -, und zweitens, indem er seinem Helden eine regressive Grundtendenz einschreibt und ihn de facto temporär in einen romantischen Vergangenheitszustand versetzt. Dem entgegen steht die lineare Zeitstruktur der Erzählung. Obgleich nämlich Ferdinand zunächst regressiv agiert und ihm die Versetzung in einen entsprechenden Raum nicht vorenthalten bleibt, vollzieht er doch auch eine Entwicklung. Er wird sich seiner Lage als Opfer einer Intrige und seiner >artifiziellen< Umwelt bewusst - er lernt im übertragenen Sinne die >Romantik< als eine nicht mehr lebbare, allenfalls im distanzschaffenden Modus einer reaktivierbaren Kunstform und -richtung zu begreifen, die mit der Wirklichkeit nur in eingeschränktem Maße vereinbar ist. Die Folge ist ein Einstellungswechsel Ferdinands. So stellt er einerseits erbittert und lachend fest: »Die Waldeinsamkeit [...] hat mich zugrunde gerichtet« (ebd.: 930). Andererseits betritt er gemeinsam mit seiner 
Frischvermählten Sidonie erneut den Raum seiner Gefangenschaft und harmonisiert die Bezüglichkeit zur Romantik mit einem beginnenden bürgerlichen Leben im Stand der Ehe. Anders gewendet ließe sich dies als Initiationsgeschichte mit glücklichem Ausgang lesen. Die Modifikation gegenüber dem goethezeitlichen Modell aber ist offensichtlich, wird der Held schließlich in der Transitionsphase äußerlich und innerlich isoliert. Und doch folgt auch das vorliegende Modell einem linearen und unidirektionalen zeitlichen Verlauf, an dem eine Entwicklung der Figur - gleichwohl als deutlich sprunghaft markiert - ablesbar ist. >Romantik< in Waldeinsamkeit wird einem Statuswechsel unterzogen: vom Status der Wirklichkeitsintegrität - >Romantik< als Teil der Wirklichkeit im Sinne einer Wirklichkeitssphäre der kunstproduktiven Bezüglichkeit des Subjekts zur Natur - hin zum Status der Differenz zwischen >biedermeierlicher Wirklichkeit einerseits und romantischer Kunst/Ideologie als Bezugspunkt innerhalb dieser Wirklichkeit andererseits. Indem der Text das Konzept der Romantik noch beibehält, es lediglich umdeutet und damit das Moment der Rückschau auf sie und auf die romantische Immersion vonseiten der Figuren über das Ende hinaus zulässt, verfährt er anders als Der fünfzehnte November, worin das zirkuläre Zeitmodell am Ende aufgegeben und in ein rein-lineares überführt wird.

Ähnlich wiederum wie Der fünfzehnte November realisiert auch Zschokkes Der tote Gast die Modellierung zirkulärer und linearer Zeitkoppelungen: Der Rückkehrer Georg Waldrich und seine Ziehschwester Frederike Bankes verbindet eine gegenseitige Liebe, deren Zukunft durch die Aussicht auf eine vom Vater arrangierte Heirat bedroht wird. Zusätzlich zu diesem Problem im kleinen Rahmen sind verlobte Frauen im dargestellten Teilraum grundsätzlich gefährdet durch die regelmäßige Wiederkehr eines ominösen Geistes, der alle 100 Jahre in der Adventszeit mordend durch das Dorf zieht. Dem Handlungsverlauf ist ein Metaereignis angeschlossen, infolgedessen der Handlungsraum - zwar nur teilweise, dafür aber wesentlich - von einem potenziell fantastischen zu einem nichtfantastischen Raum umsemantisiert wird. Zirkularität ist mit der regressiven Ausrichtung des Raums Herbesheim zu Beginn verbunden: Ihm ist die Orientierung an der Vergangenheit derart deutlich eingeschrieben, dass sich neben der stark betonten Aufgeklärtheit und Vernunft des Vaters Bankes die Dominanz einer abergläubischen Realitätsauffassung abzeichnet und damit verbunden der zyklische Auftritt eines fantastischen Elementes einstellt, dessen Entstehung und Wirken sich 200 Jahre zurückverfolgen lässt. Mit Erzähleinsatz ist der genaue Ursprung des Schreckens aufgrund einer lückenhaften Dokumentenlage nicht eindeutig zu rekonstruieren. Bemerkenswert aber ist, dass die Problematik auf dieser Ebene - der des Kollektivs - überhaupt erst durch die detaillierte Erzählung Waldrichs in Gang gesetzt wird, der den Aberglauben des Ortes ausnutzt, um seinen 
- ihm zunächst unbekannten Widersacher - zu dämonisieren und Frederike für sich zu gewinnen. Einher geht damit eine >Entzauberung < von >Welt $<$ und auf den ersten Blick ebenfalls eine Aufgabe des zirkulären Zeitmodells: Im Endzustand wird das Narrativ um den toten Gast als bloße Fiktion enttarnt und erhält den Status einer für die Realität folgenlosen Sage. Die Bedrohung wird trivialisiert und als bloße, durch den Aberglauben hervorgerufene Verblendung verlacht. Sogar die potenzielle Rivalität der beiden Anwerber löst sich in gegenseitiges Einvernehmen und Freundschaft auf.

Allerdings wird das Weltmodell auch hier nur teilweise in ein lineares Entwicklungsmodell eingebettet und ist allein einer Erzähllogik verpflichtet, die in dieser Hinsicht als entromantisierend klassifiziert werden kann. Die Substitution nämlich eines für den Teilraum gültigen zirkulären Modells findet durch ein andersgelagertes, linear-zirkuläres Modell statt, das die Problematik, die der Zwischenphase eigen ist, in zeitreflexiver Hinsicht latent indiziert. Denn bereits zu Beginn wird angezeigt, dass sich die Gegenwart durch eine politisch-zeitgeschichtliche Prozessualität auszeichnet, die im Zeichen der Französischen Revolution und der Vorherrschaft Frankreichs in Europa steht und sich schließlich in den Befreiungskriegen auch in Deutschland entlädt. Herbesheim wird davon allenfalls tangiert, ist am europolitischen Geschehen nur indirekt beteiligt - ebendies dient aber als Grund für die Rückkehr des Hauptmanns Waldrich, dessen Garnison Stellung in Herbesheim bezieht. Das heißt, ohne das politische Geschehen, das die lineare Entwicklung der dargestellten Welt anstößt und zu tragen scheint, wäre Waldrich nicht erneut vor Ort. Jedoch ist das, was ihm widerfährt und wie er agiert als hochgradig regressives Handeln zu werten, ein Handeln, das wiederum Zirkularität erzeugt: Erstens kehrt Waldrich tatsächlich in dasjenige soziale Umfeld zurück, das er vor seiner Laufbahn als Soldat verlassen hatte. Zweitens - und noch folgenschwerer - verliebt er sich in seine Ziehschwester. Verzahnt mit diesen Umständen ist die Doppelcodierung des individuellen Entwicklungsmodells als zirkuläres Modell, insofern das Modell am Ende der Transitionsphase, die als solche vom Text deutlich markiert ist, die Rückkehr in den Ursprungsraum vorsieht und eine endogame Paarbildung - gegenüber einer optionierten exogamen - als wünschenswert ausstellt. Dadurch wird zwar eine - und zwar die offensichtliche - Variante von Zirkularität (= der Zyklus des toten Gastes) fallengelassen, diese aber lediglich durch eine andere, latente Variante ersetzt. Der Loslösung von Zirkularität auf der Kollektivebene wird die Absage an ein exogames Paarbildungsmodell durch die jüngere Generation zugunsten einer endogamen Paarbildung entgegengestellt, die mit einer autopoietischen Funktionsweise von >Kultur $<$ im kleinsten Sozialraum gleichbedeutend ist: die quasiinzestuöse Selbstreproduktion in der Familie. Zirkularität wird lediglich verschoben, nicht aber aufgehoben. 
Ähnliches lässt sich in Stifters Der Hagestolz beobachten. Die Erzählung verfügt im Gegensatz zu Der tote Gast - und später im Übrigen auch Gerstäckers Germelshausen (1862) - von vornherein über keine offensichtlich-zyklische Teilstruktur. Allerdings, so hatten wir herausgestellt, substituiert er ein Zukunftskonzept, das Autonomie unter Ausschluss der Ehe vorsieht, durch ein Zukunftsmodell der Heteronomie und endogamen Partnerwahl und stellt auf diese Weise Zirkularität auf anthropologischer Ebene her. Die Normalisierung des Subjekts sieht hier vor, die Loslösung von der Familie zu vermeiden und das Subjekt zur endogamen Partnerwahl zu bewegen. Maximale Endogamie ist der anzustrebende Wert; installiert wird dadurch ein Zukunftsmodell, in dem mit der Vergangenheit restaurativ umgegangen wird. Das >richtige< Lebenslaufmodell zielt demnach darauf ab, die Dominanz der regressiven gegenüber der progressiven Richtung zu akzeptieren. Victors Initiation glückt infolge seiner Akzeptanz - sie >glückt $<$ jedoch zum Preis der Selbstaufgabe, die der Text als solche in der Applikation der goethezeitlichen Initiationsgeschichte zu kaschieren versucht. >Regression< wiederum ist mit der Restauration von >Vergangenheit< in der Zukunft verknüpft und damit mit ihrer potenziell zyklisch-iterativen Rekapitulation verschränkt.

Aus alledem wird deutlich: Die Zwischenphase projiziert >Regression< und >Progression< auf Zirkularität und Linearität, indem sie diese mit jenen in Verbindung setzt. Treten regressive Strukturen in Texten auf, so sind sie an der Vergangenheit orientiert und streben an, die krisenhafte Gegenwart durch die Erneuerung der Vergangenheit zu überwinden. Sie heben auf ein zirkuläres Zeitverständnis ab, indem sie die Vergangenheit auf die Zukunft und die Zukunft auf die Vergangenheit beziehen. Progressive Strukturen tendieren hingegen dazu, sich von der Vergangenheit zu lösen und andere Konzepte umzusetzen und verfolgen ein lineares Verständnis von Zeit, wobei sie jedoch auf die Abkapselung von der Vergangenheit pochen.

Ganz gleich also, in welcher Realisierungsform >Regression< und >Progression $<$ - wie oben in Form verschiedener Dimensionen - aufgefächert vorliegen mögen, auf abstrakt-semantischer Ebene läuft ihre Koppelung stets auf eine Problematisierung von $>$ Zeit< hinaus.

\subsection{Figuren}

Kommen wir von Weltsystemen, ihrer Beschaffenheit und inneren Regulationen zu ihren Bewohnern. Figuren, so konnte bis hierher nachvollzogen werden, fungieren nicht nur als Träger temporaler Merkmale, deren Funktion in der Staffage fiktionsintern realexistenter, anthropomorpher Wesen bestünde - getragen etwa 
vom Alter einer Figur und seiner Klassifikation beispielsweise als Jüngling. Vielmehr wird über das Textelement der Figur, über ihre Semantik, ihre Konfligierung mit anderen Elementen, ihre Wahrnehmung und über ihr Erleben von Zeit zu einem fundamentalen Problem erhoben: Texte nutzen Figuren, um Zeit zu semiotisieren und zu reflektieren und darüber ihre eigene Beschaffenheit und ästhetischen Möglichkeiten eines von der Goethezeit abhängigen Nachfolgersystems zu artikulieren. Tatsächlich sind Figuren »eine Grundkomponente der erzählten Welt« (Martínez 2011: 145); sie sind hier aber noch mehr als das: Denn neben der Mehrfachcodierung ihrer Temporalsemantik thematisieren sie Zeit explizit, indem sie sich mit der Vergangenheit auseinandersetzen, ihre Zukunft planen oder über Gegenwartszustände klagen, und sie tun dies implizit, indem sie in epochalevolutionärer oder in ideologischer Hinsicht im Kontext der dargestellten Welt tradierte respektive anachronistische oder modern-neuartige Werte und Normen vertreten und >regressiv $<$ oder > progressiv $<$ motiviert sind.

Im letzten Kapitel hatten wir in Auseinandersetzung mit der Textinstanz der Figur Initianden fokussiert sowie Bedingungen und Möglichkeiten einer gelingenden Initiation im Rahmen eines gegenüber der Goethezeit modifizierten Erzählmodells diskutiert. Wenn wir die Perspektive in diesem Teil erweitern, so geht es uns um die Erfassung von Dynamiken, denen Welten unterworfen sind. Neben der statischen Grundordnung, die uns im letzten Kapitel beschäftigt hatte, sollen so verstärkt Verschiebungen von diegetischen Gefügen in den Fokus rücken.

Wir haben dies zuletzt in Ottos Lehnspflichtigen beobachten können: Erstens etabliert der Text die Anlage einer >regressiven Struktur< (Adel), einer >progressiven Struktur< (aufständisches Volk) und einer >mediatorischen Struktur< (Hannah und August). Zweitens überführt er diese in einen dynamischen Handlungsverlauf, indem er sie in konfligierende Beziehung setzt und in Bewegung bringt: Hannah und August konspirieren, die Aufständischen dringen in den ihnen fremden Raum ein. Drittens zeigen sich Auswirkungen dieser Bewegungen sowohl für die Figuren als auch für das Weltsystem insgesamt: August und Hannah sterben, die Ordnung wird geringfügig umgestellt.

Eine derartige Blicköffnung erlaubt es, der konkreten Realisierung von $>$ Regression< und >Progression< und ihrer Relation zur Reflexion von Zeit im Literatursystem nachzugehen. Denn wenn Zeitreflexion das prägende Merkmal und wenn ein wesentliches Epochenspezifikum der hier gestalteten Zeitreflexion die als problematisch wahrgenommene Determination der Gegenwart durch die Vergangenheit ist, und wenn weiterhin deren Problematisierung die Modellierung von >Zukunft< als Verhandlungsraum nach sich zieht, dann ist auch die Semiotisierung von $>$ Regression $<$ und $>$ Progression $<$ in und mit den Figuren signifikant 
und konstitutiv für diesen Komplex, da an ihr die temporalsemantischen Segmente überhaupt erst konkret in Erscheinung treten.

Mit dieser Zeitsemiose in Figuren zeigt sich nicht zuletzt auch der Umgang des Literatursystems mit der selbst auferlegten Problematik des Interims wie auch mit Lösungsstrategien, die anzustrebende und wünschenswerte oder nicht erstrebenswerte Zustände implizieren können. Denn aufgebaut ist der Reflexionsbereich zwar über die Leitdifferenz $>$ Alt $<$ vs. $>J u n g<$, seine Zuordnung allerdings ist variabel: Figuren beider Gruppen können regressiv oder progressiv charakterisiert sein, abhängig von der Konkretisierung der diegetischen Heterogenität und des anthropologischen Fokus. Dazu sollten Figuren im Handlungskontext betrachtet werden: Wesentlich sind dafür subjektiv-statische wie auch handlungsbezogenflexible Personen-Charakteristika, die Ereignisstruktur eines gegebenen Textes, die Zuweisung von Figuren im semantischen Feld bestehend aus den oben genannten Räumen A bis E, ihr Verhältnis zu anderen Figuren ihres sozialkulturellen Umfeldes und - je nach Geschehensverlauf - auch ihre Bewegungen und Raumwechsel.

Im Anschluss an die bisherigen Ausführungen zu dominanten Weltsystemen wird zuvorderst die Semiose und die Signifikation des Verhältnisses von etischer, emischer Zeit und subjektiver Zeit in den Blick genommen. Denn offensichtlich kommt eine Konfrontation mit der Vergangenheit durch eine Störung emischer Zeit zustande: Die Gegenwart oszilliert zwischen einem Zeitverständnis, das epistemisch einerseits durch die Erfahrung aus der Vergangenheit und andererseits durch ein davon losgelöstes Verständnis angereichert ist, das die Vergangenheit kritisch beäugt und den aktuellen Status als Krise und Übergangszustand, als unverständlich und unerträglich beschreibt. Entsprechende Ergebnisse dienen als Grundlage, um zum einen signifikante Relationsmuster zwischen Zeitreflexion und literarischer Anthropologie zu erfassen, und zum anderen, um >Zerrissenheit $<$ zu erörtern - einem Merkmal, das die Zwischenphase appliziert und epochenspezifisch im Sinne figürlicher Kulminationen von >Zeitstörungen< ausbildet.

\section{Zeit, Kultur, Individuum: Die Inkompatibilität von etischer, emischer und subjektiver Zeit bei Mundt, Eichendorff und Stifter}

Eines der Hauptprobleme, an dem sich die Zwischenphase abarbeitet, besteht darin, dass die Auffassung von Zeit aufseiten der Individuen von der geschichtlichen Zeit abweicht, in der das Geschehen situiert ist. Dabei geht es nicht um fiktionsintern tatsächlich realisierte Zeitparadoxien - herbeigeführt etwa durch 
Zeitreisen -, sondern um den Kontrast, die Divergenz zwischen mentalen Zeitkonzepten einerseits und diegetisch-ontologischen Zeitmodellen andererseits, und zwar im Hinblick auf das figürliche Erleben dargestellter Zeitgeschichte.

Das Problem lässt sich anhand der Unterscheidung zwischen etischer, emischer und subjektiver Zeit nachvollziehen. Als etische Zeit hatten wir die unabhängig von kultureller oder subjektiver Ausdeutung übergreifende, allumfassende und intersubjektiv wahrnehmbare Zeit definiert, als emische Zeit ihre kulturspezifische Konzeptualisierung, als subjektive Zeit die an das Erleben der Figuren gekoppelte Zeit. Eine Besonderheit literarischer Texte gegenüber anderen Formen artifizieller Artefakte liegt ja nun bekanntlich darin, dass sie Zeit und Zeitlichkeit - in einem engeren Sinn ${ }^{11}$ - nicht direkt abzubilden imstande sind und sie sie stattdessen literarisch semiotisieren und mittels Semiotisierung erzählte Welten temporal semantisieren und strukturieren. Wie unter Zuhilfenahme von de Toros Taxonomie ersichtlich, reicht dabei die Reichweite über eine schlichte Benennung von Erzählzeit und erzählter Zeit hinaus.

Die dominant gestaltete etische Zeit in Welten des Literatursystems ist eine chronometrische, linear und unidirektional verlaufende Zeit, die insofern >objektive Zeit< genannt werden kann, als sie sich als (etwa durch Gottheiten oder fantastisch-wunderbare Gesetzmäßigkeiten) nichtsteuerbar verhält. Sie fungiert vielmehr als eine jeglichen Instanzen übergeordnete, der Welt eingeschriebene, konsistente Dimension. Geschichtliche Prozesse getragen durch kollektives Handlungsgeschehen und individuelle Handlungsverläufe lassen sich so auf einem Zeitstrahl abbilden, ohne dass - wie denn teilweise in der Literatur des 20. und 21. Jahrhunderts - in ihrer Rekonstruktion Widersprüche oder temporale Inkohärenzen auftreten würden. ${ }^{12}$ Abweichungen von diesem Modell sind freilich vorhanden - dann in Form temporalsemantischer Heterogenität des Raums, wie im Fall des Inselraums in Der Hagestolz, der nicht nur durch die Überlagerung von >Alt< und $>$ Jung $<$ binnenstrukturiert ist, sondern auch gegenüber dem Außenraum ein retardiertes Zeitsystem aufweist; oder wie im Fall des Städtchens

\footnotetext{
${ }^{11}$ Im weiteren Sinn grenzen sich Texte der Dichtung - wie schon Lessing in seinem LaokoonAufsatz (1766) ausgeführt hat - durch ihre immanente Zeitlichkeit von Werken der Bildenden Kunst ab (vgl. Lessing 1990: 115 f.). Ihre Zeitlichkeit basiert auf einer im Text fixierten Handlung, die im Rezeptionsprozess dynamisiert wird. Wir wollen an dieser Stelle davon ausgehen, dass schriftsprachliche künstlerische Erzähltexte idealgenetische Prozesse abbilden und diese Prozesse idealiter zeitlich konstituiert sind, somit Zeit - wie auch Raum, Figur, Erzähler - ein fiktives Konstrukt ist und als solches im Text angenommen werden muss. Vgl. dazu auch Genette (2010 [1972/1983/1994]: 17 f.) u. Blödorn/Brössel (2020: 17-24).

${ }^{12}$ Vgl. beispielsweise die Erzähltexte der Strömung des Nouveau Roman im Allgemeinen und die Texte von Alain Robbe-Grillet (unter anderem La Maison de rendez-vous [1965]) im Besonderen.
} 
Kleinweltwinkel in Mundts Moderne Lebenswirren, ein ebenfalls mit retardierter Zeit belegter und temporalsemantisch von der Außenwelt separierter Teilraum. Darüber hinaus werden die Eigenschaften der etischen Zeit in anderen Texten insbesondere beim Verständnis einer emischen Zeit nicht umstandslos hingenommen - ja mehr noch: Etische Zeit wird stellenweise ganz offen in Frage gestellt. Mit Ordnungswechseln, die eine Krise der fokussierten Gegenwart mit sich bringen, hängt ganz offensichtlich auch die Reflexion von Zeit zusammen. Und das betrifft zum einen die Reflexion eines >Bruchs $<$ in der (geschichtlichen) Zeit wie auch zum anderen die Möglichkeit eines neuen Zeitverständnisses, das ein gegebenes Verständnis ersetzen könnte. Gänzlich entgegengesetzt zur etischen Zeit erscheint denn gar die Realisierung der subjektiven Zeit - Individuen verhalten sich in diesem Zusammenhang in temporaler Hinsicht teils orientierungslos: So haben Figuren in unterschiedlichen Kontexten gemein, dass sie sich in ihrer Welt nicht mehr problemlos zurechtfinden und dies dann auch zeitreflexiv zum Ausdruck bringen.

Aufgerufen wird dieses Problemfeld in Texten seit den 1830er-Jahren und hat dort seinen hauptsächlichen Verhandlungsort. In Textkorpus A findet es sich allenfalls marginal ausgebildet, in Textkorpus $\mathrm{C}$ geht die Offensivität, mit der es auf der Textoberfläche auftritt, zurück und wird durch subtilere Konstellationen ersetzt. Man kann daraus den Schluss ziehen, dass sich die Spätromantik bis Mitte der 1820er-Jahre augenscheinlich zwar in anderen Bereichen - wie zum Beispiel im Fall der Initiationsgeschichte - sukzessive von bestimmten Mustern und Modellen abzusetzen beginnt und dies mit zeitreflexiven Strukturen versieht - aber eben (noch) nicht die genannten Schaltstellen geltend macht. Dieser Befund bestätigt jedenfalls die obige Feststellung, dass wir die Koppelungsstruktur (>Regression/Progression $<$ ) in diesem innerepochalen Abschnitt nicht vorfinden. Genannte Ausnahmen stellen Zschokkes Der tote Gast und Addrich im Moos dar. Ersterer unternimmt die Umsemantisierung eines seiner diegetischen Teilräume mittels Re-Narrativierung und transponiert damit Zirkularität von der Kollektivebene auf die Individualebene. Addrich im Moos setzt ebenfalls Kollektiv- und Individualebene in Beziehung: Die gewaltsamen politischen Auseinandersetzungen korrespondieren mit der Findung des Paares, dessen Beziehung durch einen Dritten bedroht wird sowie dadurch, dass beide Figuren mit der Umdeutung ihres Verhältnisses als Ziehgeschwister hin zu einem Liebespaar >kämpfen< müssen. Beide Texte antizipieren ihrer Anlage nach Konfliktanordnungen der 30er- und 40er-Jahre. ${ }^{13}$ Im Unterschied dazu scheinen >präく- oder frührealistische Texte der

\footnotetext{
${ }^{13}$ Dahingegen arbeiten sich andere Texte Zschokkes - obwohl ihre Titel auf eine entsprechende reflexive Anlage hindeuten mögen (Nur eine zwölfstündige Todesangst, Die Nacht
} 
1840er-Jahre gegenüber Texten der 30er-Jahre die deutlichere Tendenz aufzuweisen, Zeitprobleme zwischen erzählter Welt, dargestellter Kultur und Subjekt in anderen (und zwar anthropologischen) Problemen zu verankern und hierdurch mit Zeitreflexion zu operieren. Dass eben >Zeit< ein tiefgreifendes Problem in Hebbels Die Kuh ist, lässt sich, wie besprochen, nur auf den zweiten Blick ersehen - oberflächlich besehen dreht sich der Text um eine materialistisch-frühkapitalistische Problemstellung. In Stifters Der Hagestolz sind deutliche Kaschierungsstrategien benannt worden - doch auch dort ist der Umgang mit >Zeit< erst bei näherer Auseinandersetzung zutage getreten. Und letztlich unterstreicht auch Die Lehnspflichtigen die Hypothese: Die geschichtliche Zeit darin verhält sich >brüchig<. Das Kontinuum reißt ein. Figuren haben sich entsprechend >ihrer Zeit< zu stellen.

Wie genau werden etische und emische Zeit semiotisiert, inwiefern davon eine dezidiert subjektive Zeit abgesondert, und wie verhalten sich diese Dimensionen zueinander? Beobachten lassen sich zwar verschiedene Strategien der Differenzierung und Semantisierung der drei Zeitdimensionen; ihre Semiose und gegenseitige Relationierung indessen laufen stets auf die Relevantsetzung von Zeit hinaus. Dieser Komplex ist zentral zur Behandlung unserer Thesen - illustrieren wollen wir ihn anhand von Mundts Moderne Lebenswirren, Eichendorffs Das Schloß Dürande und Stifters Bergkristall.

Mundts Moderne Lebenswirren - im Untertitel Briefe und Zeitabenteuer eines Salzschreibers - ist der Gattung des Briefromans zugehörig und modelliert explizit eine Reflexion von Zeit, die der Text am Protagonisten Seeliger vorführt. Dieser schildert seiner Geliebten Esperance in mehreren Briefen seine Situation in Kleinweltwinkel, bevor jene ihn zum Aufbruch bewegt und zu sich holt. Gerahmt ist das Konvolut an Briefen durch die Vorrede eines fiktiven Herausgebers, der neben einer Authentisierungsstrategie - »diese Briefe [sind] wirklich geschrieben« (Mundt 1834: 1) - ebenso auf den wesentlichen Aspekt der FormInhalt-Korrespondenz verweist. Denn offensichtlich repräsentiert das »Wirrwarr« (ebd.) der Briefe Seeligers die Widersprüchlichkeit seines damaligen Lebens, wobei >damals < - dies lässt sich aus dem Gegebenen rekonstruieren - kaum sechs Monate zurückliegt. Eine erste Beobachtung könnte lauten: Das, was der Text verhandelt, verlagert er gleichermaßen auf seine zeichenhafte Oberfläche und macht es explizit. Es geht um die Auseinandersetzung mit >Zeit $<$ im literarischen Schreiben.

in Brczwezmcisl, Der Abend vor der Hochzeit) - an verschiedenen thematischen und motivischen Komplexen der Goethezeit ab, ohne dabei klare Divergenzen zwischen etischer und emischer Zeit in den Vordergrund zu rücken. 
Etische Zeit - verstanden als objektive und physikalische Zeit, die linear und unidirektional abläuft - lässt sich an den Datierungen ausmachen sowohl der Vorrede als auch der Briefe: Die Vorrede ist datiert auf »Pfingstsonntag, 1834«, die Briefe umfassen einen Zeitraum vom 1. Mai 1833 bis 1. Januar 1834. Dabei ist die Wahl der Briefform natürlich signifikant. Zum einen bildet die Chronologie der Briefe einen Zeitverlauf ab, den man auch unabhängig von der Figur und ihren Schriften nachvollziehen kann; zum anderen zieht die Unregelmäßigkeit ihrer Datierung die Übertragung etischer Zeit in fassbare, segmentale Zeitträger nach sich, die einen spezifischen Umgang mit ihr offenlegen. Für die Darstellung von >Welt< bedeutet das: Wir haben es mit einem Fokus auf einen subjektiven Umgang zu tun, der wiederum die Reflexion des gegenwärtigen Selbstverständnisses von >Kultur< thematisiert. In direkter Anlehnung steht dies ferner mit der unmittelbaren Lebenswirklichkeit des Entstehungskontextes - zumindest in zeitlicher Hinsicht -, denn publiziert worden ist Mundts Text tatsächlich 1834. Eine zweite Beobachtung wäre also: Der Briefroman fusioniert seiner Form nach einen kontinuierlichen mit einem diskontinuierlichen Zeitverlauf und steht ästhetisch in der Nähe zur Lebenswirklichkeit des Entstehungskontextes. Emische und subjektive Zeit erscheinen gestört. Konstatiert wird nämlich eine Gegenwart, die durch politische Unruhen beziehungsweise eine trügerische Ruhe, durch ideologische Divergenz und »geistige[] Überbevölkerung « (ebd.: 17) und eine »Zeitunruhe« (ebd.: 138) geprägt ist. Sinnfällig ist auch, dass dies aus der Kollision von $>$ Regression< und >Progression< resultiert, dass das »Prinzip der Gegenwart« hervorgeht aus dem Kampf zwischen dem »Prinzip der Vergangenheit« und dem »Prinzip der Zukunft« (ebd.: 187) und dass die Gegenwart einer Bannung zwischen »Fortschritt, Stillstand und Rückschritt « (ebd.: 237) gleichkommt. Ein Gesprächspartner Seeligers namens Mundus hebt auf ein zirkuläres Zeitkonzept ab, wenn er mit Hilfe des Ouroboros-Symbols Zeit als »Kreis ohne Anfang und Ende« (ebd.: 59) beschreibt:

Darum sind auch alle Uhren rund, weil sie in dieser Form den Verzweiflungskampf der Zeitschlange zwischen Rückwärts und Vorwärts mathematisch richtig vorstellen, indem dieselbe [...] sich vor Angst in den Schweif beißt und so einen Kreis beschreibt, den die Uhrmacher sinnbildlich festgehalten haben. Deshalb aber auch ist die Zeit, weil sie die Schlange ist, die Allverführerin, die immer sucht, wen sie verlocke. (Ebd.)

Kulminationspunkt dieser Problematik ist das schreibende und dichtende Subjekt, das reagiert, reflektiert und (künstlerisch) tätig wird. Am Lebensausschnitt Seeligers ausgerichtet entwickelt der Text sein Zukunftsmodell: Ein Entwicklungsmodell lässt sich überhaupt nicht nachvollziehen, noch nicht einmal im Rahmen einer 
modifizierten Initiationsgeschichte. Im Gegenteil wird der Protagonist fortwährend mit widersprüchlichen ideologischen Überzeugungen belegt und mit ihm ein >an der Zeit Erkrankter<vorgeführt (vgl. ebd.: 11), der schließlich am Ende in den Zustand der Zeitlosigkeit überführt wird und resigniert, gleichwohl der Text dies mit einer Zukunftsaussicht auf Kunstproduktion und mit der Zusammenführung mit Esperance verbindet. Die Ambivalenz zeigt sich auch in temporalsemantischer Hinsicht: Zeitlich situiert ist das Ende nach dem Jahreswechsel und stellt potenziell einen Neuanfang dar - allerdings ist Seeliger mit 26 Jahren merkwürdigerweise bereits vorzeitig gealtert (»Erschrick nur nicht, wenn Du mich grau und gealtert wiederfindest«; ebd.: 268). Seine Liebesbegeisterung, »die in allen Takten [seines] Zeitmaßes sprüht (ebd.: 221) wird von Esperance einerseits vorzeitig gemäßigt (»Nur erwarte nicht mehr, als Du weißt«; ebd.: 257) und andererseits zugleich doch mit der Hoffnung auf eine gemeinsame Zukunft verknüpft. Eine dritte Beobachtung könnte demnach lauten: Die Störung emischer Zeit ausgelöst durch politische, kunstästhetische, anthropologisch-zwischenmenschliche (Um-)Brüche kondensiert der Text im schreibenden Subjekt, das dies zeitreflexiv re-formuliert. Das Subjekt wird in seiner idiosynkratischen Empfänglichkeit zum Spielball von Zeittendenzen, die ihm durch andere Figuren - insbesondere Zodiacus - nahegebracht werden. Die letztendliche Überführung in einen Zustand der Zeitlosigkeit ist äquivalent mit Resignation, die der Roman rückbindet an die eigene Stellung als literarisches Werk seiner Zeit:

Dies Buch, und ich darf es als bloßer Herausgeber wohl gestehen, liebe ich gerade deshalb, weil es gar keine Resultate hat, sondern nur dazu reizt, dieselben zu suchen. Es ist gerade so resultatlos, als unsere Zeit es noch bis auf diese Stunde ist, und ein Buch muß nicht klüger sein wollen, als seine Zeit. (Ebd.: 2)

Demgegenüber liegt mit Eichendorffs Das Schloß Dürande ein Text vor, der einerseits etische, emische und subjektive Zeit ontologisch differenziert, die Zeitdimensionen andererseits aber strukturell-semantisch korreliert und in metatextuellselbstreflexiver Weise mit >Regression< und >Progression< in Verbindung bringt. Abermals haben wir es mit einer Erzählung zu tun, die anthropologischontogenetische Probleme mit sozial-phylogenetischen Problemen relationiert: Der Jäger Renald Dübois setzt sich gegen die Liebesbeziehung zwischen seiner Schwester Gabriele und dem Grafen Hippolyt zur Wehr, fordert nach ihrer mutmaßlichen Entführung durch den Grafen eine öffentliche Bekanntgabe ihrer Verbindung, tötet beide und - in Erkenntnis der wahren Liebe zwischen Gabriele 
und Hippolyt - am Ende sich selbst. Im Zusammenhang damit steht der revolutionäre Umsturz des absolutistischen Gesellschaftssystems, den Renald selbst entscheidend in Gang setzt.

Die erste Auffälligkeit des Textes ist die zeitliche Rahmung in Form einer narratorialen Retrospektive, die ein einfaches Zeitmodell explizit macht: Ausgegangen wird - ähnlich wie in Stifters Der Hochwald - von einem Zukunftszustand, der als trümmerhaft, einsam und menschenleer beziehungsweise entkultiviert semantisiert ist und dessen zeitliche Position zum Geschehen indefinit bleibt (»ehemals«, »dazumal«, »in jener Zeit«; Eichendorff 1993 [1837]: 423). Konstatiert wird damit von Beginn an, dass die erzählten Ereignisse ein negatives Zukunftsbild nach sich ziehen, in dem die Figuren absent sind und ihre Zukunft gekappt ist. Die temporale Situierung des Geschehens wird zwar nicht explizit datiert, ist aber eindeutig als Zeit der französischen Revolution identifizierbar. Dieses also ein wesentlicher Aspekt emischer Zeit: verweist die temporale Situierung schließlich auf einen entscheidenden Einschnitt in der Kulturgeschichte, der - und dies ist im Text ebenso entscheidend - einhergeht mit einer Störung des Verhältnisses von emischer und etischer Zeit. Letztere erscheint als diegetische Konstante kontinuierlich und in Form wiederkehrender Tageszeiten zirkulär markiert, während der Zyklus der Jahreszeiten unabgeschlossen bleibt. Die zeitliche Spanne der gerahmten Handlung umfasst ein knappes Jahr, einsetzend im Sommer und endend im Frühling des darauffolgenden Jahres. Die explizit genannten Jahreszeiten treten doppelcodiert in Erscheinung: Stets indizieren sie die (unmarkierte) Natürlichkeit der dargestellten Welt und setzen darüber hinaus Marker auf individueller oder kollektiver Handlungsebene, die die verhandelte Problemlage hervorheben. Bezeichnend beispielsweise ist, dass der entstehende Konflikt an einem »schwülen Sommerabend (ebd.; Hervorhebung von mir, S. B.) situiert ist. Denn Signifikate von >schwül< sind neben demjenigen einer bedrückenden und tropisch-heißen Wetterlage ebenfalls >ängstlich $<$ und >beklommen ${ }^{14}$ - Eichendorffs Text fügt ein weiteres semantisches Feld um >betörend< und >erotisch< hinzu, das dem Lexem späterhin übrigens auch außerliterarisch zugeschrieben wird. ${ }^{15}$ Die vordergründige Motivation Renalds besteht im Schutz der Schwester nach dem Verlust der Eltern - der eigentliche Handlungsantrieb aber ist der latent-regressive Wunsch, den unmittelbaren Vergangenheitszustand eines Familiensubstituts mit der Schwester wiederherzustellen, die er unbewusst begehrt. In

\footnotetext{
${ }^{14}$ Vgl. den Art. »Schwül« in Grimms Deutschem Wörterbuch (Grimm 1854-1961).

${ }^{15}$ Vgl. den Art. »schwül « auf Duden online (duden.de/rechtschreibung/schwuel; 22.12.2020); auch zu beobachten beispielsweise in Stifters Der Hochwald (»empfänglichere, schwülere Herzen«; Stifter 1980b [1842/1844]: 302).
} 
der Attribution der Jahreszeit findet also auch Renalds Gemütszustand Ausdruck: in der Angst, seine Schwester zu verlieren, verbunden mit seiner latent-erotischen Leidenschaft für sie - verstärkt durch die Gestaltung der Figurenwahrnehmung (»es flimmerte ihm vor den Augen, als könnte er sich in einem schweren Träume noch nicht recht besinnen.«; ebd.: 424) und durch die Konzeption seiner $>$ Person $<.{ }^{16}$ In metaphorischer Übertragung findet sich $>$ Schwüle $<$ ferner zur Umschreibung der aufkommenden Revolution: »[D]er junge Graf Dürande hatte [...] so viel Wunderbares gehört von den feurigen Zeichen einer Revolution [...], daß ihm das Herz schwoll wie im nahenden Gewitterwinde. Er konnte es nicht länger aushalten in der drückenden Schwüle.« (Ebd.: 440) Im Herbst entflieht Gabriele dem - offenkundig mit >alt< attribuierten (vgl. ebd.: $428 \mathrm{f}$.) - Kloster, in dem Renald sie untergebracht hatte; Renald erreicht Paris, um sein Recht einzufordern, und gerät dort an Revolutionäre: Die Jahreszeit des Herbstes formiert mithin einen Zeitraum der endgültigen Ablösung der einen Figur von der anderen. Im Winter kündigen sich die »feurigen Zeichen einer Revolution « (ebd.: 440) an, das Jahr geht dem Ende entgegen, wie auch das Sozialsystem vor seinem Ruin steht. Versehen wird die Jahreszeit dabei mit der Semantik des Scheinhaften: Ebenso wie Renald Gabriele mutmaßlich auf dem Schloss des jungen Grafen vermutet, so trügt auch der Winter: »Es war einer jener halbverschleierten Wintertage, die lügenhaft den Sommer nachspiegeln, die Sonne schien lau, aber falsch über die stillen Paläste« (ebd.: 446). Sinnfällig - wie schon in Ottos Lehnspflichtigen - ist daneben die Funktionalisierung des Frühlings als Jahreszeit des möglichen Neuanfangs - sowohl auf Kollektivebene, auf der das alte, absolutistische System dem Untergang geweiht ist, ebenso wie auf Individualebene, die in Form der affektiven Handlungsweise Renalds mit der anderen Ebene parallelisiert wird. Denn homolog mit dem alten, kranken Grafen, der - während die Bedrohung durch die Aufständischen zunimmt - störrisch-standhaft an alten Formen festhält, verhält sich Renald mit seinem Wunsch auf Rückkehr in den vergangenen Zustand der geschwisterlichen Idylle.

\footnotetext{
${ }^{16}$ Im Text finden sich Hinweise auf die Konzeption Renalds als markiert leidenschaftlicher Mensch: »[S]ie konnte gar nicht begreifen, warum er böse sei « (Eichendorff 1993: 425); »[d]u bist heute rasend « (ebd.: 426); »wie er auf seinem Bett vor Weinen schluchzte« (ebd.); »es wollte ihm das Herz zerreißen (ebd.: 446); »er kann entsetzlich sein« (ebd.: 450); »wilde[r] Jäger « (ebd.: 451) und: »spielten feurige Figuren wechselnd auf dem dunkeln Grund seiner Seele: schlängelnde Zornesblitze und halbgeborene Gedanken blutiger Rache« (ebd.: 445). Leidenschaft wird am Ende zusätzlich explizit als existenzielle Bedrohung ausgewiesen: »Du aber hüte dich, das wilde Tier zu wecken in der Brust, daß es nicht plötzlich ausbricht und dich selbst zerreißt.«(Ebd.: 465)
} 
Noch bestimmter lenken Tageszeiten den Blick auf die Wertigkeit der Ereignisse, wobei dem Segment der Nacht - versehen mit höchster Ereignishaftigkeit - eine exponierte Stellung zukommt. Geheime Liebschaft und geschwisterlichharmonischer Vergangenheitszustand, entscheidende Konfrontationen und Auslöser für Kämpfe - alles dies ist nachts situiert oder wird mit der Nacht in Verbindung gebracht. So situiert der Text den bewaffneten Schlagabtausch bei Einnahme des Schlosses Dürande bezeichnenderweise in »wilde[r] Nacht « (ebd.: 458), während ferner auf Individualebene die Relationierung von Gabriele zu diesem Zeitsegment ins Auge sticht:

Die Priorin wollte die arme Gabriele trösten, aber sie hatt' es nicht nötig, so wunderbar war das Mädchen seit jener Nacht verwandelt. Sie fühlte sich, seit sie von ihrem Liebsten getrennt, als seine Braut vor Gott, der wolle sie bewahren. Ihr ganzes Dichten und Trachten ging nun darauf, ihn selber auszukundschaften, da ihr niemand beistand in ihrer Einsamkeit. (Ebd.: 429)

Denn mit dieser > Verwandlung < und ihrem Bezug zur Nacht grenzt sie sich von anderen Frauen ab:

Damals saß sie eines Abends noch spät mit der jungen Schwester Renate am offenen
Fenster der Zelle, aus dem man in den stillen Klostergarten und über die Gartenmauer
weit in's Land sehen konnte. Die Heimchen zirpten unten auf den frischgemähten
Wiesen, über'm Walde blitzte es manchmal aus der Ferne. Da läßt mein Liebster mich
grüßen, dachte Gabriele bei sich. - Aber Renate blickte verwundert hinaus; sie war
lange nicht mehr wach gewesen um diese Zeit. Sieh nur, sagte sie, wie draußen Alles
anders aussieht im Mondschein [...].

Wie du auch so allein im Dunkeln durch den Wald gehen kannst, sagte Renate wieder; ich stürbe vor Furcht. [...]

Nein, entgegnete Gabriele, ich möcht' mich gern einmal bei Nacht verirren recht im tiefsten Wald, die Nacht ist wie im Traum so weit und still, als könnt' man über die Berge reden mit Allen, die man lieb hat in der Ferne. (Ebd.: 430)

Für Nicht-Verliebte ist die Nacht mit Furcht, Unsicherheit, Fremdheit, Andersartigkeit belegt; für Verliebte hingegen mit Faszination, Vertrautheit und - ganz romantisch - mit Liebe, Traum, Natur und Ferne. So, wie sich die Figur Renate also als nichtliebende Figur auszeichnet, ordnet der Text Gabriele der Liebe, genauer: der romantischen Liebe zu. Ihr romantisierender Blick aus dem Fenster des Klosters ist paradigmatisch: Gabriele verhält sich ganz gemäß dem goethezeitlichen Initiationsmodell. Sie vollzieht die Ablösung vom Sozialraum der Familie 
- und die der Zwangseinweisung in das Kloster - und wendet sich ihrem Geliebten zu: »[A]us Lieb' ist sie bei Nacht dem Grafen heimlich nachgezogen aus dem Kloster« (ebd.: 463). Bemerkenswerterweise verfährt der Text dabei so, dass mit ihrem Verschwinden aus Sicht Renalds Gabriele ebenfalls von der Textoberfläche >verschwindet< und erst am Ende wieder fokalisiert wird. Initianden, die sich >goethezeitlich verhalten $<$, hat der Text im übertragenen Sinn - wie die Figur im buchstäblichen Sinn - nicht im Griff.

Eichendorffs Text kennzeichnet über diesen grundsätzlichen Aspekt - der Störung von emischer und etischer Zeit - hinaus die Schnittstelle zwischen etischer, emischer und subjektiver Zeit als besonders defektiv. Daher rühren denn auch derart seltsam anmutende Zeitstrukturbildungen wie die Folgende:

Währenddes schnurrten im Schloß Dürande die Gewichte der Turmuhr ruhig fort, aber die Uhr schlug nicht, und der verrostete Weiser rückte nicht mehr von der Stelle, als wäre die Zeit eingeschlafen auf dem alten Hofe beim einförmigen Rauschen der Brunnen. (Ebd.: 449)

Manifest in der Turmuhr wird die Anordnung der Simultaneität von fortlaufender etischer Zeit und stagnierender emischer Zeit; zuvor wurde bereits ebenfalls mittels Turmuhren soziale Unruhe angezeigt (»draußen fern und nah die Turmuhren verworren zusammenklangen«; ebd.: 440). Hier ist die Uhr nicht gar als Messinstrument für Zeit defekt, sondern in ihrer Funktion als Taktgeber soziokulturellen Lebens (temporär) gestört. Semantisch korreliert ist diese Zeitstörung mit dem $>$ Alten<, dem Absolutismus repräsentiert durch den alten Grafen.

Draußen, nur manchmal vom fernen Wetterleuchten zweifelhaft erhellt, lag der Garten mit seinen wunderlichen Baumfiguren, Statuen und vertrockneten Bassins wie versteinert im jungen Grün, das in der warmen Nacht schon von allen Seiten lustig über die Gartenmauer kletterte und sich um die Säulen der halbverfallenen Lusthäuser schlang, als wollt' nun der Frühling Alles erobern. Das Hausgesinde aber stand heimlich untereinander flüsternd auf der Terrasse, denn man sah es hier und da brennen in der Ferne; der Aufruhr schritt wachsend schon immer näher über die stillen Wälder von Schloß zu Schloß. Da hielt der kranke alte Graf um die gewohnte Stunde einsam Tafel im Ahnensaal, die hohen Fenster waren fest verschlossen, Spiegel, Schränke und Marmortische standen unverrückt umher wie in der alten Zeit, niemand durfte bei seiner Ungnade, der neuen Ereignisse erwähnen, die er verächtlich ignorierte. So saß er, im Staatskleide, frisiert, wie eine geputzte Leiche am reichbesetzten Tisch [...] und alle Viertelstunde hackte im Nebengemach die Flötenuhr knarrend ein und spielte einen Satz aus einer alten Opernarie. (Ebd.: 449) 
Außerhalb des Schlosses ist die Zeit >aus den Fugen< geraten; innerhalb seiner Mauern wird an der alten Ordnung festgehalten. Wie schon in anderen Beispielen - wie etwa in Der Hagestolz - beobachtet, ist dabei das >Alte $<\operatorname{mit}>$ Tod< semantisiert. Und wie in Der Hagestolz findet sich eine Überlagerung unserer Leitdifferenz - in diesem Fall im unmittelbaren Außenraum um das Schloss herum, wo topografisch >Altes< und >Neues< aufeinanderstoßen (»vertrockneten Bassins wie versteinert im jungen Grün «). Erst mit der Ankunft des jungen Grafen als potenziellem Zukunftsträger »fing die Uhr trostreich wieder zu schlagen an « (ebd.: 451); mit ihm verbindet sich die »Hoffnung, noch Alles zum Guten wenden zu können« (ebd.). Insgeheim sehnt die Figur selbst aber einen Wechsel herbei: »Ich bin so müde, sagte er, so müde von Lust und immer Lust, langweilige Lust! ich wollt' es wäre Krieg! « (Ebd.: 441)

Neben diesem Punkt - der problematischen Verschränkung der Zeitdimensionen - schlägt sich eine Zeitstörung ausgelöst durch nichttemporale Beweggründe - nämlich Liebe und Revolution - ebenfalls in der zeitreflexiv funktionalen Einbindung der Figuren nieder. In seiner sich selbst eingestandenen Sehnsucht nach Krieg spricht Hippolyt auch von einer »spukhafte[n] Zeit« (ebd.). Über Renald heißt es: »In der Unruhe seiner Seele war er der Zeit ein gut Stück vorausgeschritten « (ebd.: 437); und: »[E]r dachte sich die verlorne Gabriele wieder in der alten unschuldigen Zeit als Kind mit den langen dunkeln Locken, es fiel ihm immer das Lied ein: >Gute Nacht, mein Vater und Mutter, wie auch mein stolzer Bruder $<$, - es wollte ihm das Herz zerreißen « (ebd.: 461). Und Hippolyt entgegnet Gabriele gegenüber: »Die Zeit fliegt heut entsetzlich [...], dich liebte ich immerdar, da nimm den Ring und meine Hand auf ewig « (ebd.: 459). Offensichtlich arbeitet der Text mit einer komplexen Korrelation der unterschiedlich gelagerten Oppositionen $>$ Alt<vs. $>$ Neu $<$ und $>$ Regression $<$ vs. $>$ Progression $<$. Denn wie aus diesen Textpropositionen ersichtlich wird, ist Renald als Figur charakterisiert, die ihre Handlung auf >Zeit< abstimmt, dem Zeitverlauf nicht passiv ausgesetzt ist und emischer Zeit entgegenarbeitet, sich aber zugleich regressiv an einem Vergangenheitszustand orientiert, den er durch seine Handlungen wiederherzustellen trachtet. Auf der anderen Seite wird der Graf aufgestellt als jemand, dessen Zeiterleben asynchron-retardiert zu etischer und emischer Zeit verläuft, der jedoch seinerseits progressiv auf die gemeinsame Zukunft mit Gabriele hin ausgerichtet handelt. Beide sind sich ihrer Zeit bewusst, erleben sie aber diametral anders und steuern zusätzlich Unterschiedliches an. Dabei ist >Alt< eigentlich und uneigentlich im Text angelegt, zum einen - in phylogenetischer, evolutionär-epochaler und soziokultureller Hinsicht - im Sozialsystem, dessen hierarchiehöchste Stände der Adel und der Klerus formieren, wobei beide entsprechend mit Zuschreibungen des >Alten $<$ und >Altmodischen $<$ versehen werden; zum anderen - in 
anthropologischer Hinsicht - im Verhalten Gabrieles und Hippolyts, die eine gegenseitige Liebe verbindet, insbesondere aber Gabrieles, die >goethezeitlich< agiert und im Rahmen goethezeitlichen Denkens nicht falsch handelt und doch scheitert. >Alt< wird im Text auf radikale Weise getilgt - durch Gewalt und Tod. Vor der Kontrastfolie des Literatursystems der Goethezeit wird wiederum die neue Anthropologie repräsentiert in der Personen-Konzeption und dem Verhalten Renalds, dessen Familie allein in der Person Gabrieles existiert - und die somit defizitär ist - und der die Loslösung von seiner Schwester und ihre Verbindung mit einem anderen Mann nicht akzeptieren kann. Codiert wird diese neue Anthropologie aber zudem auch als negativ-pessimistische, da sie destruktive und selbstdestruktive Verhaltensweisen impliziert und sich als nicht tragfähig erweist. Dieses Unvermögen wird interessanterweise ebenfalls über die Attribuierung mit >Alt< geschaffen: »Er sah so schrecklich aus, sein Haar war grau geworden über Nacht« (ebd.: 464). Daraus ergibt sich - für die junge Generation als relevante Teilklasse der Figuration - die für den Text maßgebliche Relation: $>$ Alt< agiert >progressiv<vs. >Neu< agiert >regressiv<. Bezeichnend und entscheidend ist auch, dass Renald zwar in persönlichen Belangen regressiv semantisiert ist und den unwiederbringlichen Kindheitszustand herbeisehnt, er aber in gesellschaftlichen Belangen der ausschlaggebende Katalysator des Ordnungsumsturzes ist: »Da stürzte auf einmal vom Schloß die Bande siegestrunken über Blumen und Beete daher, sie schrien Vivat und riefen Renald im Namen der Nation zum Herrn von Dürande aus « (ebd.). Mit seinem regressiven Handeln setzt also Renald auf Kollektivebene eine progressive Neuordnung in Gang. Und damit nicht genug. Dieser Vorgang wird nur aus einer Teilperspektive als wünschenswert klassifiziert, während die dominante Perspektive des Textes sowohl den Umbruch selbst als auch den Zukunftszustand negativ wertet: Inmitten des aufkommenden Umsturzes etwa - das topografische Umfeld ist mit der Aufhebung des Klosters bereits umsemantisiert - »weinte ein Kind [...], als klagte es, daß es geboren in dieser Zeit « (ebd.: 453). Und zum Zeitpunkt des Erzählens - der fiktionsinternen Zukunft - schließlich ist von »Frühlingstagen « (ebd.: 465) und zugleich von Trümmern die Rede. Das Schloß Dürande koppelt also die Leitdifferenz mit regressiven und progressiven Vektoren und weist ebendiese Anlage als vitiös und nicht zukunftsfähig aus. Es liegt daher der Schluss nahe, als Grund für die starke Negativierung von >Zukunft die hier semiotisierten, paradoxalen und kollidierenden Temporalsemantiken anzugeben.

Unscheinbarer geht nun wiederum Stifters Bergkristall vor und thematisiert (unter der Oberfläche einer Verirrungsgeschichte mit christlich-religiösem Duktus) Maßgaben im Umgang mit >Regression< und >Progression $<$ mit der Ausrichtung auf eine anzustrebende Zukunftsgestaltung - die hier glückt. Klar wird 
an diesem Beispiel (wie für die Phase der 1840er-Jahre insgesamt): Gleichwohl Zeitreflexion nicht vorrangiges Thema sein muss, ist sie dem Literatursystem dennoch eingeschrieben - und mit ihr spezifische Umgangsweisen und Denkmuster in Bezug auf Zeit. Eine offensiv-explizite Semiotisierung reflexiver Zeitstrukturen jedoch geht, wie schon gesagt, in den 1840er-Jahren gegenüber den 30er-Jahren zurück.

Bergkristall erzählt die Geschichte zweier Kinder, die am Heiligen Abend auf dem Rückweg von einem Dorf in ein anderes von einem heftigen Schneegestöber überrascht werden und sich auf einem Berg verirren, dann aber schließlich gefunden und ihren Eltern zugeführt werden. Erzählt wird darüber hinaus ein entscheidender Umschwung der (Kultur-)Geschichte ebendieser Dörfer, die bei topografischer Nähe gänzlich unterschiedlich gekennzeichnet sind und sich durch das Ereignis der Verirrung der Kinder im Endzustand sozial annähern. Der Text verhandelt Lösungswege in Abstimmung zwischen Traditionsbewusstsein und Modernismus, wählt als wünschenswerten Zustand die Vereinigung der Dörfer und bestätigt damit die >Mitte-Tendenz< unseres literarhistorischen Abschnittes.

Im Gegensatz zu den beiden vorherigen Textbeispielen wird die temporale Situierung des Geschehens hier nicht konkretisiert, stimmt jedoch grob mit dem Zeitraum der Textgenese überein. ${ }^{17}$ Trotz Fehlen dieser Explikation eines zeitlichen Kontextes sind Teilräume und Figuren mit spezifischen Temporalsemantiken versehen, die überdeckt werden von einer etischen Naturzeit und von jener separiert sind:

So spinnt es sich ein Jahr um das andere mit geringen Abwechslungen ab, und wird sich fortspinnen, solange die Natur so bleibt, und auf den Bergen Schnee und in den Tälern Menschen sind. Die Bewohner des Tales heißen die geringen Veränderungen große, bemerken sie wohl, und berechnen an ihnen den Fortschritt des Jahres. (Stifter 1982b [1845/1853]: 189)

Paradigmatisch fungieren an erster Stelle $>$ Natur $<$ und $>$ Kultur $<$, wobei $>$ Natur $<$ topografisch >oben< lokalisiert ist und durch den Schneeberg Gars semiotisiert wird. >Kultur< liegt topografisch >unten< (in Tälern) und ist binnendifferenziert in die Dörfer Gschaid und Millsdorf, die sich - »nur drei Wegstunden« (ebd.: 192) voneinander entfernt - insbesondere auch temporalsemantisch voneinander unterscheiden. Grundsätzlich sind »Sitten und Gewohnheiten in beiden Thälern so verschieden, selbst der äußere Anblik derselben so ungleich, als ob eine große

\footnotetext{
${ }^{17}$ Erstmals erschienen ist die Erzählung 1845 unter dem Titel Der Heilige Abend in der Zeitschrift Die Gegenwart. Die vorliegende Argumentation bezieht sich auf die Buchfassung, die 1853 in der Sammlung Bunte Steine publiziert worden ist.
} 
Anzahl Meilen zwischen ihnen läge« (ebd.). Millsdorf formiert den prosperierenden, handelsoffenen, ansehnlicheren und moderneren, Geschaid den isolierten, ökonomisch etwas rückständigen, aber durchaus funktionierenden und betont traditionsbewahrenden Teilraum. Das fortschrittliche Millsdorf liegt in einem tieferen Tal und ist klimatisch begünstigt, sodass »man die Erndte immer um vierzehn Tage früher beginnen konnte als in Gschaid « (ebd.: 206) - der Raum ist in dieser Hinsicht der >Zeit voraus $<$, wohingegen die Bewohner in Geschaid »sehr stettig [sind] und es [...] immer beim Alten« (ebd.: 187) bleibt:

Wenn ein Stein aus einer Mauer fällt, wird derselbe wieder hineingesetzt, die neuen Häuser werden wie die alten gebaut, die schadhaften Dächer werden mit gleichen Schindeln ausgebessert, und wenn in einem Hause scheckige Kühe sind, so werden immer solche Kälber aufgezogen, und die Farbe bleibt bei dem Hause. (Ebd.)

Des Weiteren ist demgemäß die im Kulturraum angelegte Opposition >Regression< vs. >Progression< textkonstitutiv zu nennen, ihre Virulenz verschärt sich auf Figurenebene: Zum einen in Person des in Millsdorf ansässigen Färbers, der, was sogar in Millsdorf »etwas Unerhörtes war, mit Maschinen arbeitete« (ebd.: 195); zum anderen in der Heirat des Schusters Sebastian aus Gschaid mit der Tochter dieses Färbers, Sanna, die ihrerseits nach Gschaid übersiedelt und dort alienisiert wird, ${ }^{18}$ des Weiteren schließlich durch die Kinder, die als Nachkommen eines Gschaiders und einer Millsdörferin auch auf topografischer Textebene als Grenzgänger zwischen den Räumen auftreten. Synekdochisch bilden die genannten Figuren das hauptsächliche Problem der dargestellten Kulturgeschichte ab. Denn der Färber lebt zwar im progressiven Raum und agiert dort, indem er Symbole der Industriellen Revolution nutzt, noch >progressiver`, er selbst gehört jedoch der Großelterngeneration an und ist körperlich alt. Demgegenüber bringt die Schusterfamilie zwar die Voraussetzung zur Gestaltung einer Zukunft mit - indem sie biologisch reproduktionsfähig ist -, ihre Lokalisierung und soziale Reputation im regressiven Gschaid allerdings steht dazu in hemmendem Kontrast - erkennbar daran, dass sich die (jungen) Kinder vornehmlich zwischen beiden Räumen bewegen und die Mutter im Heimatraum nachhaltig als Fremde wahrgenommen wird.

Getragen durch die dynamische Ereignisstruktur erfolgt die Tilgung ideeller Grenzen und die Harmonisierung von >Kultur $<$ : Die Rettung der Kinder hat

\footnotetext{
${ }^{18}$ Alienität und Alterität - oder >Fremdes $<$ und >Anderes $<$ - spielen für die Anthropologie der Zwischenphase eine entscheidende Rolle, die an anderer Stelle genauer untersucht worden ist (vgl. Lukas 2006). Grundsätzlich zu den Begrifflichkeiten und ihren kultursemiotischen und -semantischen Kontexten vgl. Turk 1990.
} 
die Öffnung Gschaids und die Verbindung zwischen beiden Dörfern zur Folge. Dieser tendenziellen Zukunftsgeschlossenheit steht allein die Beibehaltung der Opposition >Natur $<$ vs. $>$ Kultur $<$ entgegen: Auch über das Textende hinaus bleiben der Berg, der plötzliche Wettereinbruch, die spektakulären Naturerscheinungen rätselhaft und unergründlich, insbesondere bleibt der Natur das Merkmal der potenziellen Bedrohung von >Kulturく inhärent, obwohl die Bedrohung im vorliegenden Fall weniger gefährdend ausgefallen ist als möglich. Obschon also gänzlich anders realisiert als bei Eichendorff - der in Das Schloß Dürande die psychologische und die politische Dimension prononciert -, wird >Natur $<$ demnach ganz direkt als fremdartige Gefahr für den Menschen klassifiziert.

Die Überführung einer Ordnung A in eine Ordnung B steht auch in Stifters Text in Verbindung mit einer temporären Störung von Zeit, die der Text in der Orientierungslosigkeit der Kinder motiviert. Mit ihnen wird Zeit verhandelt: Ihr Schicksal und damit die Zukunft der Familie stehen auf dem Prüfstand. Das wesentliche Geschehen ereignet sich an Heiligabend, einer Zeit, zu der die Tage »sehr kurz« (ebd.: 203) sind. Als bedeutsam wird daneben der Umstand gekennzeichnet, dass das Verirren simultan zum Fest des Heiligen Abends geschieht, ein für die im Text dargestellte christlich geprägte Kultur (und damit hinsichtlich der emischen Zeit) eminent wichtiges Geschehensmoment, das zyklisch wiederkehrt und betont tradiert-feste Handlungsabläufe involviert. Damit überlagert die Erzählung, wie schon an anderen Beispielen herausgestellt, eine zyklische Zeitvorstellung mit der Linearität einer der Welt konstatierten Entwicklungsmöglichkeit, die wiederum in der Korrelation von wiederkehrendem Fest und einmalig-folgenreichem Ereignis fundiert ist.

Die hohe Wertigkeit ebendieses Ereignisses wird mit zeitlichen Markern indiziert: Auf dem Hinweg Richtung Millsdorf befindet sich der Naturraum in einem Normalzustand und kann problemlos durchschritten werden - abzulesen an absoluten Zeitangaben: »[a]ls sie nach Verlauf einer Stunde« (ebd.: 205); und: »[a]bermal nach einer Stunde [...]« (ebd.: 206). Auf dem Rückweg ändern sich die Wetterlage und damit der Zustand der Naturumgebung mit der Konsequenz einer Aufhebung absoluter Zeitangaben vonseiten der Erzählinstanz, die mit dem Verlust des Zeitgefühls bei den Kindern einhergeht: »Der Knabe konnte die Zeit nicht ermessen« (ebd.: 211). Entsprechend häufen sich relative Zeitangaben im Text: »[n]ach kurzer Zeit« (ebd.: 210); »[n]ach langer Zeit« (ebd.: 212); »[n]ach einer Weile« (ebd.: 215); »[n]ach einer Zeit (ebd.); »[a]ls eine lange Zeit vergangen war « (ebd.: 225). Und auch nach der Rettung heißt es zunächst noch: »[e]ndlich nach langer Zeit« (ebd.: 235). Die Einmaligkeit des Ereignisses unterstreicht schließlich auch der alte Färber und verwendet dazu - gleichwohl im 
hyperbolischen Redemodus - erneut eine absolute Angabe: »>Hundert Jahre werden wieder vergehen, daß so ein wunderbarer Schneefall niederfällt, und daß er so gerade niederfällt, wie nasse Schnüre von einer Stange hängen. Wäre ein Wind gegangen, so wären die Kinder verloren gewesen.« (Ebd.: 238)

Die drei Beispiele zeigen: Störungen von Zeit realisieren Texte ganz konkret über die Inkompatibilität von emischer, etischer und subjektiver Zeit. Die Relata $>$ Regression< und >Progression< implizieren dabei Semantiken, die primär in Figuren codiert werden. Figuren dienen demnach nicht allein als Träger von Zeit (zum Beispiel durch ihre Zugehörigkeit zu einer Altersstufe) und Zeitlichkeit (aufgrund ihres Alterns), sondern auch als Träger spezifischer Temporalsemantiken mit signifikantem Charakter. Bei diesen handelt es sich um figurenintern verankerte, psychisch-mental installierte Anlagen, die entsprechendes Verhalten initialisieren und im Verlauf des Geschehens potenziell wandelbar sein können.

\section{Zeitreflexion und Anthropologie: Relationsmuster}

Wenn Figuren im Blickpunkt stehen und wenn konstatiert werden kann, dass die Anthropologie eine der maßgeblichen Grundachsen des Literatursystems der Zwischenphase darstellt, dann können an dieser Stelle vier Relationsmuster benannt werden, die für die zeitreflexive Spezifik des Literatursystems im Allgemeinen und für die Fundierung der reflexiven Zeitstruktur II im Besonderen prägend sind.

(1) Zeitreflexion $\leftrightarrow$ Anthropologie. In Auswertung der behandelten Punkte muss zuvorderst die fundamentale Relation der wechselseitigen Implikation von Zeitreflexion und Anthropologie angeführt werden. Sie bedeutet, dass zum einen die Reflexion von Zeit ihren wesentlichen Anteil in anthropologischen Propositionen findet; ihre Strukturen sind paradigmatisch in den Figuren verankert. Andersherum ist der Literaturanthropologie, wie sie die Zwischenphase kennzeichnet, immer auch ein zeitreflexives Potenzial eingeschrieben. Verwiesen werden kann hinsichtlich dessen auf die ausführlich behandelten Texte wie Der Hagestolz, Das Bild des Kaisers, Zu Spät!, Die Lehnspflichtigen sowie Moderne Lebenswirren, Das Schloß Dürande und Bergkristall. Überall impliziert das dargestellte Menschsein Fragen nach >Zeit<- anthropologisch relevante Konstellationen, dies führen die Texte vor, dienen daher stets als entscheidende Träger für reflexive Zeitstrukturen.

(2) Etische Zeit vs. emische Zeit vs. subjektive Zeit. Das zweite übergreifende Merkmal besteht im gegebenen Bereich in der Inkongruenz und Disparität von etischer, emischer und subjektiver Zeit. Zunächst ist erstaunlich, 
dass allen diskursiven und anthropologischen >Experimenten $<$ der Zwischenphase zum Trotz (vgl. Frank 1998) etische Zeit generell konstant und linear, gleichförmig und unidirektional gestaltet ist, sie offenbar nicht Teil des charakteristischen Experimentierfelds zu sein scheint. Hingegen können die emische und auch die subjektive Zeit die abenteuerlichsten Formen annehmen (Moderne Lebenswirren; Das Schloß Dürande). Es wäre zu vermuten, dass erstens überhaupt ein Bewusstsein über eine Differenz mehrerer Zeitsphären vorherrscht, dass zweitens ein zeitreflexives Potenzial, das heißt ein Nachdenken über Zeit, über diese Differenz aufgebaut wird, und dass drittens der kulturelle Umgang mit Zeit wie auch das subjektive Erleben von Zeit offensichtlich als heikel erachtet werden. In jedem Fall gehen die Zeitdimensionen nicht überein; ihr Verhältnis zueinander ist erschüttert. Und ebendies macht einen Kern der Reflexion von >Zeit< aus. Im breiteren Kontext der Ausbildung des modernen Zeitregimes argumentiert: Hier ergibt sich in literarischer Form das wahrgenommene Auseinanderklaffen von >Erfahrungsraum $<$ und $>$ Erwartungshorizont $<$ - und die entstehende Kluft wird als Problem aufgegriffen, durchgespielt und teilweise zu lösen versucht (oftmals aber ungelöst bestehen gelassen).

(3) >Regression</>Progression< korr. >Alt< vs. >Jung $</>N e u<$. Die Verschränkungsstruktur, um die es in diesem Kapitel geht, steht in vielfältigen Beziehungszusammenhängen zur Leitdifferenz des Literatursystems. Vielfältig deshalb, weil die Leitdifferenz selbst in skalierter Form erscheint, und vielfältig auch, weil die Zuordnung der beiden Strukturmengen flexibel gehandhabt wird. Grundsätzlich erscheint denkbar, dass >junge< wie >alte< Figuren regressiv wie auch progressiv aufgestellt sein können, dass insbesondere Vertreter einer dezidiert neuen Anthropologie regressiv agieren oder dass sie gar schwanken zwischen unterschiedlichen Ausrichtungen (Das Bild des Kaisers; Das Schloß Dürande; Der Hagestolz; Die Lehnspflichtigen; Moderne Lebenswirren). Zudem konnte - schon im letzten Kapitel - beobachtet werden, dass die Leitdifferenz zwar eminenten Bestand hat, zugleich jedoch aufgeweicht ist, zum Beispiel insofern, als Figuren gleichermaßen >alt $<$ und $>$ jung $<$ sind. Neben diesen mehrschichtigen und sich gegenseitig überlagernden Anordnungen (Das Bild des Kaisers) sind indes auch eindeutigere Vernetzungen zu beobachten (Die Lehnspflichtigen). Entscheidend bei alledem ist: Die Leitdifferenz ist - wenn sie auch skaliert-mannigfaltig realisiert wird - für sich genommen statisch und bedarf einer Verbindung zur Koppelungsstruktur >Regression< vs. >Progression<, die diese dynamisiert - ihr Gefüge verschiebt, Teilmengen tilgt oder abwandelt. Und entscheidend ist auch: Die Kombinatorik aus Leitdifferenz und temporaldeiktischen Richtungsprinzipien der >Regression $<$ und der 
>Progression< ist als Funktion zwecks Aufstellung und Abwägung hochrangiger Handlungsmaximen anzusehen, die ihrerseits wichtig für die Gestaltung von >Zukunft $<$ sind.

(4) Goethezeitlich vs. nichtgoethezeitlich. Eine Dichotomie, die immer wieder ins Auge fällt und die natürlich die spezifische zeitreflexive Anlage der Zwischenphase grundiert, ist die der Gegenüberstellung von betont goethezeitlichen und andersartigen, betont nichtgoethezeitlichen Strukturen. Auch dies offenbart sich an erster Stelle in Form anthropologischer Modellierungen: Eine Figur entspricht dem goethezeitlichen Modell, eine andere einem anderen, alternativen Modell - die Engführung ist konfliktreich (Das Schloß Dürande). Dem wohnt zum einen die strukturelle Überlagerung von Leitdifferenz und Verschränkungsstruktur inne, zum anderen lenkt die Dichotomie den Blick auf das metatextuell-selbstreflexive Moment.

\section{Figürliche Kulminationen: `Zerrissenheitı und /Weltschmerz ‘ bei Büchner und Mundt in zeitsemiotischer Lesart}

Einen interessanten Spezialfall der Überlagerung anthropologischer und temporalreflexiver Problemstellungen wollen wir aufgreifen und näher beleuchten. Im Hintergrund steht dabei der Umstand, dass die Störungen von Zeit, wie sie durch diverse Ursachen zustande kommen, oftmals nicht nur generell unlösbare Konfrontationen nach sich ziehen, sondern gar für das Subjekt pathologische Folgen haben können. Wenn Figuren an >ihrer Zeit< verzweifeln, ihre Vorstellungen nicht in Einklang mit Bedingungen und Möglichkeiten der Umwelt bringen können, so verfallen sie in einen Status der >Unentschlossenheit< mit teils krankhafter Ausprägung.

Wenn im Folgenden von >Zerrissenheit< und >Weltschmerz $<$ die Rede ist, so sei darauf aufmerksam gemacht, dass wir es mit objektsprachlichen Termini zu tun haben, die metasprachlich appliziert worden sind und seitdem perpetuiert werden. Nicht ganz unproblematisch dabei ist, dass der von ihnen bezeichnete Phänomenbereich jedoch weit über diejenigen Textstrukturen hinausreicht, die vornehmlich mit diesen Begriffen versehen worden sind. Zudem ist auf die Gefahr hinzuweisen, vom singulären Einzelfall auf das Allgemeine zu schließen, ohne eine methodisch abgesicherte Basis zu schaffen, von der ausgehend wiederum die Begriffe überhaupt erst als Beschreibungskategorien tragbar erscheinen.

$\mathrm{Zu}$ diesem Zweck und um an die Argumentation anzuschließen, sei ein Gedanke, der zu Beginn fiel, aufgegriffen: >Zerrissenheit< und >Weltschmerz< 
sind transepochale, figurenbasierte Konzepte und darüber hinaus Strukturmuster, die auf anthropologischer Folie zentrale zeitreflexive Kernprobleme abbilden. Unser definitorischer Arbeitsansatz lautet daran anschließend wie folgt: Figuren, die mit >Zerrissenheit< und >Weltschmerz $<$ attribuiert sind, repräsentieren Kulminationspunkte reflexiver Zeitstrukturen, wobei Handeln gehemmt oder vor dem Hintergrund kultureller Erwartbarkeit fehlgeleitet wird, und dies aufgrund der als problematisch empfundenen, eigenen paradoxalen Temporalsemantik. Einige Teilaspekte klangen bereits an, zum Beispiel dort, wo es um Zeitkonflikte ging, die Initianden auszutragen haben, oder auch dort, wo die Aktivierung des Zeiterlebens erörtert wurde (vgl. Abschn. 2.3). Potenziell ergeben sich sogar dann schon Ausformungen des Phänomens, wenn für Figuren die Kollision von $>$ Regression< und >Progression< spürbar ist, wie zuletzt beispielsweise offensichtlich an Renald in Das Schloß Dürande: Ausschlaggebend für dessen Suizid ist die Erkenntnis, die Schwester getötet zu haben. Zuvor jedoch steht er in einem Widerspruch mit sich selbst, möchte er doch nicht die Sozialstruktur verändern - von der er schließlich selbst in beruflicher Hinsicht profitiert -, sondern (zumindest oberflächlich) lediglich sein Recht einfordern, das er allerdings - schon früh gänzlich übertrieben - gewaltsam durch Schusswaffengebrauch geltend macht. Ein Widerspruch besteht dabei darin, dass er de facto das zerstört, was er idealiter wiederherstellen möchte. Wie in diesem Fall führt Zerrissenheit auch in früheren Texten immer wieder zu Selbstverlust in Form von Wahnsinn oder Tod. >Weltschmerz< wiederum ist hingegen in dieser Hinsicht ein epochenspezifisches Implikat der Zwischenphase. Denn eine Folge von Zerrissenheit ist in diesem System neben Tod - Wahnsinn tritt auffällig selten in Erscheinung - in erster Linie die Resignation: die Abfindung mit gegebenen Verhältnissen ohne Inanspruchnahme selbstgesteuerter Änderungsmaßnahmen.

Das interepochal-invariante Grundmerkmal des Phänomens, auf das der Begriff >Zerrissenheit< angewandt wird, ist die im Subjekt installierte Polarität zweier Gegensätze, die dieses Subjekt in eine schwierige Lage versetzt: Die »Demarkationslinie, die man üblicherweise zwischen den beiden Polen zieht, [verläuft] immer durchs Ich selbst, dieses in Widerspruch mit sich selbst bringend « (Begemann 1991: 228). Gestaltete Gegensätze und die Art des Umgangs mit ihnen variieren - es geht dabei aber stets um das Verhältnis von $>$ Subjekt $<$ und $>$ Welt $<$ Ideal des Subjekts und Realität des Daseins, Anspruch und Möglichkeiten, Innenwelt und Außenwelt, Eigenes und Fremdes.

>Zerrissenheit< und >Weltschmerz< kommen in der Goethezeit als (kritische) Reaktion auf Konzepte der Aufklärung auf und können zugleich als skeptizistische Neufassung der eng verzahnten Konzepte >Individualität<, >Bildung< und $>$ Entwicklung< angesehen werden, wie auch der Verhältnisse von >Vernunft $<$ und 
>Emotion< - wie teils bereits in der Empfindsamkeit erprobt - oder der Relation von Potenzialität und Realisierbarkeit exponierter Subjektivität. Die Goethezeit selbst verläuft diesbezüglich äußerst dynamisch: Auffällig sind die Strukturmuster im Sturm und Drang (präfiguriert in Goethes Die Leiden des jungen Werthers [1774]) und in der Romantik (ausgebaut und modifiziert unter anderem in Tiecks Runenberg [1802], Eichendorffs Marmorbild [1819] und Hoffmanns Bergwerke zu Falun [1819]).

Charakteristisch für die Romantik - die ja als unmittelbares Vorgängersystem der Zwischenphase eine besondere Stellung einnimmt - ist eine ganze Reihe von Aspekten: Erstens wird \Zerrissenheit<, die Spaltung des Ich, besonders an denjenigen Figuren deutlich, die in »bipolar strukturierten Räumen auf der Suche nach sich selbst sind « (Begemann 1991: 228), deren innere Problematik also topografisch nach außen gekehrt ist und räumlich - verräumlicht - verhandelt wird (Das Marmorbild, Der Runenberg, Bergwerke zu Falun). Zweitens erscheint die Innenwelt des Subjekts in manchen Fällen eben nur bedingt als Potenzraum einer utopischen Überwindung von >Realität< denn vielmehr als deren Derivat denn entfremdet wird nur das Eigene. Subjektexterne Annahmen von >Realität< und gesellschaftlich akzeptierte Normkonformität - dies ist immer auch schon im Subjekt selbst angelegt und kann oftmals nicht von diesem unterschieden werden. Drittens ist romantische Identität - die sich gegenüber dem klassischen Modell nicht durch Harmonie, sondern durch >radikale`, prekäre, ungreifbare Idealität auszeichnet - »ein immer Ausstehendes, das niemals zur Präsenz gelangen kann, sondern notwendig durch Aufschub und Differenz bestimmt ist « (ebd.: 231). Viertens schließlich ist das subjektive >Innen< zugleich, wie Tieck es formuliert, eine Domäne der >inneren Natur<, »weltliche[r] Lüste und verbotene[r] Lüste« (Tieck 1985: 156), in der »das Niedrigste, das entkörperlichte Ideal und das sinnliche Begehren, das Heilige und das Sexuelle amalgamiert und verwechselt werden « (Begemann 1991: 234). Es kommt auffallend oft zur Spaltung des Subjekts (etwa beim Doppelgänger), das zwischen einer Befangenheit (in bürgerlichen Normen und Werten und im Tabubewusstsein) und dem Streben nach Loslösung (von diesen) steht.

Auch im Fall dieses Grundmusters kommt es, ähnlich der Initiationsgeschichte, zu einer modifizierten Applikation: In der Zwischenphase gewinnen primär zwei Aspekte an Bedeutung, die die subjektiv-individuelle erfahrene Insuffizienz grundieren und die beide wichtig in unserem Zusammenhang sind: ${ }^{19}$

(1) die Inkompatibilität eigener Vorstellungen, Wünsche und Bedürfnisse mit dargestellten soziokulturellen Systemzuständen (Problemfeld >Figur und Welt $<$ );

${ }^{19}$ Die Aspekte finden sich in ähnlicher Form bei Rinsum/Rinsum (1992: 42). 
(2) die (bewusste/unbewusste) Erfahrung als Angehöriger einer nachrangigen Generation gegenüber der Eltern- und Großelterngeneration; die (bewusste/unbewusste) Erfahrung der familiären Defizienz (Problemfeld $>$ Figur und (Herkunfts-)Familie $<$ ).

Offensichtlich handelt es sich bei >Zerrissenheit< im postromantischen Literatursystem konkret um ein zweifach gelagertes - subjektinternes und diegetischontologisches - Textmuster, das in ersterem Fall ganz allgemein mit >Unentschiedenheit< bezeichnet werden kann: die (bewusste oder unbewusste) Manifestation mental-psychischer Inkonsistenz und aktionale Unentschlossenheit in unterschiedlichen Hinsichten, die vom Subjekt negativ erfahren wird und sich in affektiver, biografischer und ideologischer Diskontinuität äußert (vgl. Landshuter 2007: 94). Figuren sind handlungsunfähig oder schwanken zwischen verschiedenen Handlungsoptionen, die sie abwechselnd $\mathrm{zu}$ realisieren anstreben und wieder fallen lassen. Der zweite Fall meint die Inkonsistenz von $>$ Welt $<$ im Gegenwartssegment und ihre Auswirkung auf die Protagonisten. Wir sprechen daher auch von einem Gegenwartskippmodell. Auch Textwelten - nicht allein Figuren - sind ambivalent-heterogen aufgebaut hinsichtlich der vorherrschenden Dominanz von in die Vergangenheit reichender Instanzen, die bisweilen jedoch auch als untragbar und nicht zukunftsfähig semantisiert sind. >Zukunft $<$ wird dadurch zum offenen Möglichkeitsraum - ebenso aber zum kardinalen Problem, das es anzugehen gilt. Im Zusammenhang mit den oben genannten Verschiebungen gegenüber der Romantik, ließen sich diverse Untersuchungsfelder ausmachen, die teils bereits auch schon anklangen. Erinnert sei an Das Schloß Dürande, worin auf Ebene der Figuren wie auch auf Ebene der dargestellten Welt >Zerrissenheit< vorexerziert und dies auf Ebene der Narration zur Begründung einer stark negativierten Zukunft funktionalisiert wird. Obwohl das Muster in beiderlei Hinsicht zu beobachten ist, erscheint es sinnvoll zu unterscheiden: >Zerrissenheit< verwenden wir im Folgenden ausschließlich für Figuren; für >Welten $<$ besteht bereits der Begriff der Heterogenität. Dessen ungeachtet ist es freilich das Verhältnis von Figur und Welt, das ausschlaggebend für die Ausbildung dieses Strukturmusters ist. Wir hatten bereits herausarbeiten können, dass die Störung von Zeit nicht eigentlich im Weltsystem selbst begründet liegt, sondern erst durch die Inkongruenz und Disparatheit von etischer, emischer und subjektiver Zeit zustande kommt. Das Subjekt ist nicht eo ipso in pathologischer Steigerung uneins mit sich selbst, sondern bildet dies reaktiv aus, als Effekt, in Reaktion auf die Erkenntnis des eigenen Unvermögens.

Den Extremfall dafür liefert zunächst Büchner. Lenz selegiert einen Lebensabschnitt seines Helden, in dem nicht mehr allein die Zerrissenheit der Figur 
eine Rolle spielt, sondern bereits Konsequenzen dieses Zustands mehr als deutlich hervortreten. Bemerkenswert ist demnach neben der Personen-Konzeption (in ihrer pathologischen Ausformung) auch das Zeitmodell der dargestellten Welt (das die Zustandsveränderung der Figur nachvollziehen lässt) und insbesondere natürlich das Verhältnis des Helden zu seiner Umwelt im Gegenwartssegment - das wiederum als hochproblematisch gekennzeichnet ist.

Rekonstruiert werden kann ein einfaches Zeitmodell. Lenz hat sein heimisches Umfeld verlassen, dem er in der vorgelagerten Vergangenheit zugehörig gewesen ist, und hält sich bei Oberlin auf. Der Vater versucht ihn mehrmals zu kontaktieren und mittels anderer Figuren zur Räson zu bringen, einmal über Kaufmann, dann über Oberlin; doch vergeblich: der Kontakt wird vonseiten des Helden nicht wieder aufgenommen. Lenz - referiert wird ja ganz offenkundig auf den Dichter des Sturm und Drang - ist mit Erzählbeginn bereits als Schriftsteller mehrerer Dramen in Erscheinung getreten, das Schreiben indes gehört im Verlauf des Geschehens nicht mehr zu seinen Tätigkeiten. Doch spricht er eine kunstästhetische Entwicklung an, der er skeptisch gegenübersteht und die beim Gegensatz von Realismus und Idealismus ansetzt; Lenz selbst plädiert für eine realistische Kunst, die offensichtlich aber aktuell gegenüber der anderen Richtung einen schweren Stand zu haben scheint.

Der Text macht also in mehrfacher Hinsicht klar, dass > Vergangenheit< und >Gegenwart< inkonsistent ineinander übergegangen sind, dass Brüche vorliegen, die in Diskontinuitäten der Figurenbiografie, aber auch im Erzählen selbst ablesbar sind. Das Gegenwartssegment folgt angesichts der Hauptfigur auf den ersten Blick einem Prozess der `Entleerungく, oder wie im Rahmen dieser Studie verhandelt: der Reduktion hin zu einem resignierten Dasein. Am Ende und angesichts der nicht weiter thematisierten Zukunft heißt es dahingehend: »Er schien ganz vernünftig, sprach mit den Leuten; er tat alles wie es die anderen taten, es war aber eine entsetzliche Leere in ihm, er fühlte keine Angst mehr, kein Verlangen; sein Dasein war ihm eine notwendige Last. - - So lebte er hin.« (Büchner 1992 [1839]: 250) Die Aussage der Erzählinstanz, dass Angst und Verlangen nicht mehr verspürt werden, impliziert deren vorheriges Vorhandensein - das wiederum eine genauere Betrachtung der Personen-Konzeption im bis dahin präsentierten Handlungsverlauf nahelegt. >So lebte er hin richtet sich in eine statische Zukunft, die als nicht erwünschter, aber notwendig hingenommener Zustand entworfen wird. Man muss auch hier von einer Negativierung sprechen. Ist also die Schnittstelle zwischen >Vergangenheit< und >Gegenwart $<$ durch die Verschärfung des mental-psychischen Zustands der Figur zu beobachten, der von Zerrissenheit zu pathologischen Verhaltensstörungen führt, so ist der Übergang hin zur >Zukunft< über das Textende hinaus durch die Rücknahme auffallender Verhaltensstörungen 
festzustellen; das Innenleben des Protagonisten aber verbleibt als unberechenbar krankhaft markiert. Und ebendies ist der entscheidende Punkt. Blickt man nämlich genauer auf die Figurensemantik, so ist eine Konstanz sinnfällig: die der Semantik der Leere. Zu Beginn heißt es ausdrücklich: »[E]r war im Leeren« (ebd.: 226). Und: »[E]s wurde ihm leer« (ebd.: 227). Der Prozess der Entleerung, der hier temporär auftritt und narrativ nachvollzogen wird, entspricht dabei vielmehr nur dem >Wellental< eines iterativ verlaufenden Lebensphasenmodells bei Lenz. Denn tatsächlich arbeitet auch Büchners Text mit einem zyklischen Zeitmodell, das er substantiiert in seiner Hauptfigur und das er linearisiert im fortschreitenden Prozess der geistig-körperlichen Verkümmerung. Lenz ist Gefangener seines Selbst, das er nicht versteht und dem er hilflos ausgesetzt ist. Er wird gegenüber seiner Umwelt immer unverständlicher, wie auch ihm seine Umwelt immer gleichgültiger wird. Entscheidend ist: Das Erscheinungsbild des Helden und seine Auseinandersetzung mit sich selbst und der Welt ist ausschließlicher Erzählanlass des Textes. Lenz ist fokalisiert, die Informationsvergabe protagonistenzentriert, der Einblick in die Textwelt egozentrisch. Zu klären wäre demnach der Zusammenhang von Zerrissenheit und Zeitreflexion.

Zerrissenheit tritt lexikalisch explizit auf. Es »riß [...] ihm in der Brust« (ebd.: 226); Lenz erscheint bei Oberlin in zerrissenen Kleidern (vgl. ebd.: 227); »er riß sich mit den Nägeln« (ebd.: 228); ihn treibt es nach einem »Abgrund, zu dem ihn eine unerbittliche Gewalt hinriß (ebd.: 239). Daraus ließe sich folgern: Das Strukturmuster wird auf der Textoberfläche in eigentlichem und uneigentlichem Redemodus aufgebaut. Die Pathologie des Erscheinungsbildes von persönlicher Zerrissenheit, auf die beide Modi hinauslaufen, zeigt sich darin, dass Lenz an einem innerlichen Schmerz - an der Schnittstelle also zwischen Körper und Geist - leidet, der sich in massiven Schüben äußert (»unendliche Qual«; ebd.: 237), ihm selbst aber unerklärlich und fremd ist (»unnennbare Angst«; ebd.: 227; »sonderbare Angst«; ebd.: 229) und teils in manischem Handeln, teils in Katatonie mündet. Pathologisch ist der Sachverhalt auch deshalb zu nennen, da er offensichtlich fortwährend auf der Schwelle zum Selbstverlust steht (»Abgrund«; »als müsse er sich auflösen «; ebd.: 232) und doch dagegen ankämpft. Dies zeigt sich ferner im unmittelbaren Schwanken zwischen zwei entgegengesetzten, disparaten Gemütszuständen:

[S]ein ganzer Schmerz wachte jetzt auf, und legte sich in sein Herz. Ein süßes Gefühl unendlichen Wohls beschlich ihn. (Ebd.: 231; Hervorhebungen von mir, S. B.)

[E]r lag in den heißesten Tränen, und dann kam plötzlich eine Stärke, und erhob sich kalt und gleichgültig, seine Tränen waren ihm dann wie Eis, er mußte lachen. Je höher 
er sich aufriß, desto tiefer stürzte er hinunter.« (Ebd.: 239 f.; Hervorhebungen von mir, S. B.)

Zielpunkt ist immer wieder die Ruhe, ein Befinden, das ihm zwar gelegentlich vergönnt ist, aber nicht von nachhaltiger Dauer sein kann (vgl. ebd.: 227, 228, 230, 231, 236 u. 249). Die Folgen: Die Figur ist verwirrt, verhält sich selbstdestruktiv (bis hin zu Suizidversuchen) und verfällt zunehmend dem Nihilismus (»gar nichts, gar nichts«; ebd.: 244). Lenz' psychisch-physische Verfassung nimmt bei all dem sukzessive ab (»Zustand immer trostloser geworden«; ebd.: 246). Parallel zur zyklischen Entleerung erfolgt somit auch ein sukzessiv-fortlaufender Prozess der Degression: Der Text überlagert in seiner Hauptfigur und in Form der Figurenpathologie zyklisches und lineares Zeitmodell.

Von besonderer Brisanz - da hierin Gründe für diesen Extremzustand zu vermuten sind - ist angesichts dieser Sachlage der Stand der Figur zwischen >Vergangenheit< und >Gegenwart $<$, der aus den gegebenen Textinformationen allerdings nur ansatzweise zu rekonstruieren ist - die dargelegte Konstitution jedenfalls wird in Verbindung gebracht zur Reflexion von Zeit:

Unterdessen ging es fort mit seinen religiösen Quälereien. Je leerer, je kälter, je sterbender er sich innerlich fühlte, desto mehr drängte es in ihn, eine Glut in sich zu wecken, es kamen ihm Erinnerungen an die Zeiten, wo alles in ihm drängte, wo er unter all seinen Empfindungen keuchte $[\approx>$ Leben $<]$; und jetzt so tot $[\approx>$ Tod $<]$. (Ebd.: 241)

Es deutet sich ein Zustand in der Vergangenheit an, der mit >Leben< attribuiert wird, demgegenüber der Zustand in der Gegenwart explizit in Todesnähe rückt. Beim Bibellesen, so heißt es auch, gehen »alte vergangne Hoffnungen in ihm auf « (ebd.: 229). Tatsächlich verschafft ihm die von Oberlin ermöglichte, selbst abgehaltene Predigt Linderung. Doch der Gesamtkomplex dreht sich nicht ausschließlich um religiös motivierte Zweifel, die Lenz wiederholt heimsuchen. Denn: »Ahnungen von seinem alten Zustande durchzuckten ihn, und warfen Streiflichter in das wüste Chaos seines Geistes« (ebd.: 239). Und: »[E]s drängte in ihm, er suchte nach etwas, wie nach verlornen Träumen, aber er fand nichts« (ebd.: 225). Die Vergangenheit wird verschleiert, sie ist präsent, ohne zugleich auch benannt werden zu können, geschweige denn, dass ihr Abbruch zu erklären wäre. Für Lenz liegt sie gar im nicht erfassbaren Irrealis: »[E]r war sich selbst ein Traum« (ebd.: 227); »als sei Alles nur ein Traum« (ebd.: 229). Sinnfällig ist auch, dass Lenz wiederholt als kindlich beschrieben wird, er also in übertragenem Sinne im Kindstatus verblieben ist (vgl. ebd.: 227, 229, 230 u. 248), er sich von seiner 
Vergangenheit nicht zu lösen vermochte. Die Koppelung zwischen krankheitsbedingter Ahnungslosigkeit und körperlicher Entwicklungsstagnation ist für sich genommen nicht paradoxal: Schließlich steht beides nicht in logischem Widerspruch zueinander. Semiotisch ist sie aber dennoch nicht uninteressant, denn die Temporalsemantik der Figur weist durch diese Anlage (Marker: >Intransparenz der Vergangenheit< und 〉Stagnation der biologisch-subjektiven Zeit $<$ ) im Verbund mit Zerrissenheit den eigentlichen Grund für die Krisenhaftigkeit der Gegenwart und die Negativierung der Zukunftsaussicht.

Es lässt sich hinsichtlich der zeitreflexiven Stoßrichtung des Textes also Folgendes festhalten: Schaltstelle und Zugang der uns präsentierten Welt ist die Hauptfigur. Mit ihr wird >Welt< unverkennbar als massiv problematisch inszeniert; zumindest was das Verhältnis von >Subjekt< und >Welt< anbelangt: Lenz »hörte im Schlaf, wie die Uhr pickte« (ebd.: 238). Man fragt sich zudem, wie die positiv attribuierte Vergangenheit aussieht. Doch der Text belässt es bei Andeutungen und versperrt den Blick in das der Gegenwart vorangegangene Zeitsegment; die Rekonstruktion verläuft ins Spekulative. Ebendies sind zwei Aussagen des Textes: Die Gegenwart ist von der Vergangenheit überlagert und doch auch von ihr separiert; der Bruch mit ihr führt zu einem unlösbaren, akuten Problem, das bis in die Zukunft hinein besteht. Unlösbar ist das Problem aber auch deshalb, da >Vergangenheit< zwar präsent und die Auswirkungen der gescheiterten Loslösung von ihr nachhaltig belastend sind, ihre Hintergründe und Begebenheiten aber nicht mehr einsehbar, nicht mehr nachvollziehbar und verstehbar sind. Zerrissenheit in Büchners Text zeigt sich also als Effekt, der aus einer in der Gegenwart nicht mehr nachvollziehbaren Orientierung an der Vergangenheit hervorgeht, oder: als Symptom einer ins Krankhafte gesteigerten Verschlossenheit in der eigenen Gegenwart. Die Figur nimmt sich selbst als unzulänglich wahr, die zwischenmenschliche Interaktion mit ihrer Umwelt ist in weiten Teilen erheblich gestört bis unmöglich. So wie der Einblick in die für die Figur inzwischen rätselhafte Vergangenheit verschlossen bleibt, so ist auch die Zukunftsaussicht massiv eingeschränkt und die Zukunft am Textende negativiert - was als Folge der in Wahnsinn gesteigerten Zerrissenheit inszeniert wird. Büchners Lenz fokussiert demnach den Helden und verfährt in der Vermittlung von Welt radikal protagonistenzentriert: Die Störung des Protagonisten gerät zur Störung der dargestellten Welt insgesamt, die aus Sicht der Figur nicht mehr erschlossen werden kann und deren interaktionaler Kontakt beinahe gänzlich verloren ist. Rätselhaft bleibt, wie es zur Störung gekommen ist, offenbleibt, ob die Probleme lösbar sind. Held und Welt befinden sich im Zustand einer fundamentalen und nachhaltigen Krise.

Doch stellt Büchners Text sicherlich einen in seiner extremen Konzentriertheit (und Egozentriertheit) einzigartigen Sonderfall dar. Geläufiger ist die Spielart, 
wie sie in Mundts seitenstarker und bemerkenswerter Novelle Madelon oder Die Romantiker in Paris vorliegt, ein Text, der jedoch ebenso wie Lenz Zerrissenheit an die Reflexion von Zeit rückbindet und die Handlungsgegenwart als Aushandlungsort schwerwiegender Probleme mit negativem Ausgang gestaltet. Diese Probleme sind indessen vielfältig: Madelon - eigentlich: Magdalene Larosette, geborene von Ramberg - lebt verwitwet und gemeinsam mit einem väterlichen Freund, Marquis Cidevant, in Paris, wo sich - situiert ist das Geschehen 1829/1830 politische Unruhen ankündigen und schließlich tatsächlich eskalieren. Das erste Problem des Textes: Die dargestellte Welt befindet sich im Systemumsturz, der das Leben des Figurenensembles jedoch allenfalls tangiert und keine direkten Konsequenzen hat. Heißblütig verehrt wird Madelon vom Bildhauer (mit dem mit Blick auf die Reflexivität des Textes natürlich bezeichnenden Namen) Narziß, der als Zerrissener vorgeführt wird und am Ende ihren tragischen Tod zu verantworten hat. Zuvor jedoch wird sie aufgesucht von Major Eichen und dessen Tochter Rosalie. Eichen bewegt Madelon zur zwischenzeitlichen Rückkehr in das heimatliche Koblenz, um ihr die Geschichte ihres Hauses zu offenbaren, die eng mit der Geschichte ihrer Mutter verknüpft ist. Sie erfährt, dass diese nach dem Tod des Vaters eine Freundschaft mit Eichen aufgebaut hatte und dass jener mit einem im Haus verborgenen Geldbetrag, auf den er zufällig gestoßen war, das marode Haus renovieren lassen wollte. Sie kommt daraufhin auf der Suche nach dem Geld, das Eichen ihr verschweigt, unglücklich zu Tode. Eichen lässt das Haus einreißen, ein Neues errichten und darin einen Raum im Stil des mütterlichen Umfeldes gestalten. Die Offenbarung gegenüber Madelon dient dem Seelenheil Eichens, der die Last der Vergangenheit nicht mehr erträgt. Das zweite Problem also: die Offenbarung und Enträtselung der Vergangenheit, mit denen die Kindergeneration konfrontiert wird. Narziß wiederum ist nach deren Besuch in Paris überwältigt von Rosalie, reist ihr nach einem Fauxpas hinterher und rettet sie in einem dramatischen Moment aus dem brennenden Haus. Der Eheschließung entzieht er sich dann aber jedoch, reist nach Frankreich zurück und ersticht auf einem Maskenball Madelon wie auch sich selbst. Das dritte Problem: das Künstlersubjekt als Zerrissener, dessen Handeln negative Konsequenzen nach sich zieht.

Die temporalstrukturelle Anlage, die der Text entfaltet, ist dem zu entnehmen: Installiert wird ein komplexes Zeitmodell mit mehrphasigem Vergangenheitssegment. Die Gegenwart befindet sich in mehreren Hinsichten in einem Zustand des Umbruchs. Die Zukunft erscheint negativiert - im Tode der einen und im resignativen Rückzug der anderen. Die Verfasstheit der Figuren wie auch der Fortgang der Handlung werden durch die Textlogik als nicht tragbar gewertet, das Figurenensemble hat mit der Tilgung der Hauptfigur persönliche Einbußen hinzunehmen. Zerrissenheit zeigt sich dabei in einer für die Epoche typischen Spielart, 
und zwar primär angesiedelt im Aktionsfeld $>$ Liebe $<$. Wie auch Ungern-Sternbergs Die Zerrissenen geht es dem Text um einen jungen männlichen Protagonisten, der zwischen verschiedenen Liebes- und Paarbildungsoptionen wählen muss - und damit überfordert ist und scheitert. Wie ist das umgesetzt und inwiefern wird dabei Zeit reflektiert? Narziß steht zwischen drei Frauen. Zum einen verband ihn in der jüngsten, dem Textgeschehen vorgelagerten Vergangenheit ein Verhältnis mit Madelon, das allerdings nur kurz währte. Zum anderen erscheint ihm mit Erzählbeginn Rosalie als neues Ziel seiner Sehnsüchte. Zwischenzeitlich hatte er zusätzlich eine ebenfalls kurze Affäre mit Susanne, der Kammerzofe Madelons. Die Gesamtkonstellation führt zu einem subjektinternen Krisenherd und hat für alle Beteiligten nachhaltige Folgen.

Konkretisiert wird Zerrissenheit wie auch bei Lenz ebenfalls auf der Textoberfläche. Die Rede ist von »Herzklopfen « (Mundt 1832: 18), von »zerrissene[m] Streben« (ebd.: 84) und »zerrissene[r] Seele« (ebd.: 105), von Ruhelosigkeit (vgl. ebd.: 88) und Unentschlossenheit (vgl. ebd.: 91); Narziß befindet sich im »Streit mit sich selber« (ebd.: 88) und ist sich »seiner selbst nicht mehr mächtig « (ebd.: 96); schließlich spricht sogar seine Mutter von Krankheit (vgl. ebd.: 216), die Erzählinstanz von »Wahnsinn « (ebd.: 241). Während Lenz sich bereits in einem Endstadium von Zerrissenheit und in schwelendem Wahnsinn befindet, so ist Narziß einem Prozess zunehmender Verschlimmerung seines Zustands unterworfen. Zwar ist der Zwiespalt, der sich für die Figur in den beiden unterschiedlichen Frauentypen Madelon und Rosalie ergibt, von Beginn an gegeben. Allerdings versucht die Figur fortwährend - wenn auch wider besseres Wissen - von Madelon loszukommen und Rosalie für sich zu gewinnen und zu ehelichen. Ein grundlegendes und fatales Problem aber wird durch die Einsicht in das eigene Innenleben manifest:

Ein Franzose, wie kann er anders, vor der Langenweile muß er die Flucht ergreifen, und so, Mutter, bin ich davon geflohn zwei Tage vor der Hochzeit! [...] Viel, viel hätte ich darum geben, wenn ich in der Ruhe hätte Ruhe finden können! Aber auf mich muß Niemand vertrauen! Ich habe mir selbst nie treu bleiben können, wie sollte ich es Andern sein! Die Untreue ist meine Göttin [...]. (Ebd.: 211)

Was habe ich denn anders gethan, als ein langweiliges deutsches Kleinstädterleben und eine langweilig gewordene, zu simple Liebe, die nur künstliche Erdichtung meiner Phantasie gewesen, plötzlich wieder verlassen [sic!], ehe dadurch der lebensbewegliche Pariser ganz in mir getödtet worden? (Ebd.: 212)

Ich besinne mich immer deutlicher auf Dich und Deinen Liebeszauber, mit dem Du mich einmal berauschtest und mich dann im Rausch wieder hinausstießest auf die öde Straße, wo ich mir das Herz erfrieren mußte in der dunkeln Winternacht! Du hast mich so verzaubert durch Dein Wesen, daß ich so wild wurde und umherschwärmte ohne 
Ruh wie ein trügender Irrstern, welcher Jeden, der an ihn glaubte, in den tödtlichen Abgrund hinunterlockt! (Ebd.: 240 f.; Hervorhebung im Original)

Narziß wird als unsteter und beziehungsunfähiger Mensch gezeichnet, ein Zerrissener, der sich selbst die eigene Verfasstheit eingesteht. Er macht aber ferner Madelon für diesen Charakterzug verantwortlich, und mehr noch: tötet sie dafür. Am Ende ist - mit den drei Parzen der römischen Mythologie gesprochen sogar der »Lebensfaden [...] zerrissen« (ebd.: 244). >Liebe< korreliert also - aus männlicher Perspektive - plötzlich auftretendes, kurzes, leidenschaftliches Glück ohne lange Dauer, ohne aber auch gänzlich zu erlöschen, was zu psychischmentalen Konflikten führt und gewalttätige wie endgültige Handlungsakte nach sich zieht. Das allerdings hat zur Folge, dass die gesamte junge Generation hinsichtlich eines der für die dargestellte Welt - neben der Auseinandersetzung mit der ambivalenten Vergangenheit - wichtigsten Belange scheitert: Paarbildung. Narziß lässt Rosalie sitzen, Dubois wird seiner Möglichkeit beraubt, mit Madelon zusammenzukommen.

Nun stellt sich berechtigterweise die Frage, warum es gerade Madelon ist, die Narziß für seinen Zustand zur Rechenschaft zieht - wäre doch ebenso Susanne, die zwischendurch als Verräterin agiert, potenzieller Angriffspunkt gewesen. Der Text begründet dies mit einem kunstreflexiven Zug, der in einem weitreichenden zeitreflexiven strukturellen Netz angelegt ist. Dabei sind zwei Aspekte von Bedeutung: Zum einen die Semantik der Figur Madelon, speziell in Abgrenzung von Rosalie; zum anderen die Typisierung des Künstlers Narziß, in der sich der eigentliche Grundzug der hier vorliegenden Form von Zerrissenheit nachweisen lässt und der zeitreflexiv unterbaut ist. Wenn Narziß in der zuletzt zitierten Passage von »Liebeszauber« spricht, so deutet er damit offenkundig auf ein Modell hin, das die Romantik inflationär in Anschlag bringt: Der Jüngling unterliegt der erotisch konnotierten Anziehungskraft einer meist fantastisch-wunderbar fundierten Entität und gerät dadurch bedingt in Gefahr, vom - textideologisch rechten - Weg abzukommen. Indem er auf dieses Modell zurückgreift, offenbart Narziß damit ein Wissen, das ihn von romantischen Figuren unterscheidet. Denn während letztere dem Zauber unterliegen und ihm entweder entkommen (Das Marmorbild) oder ihm gänzlich nachgeben (Der Runenberg), ohne dabei aber einen autoreflexiven Bezug zum eigenen Status als romantische Figur herzustellen, stellt Narziß ebendiesen Bezug her. Der Text arbeitet demnach wie auch Vischers Cordelia mit Topoi, die er aufgreift und mit Bedeutung auflädt. Dies unterstreicht die explizite Zuordnung Madelons zur >romantischen Liebe<, der eine explizit >klassische Liebe $<$ in Person Rosalies entgegengestellt wird. Zunächst wird Madelon mit >Romantik< und >Romantizismus< in Verbindung gebracht: Sie ist die »Venus des 
Romanticismus«, die »romantische Venus « (beide ebd.: 60) oder gar die »Göttin der romantischen Liebe« (ebd.: 59). Semantisiert wird die Liebe zu ihr mit süßer und wilder Unruhe, mit Entzücken und Schwärmen, mit Fantasie, mit sinnlichem Träumen, Lust und Sehnsucht, mit der Ambivalenz aus Glück und Elend, mit Leidenschaft (vgl. ebd.: 10), kurz: eben mit »romantische[r] Liebe« (ebd.: 91). Den Gegenpart nimmt aus Narziß' Sicht Rosalie ein, die bezeichnenderweise, mit Sanftheit, Wahrheit, Klarheit, Milde, ohne Verführung, als gediegenes Glück (vgl. ebd.: 11 f.) attribuiert wird. Beide Formen präsentiert der Text aus Narziß' Sicht als nichtrealisierbare Extreme: Die eine Form ist zu unstet und durch ein Übermaß an Leidenschaft geprägt, die andere im Gegenteil - Narziß sagt es selbst - durch Langeweile. Das Hauptproblem stellt dabei der Mann dar, der weder das eine überwinden, noch das andere akzeptieren kann.

Die Figurensemantik Madelons aber ist mindestens in einer weiteren Hinsicht bemerkenswert. Sie repräsentiert eine nach Frankreich Übergesiedelte und hat mit ihrer Verwitwung die genannten Merkmale überhaupt erst angenommen. Es ist zu vermuten, dass sie zuvor - ähnlich wie in der Handlungsgegenwart Rosalie - die im Text als >klassisch < bezeichnete Liebe vertreten hat. Dafür spricht neben der Nationalität auch die Parallelführung des Alters der Figuren: In der Handlungsgegenwart ist Madelon 26 Jahre alt, mit 16 Jahren heiratet sie einen französischen Offizier; Rosalie ist ihrerseits zum Zeitpunkt der gegenwärtigen Handlung 16 Jahre alt und steht als potenzielle Heiratsoption zur Verfügung. Das, was mit Madelon in der jüngeren Vergangenheit verhandelt wurde, wird nun erneut mit Rosalie verhandelt. Da Paarbeziehungen insgesamt eine erhebliche Rolle im Text spielen, ist diese Konstellation natürlich von besonderer Prägnanz. Partnervereinigungen in der Vergangenheit glücken nur temporär: Madelons Mutter Juliane lebt bis zum Tod ihres Mannes in einer unglücklichen Ehe; ihre Beziehung zu Eichen stagniert als platonische. Madelon selbst ehelicht zwar einen Mann von Rang, der jedoch frühzeitig verstirbt, woraufhin sie in die Armut abzurutschen droht. Ihre aktuelle Beziehung zu dem Marquis Cidevant ist ausdrücklich als > Vater-TochterBeziehung \ gekennzeichnet. Neben ihrer temporären Realisation unterscheiden sich die wesentlichen Partnerbeziehungen der tieferen Vergangenheit von den Versuchen der Paarfindung der Gegenwart hauptsächlich dadurch, dass sie fruchtbar gewesen waren und Nachwuchs hervorbringen konnten. In der Gegenwart scheitern alle diese Versuche schon vor der Hochzeit. Wenn von der Kindergeneration - und damit von der Gegenwart - erwartet wird, Probleme der Vergangenheit in den Griff zu bekommen und sie zu lösen, so enttäuschen ihre Vertreter auf ganzer Linie: Wie schon Madelon wird Rosalie zunächst unverheiratet und kinderlos bleiben; Eichen zieht sich mit seiner Tochter resigniert zurück. Die Hauptfiguren 
Madelon und Narziß werden gar durch Tod getilgt. Probleme, die der Text entwirft, werden durch die Vergangenheit aufgeworfen, bleiben allerdings unlösbar über das Textende hinaus bestehen. Madelon figuriert in diesem Großzusammenhang diejenige Stelle, an der >Vergangenheit< gebündelt als Problem zutage tritt, ebenfalls Gegenwartsprobleme ausgetragen werden und >Zukunft $<$ ausgehandelt wird: Sie ist Anlaufpunkt für Eichenau zur Klärung seiner »düstere[n] Verschuldungen der Vergangenheit« (ebd.: 38) und ist Narziß' Ziel des Begehrens. An ihrem Tod wird die Negativierung der Zukunft offenkundig, jedenfalls auf Individualebene. Eine >Kappung von Zukunft< hatte sie bezeichnenderweise zuvor schon selbst unternommen: Sie kehrt nach der Konfrontation mit der familiären Vergangenheit verändert nach Paris zurück und »schwört es sich selbst zu, daß sie sich auf immer der Liebe verschlossen habe« (ebd.: 186) und beschließt, »sich selbst jedes Glück und jede heitere Zukunft standhaft zu verweigern« (ebd.: 187).

$\mathrm{Zu}$ lesen ist dieser Zusammenhang jedoch nicht allein in anthropologischer Hinsicht, sondern, wie gesagt, eben auch in kunstreflexiver. Narziß befindet sich in einem »Künstlerzwiespalt« (ebd.: 83) - und zwar wie schon Lenz zwischen idealistischem und realistischem Kunstanspruch -, er empfindet sein Handeln als »zerrissenes Streben« (ebd.: 84) und erachtet Liebe als Strategie zur Lösung seiner Lage. Insofern erlangen die obigen Ausführungen eine weitere Deutungsebene: Wenn Narziß in Liebesdingen unentschlossen agiert und gleichzeitig für gegenteilige Optionen jeweils heftig und doch aber nur zeitweilig überzeugt plädiert, so tut er das auch - und vor allem - in ästhetischer Hinsicht. Gegenüber Eichen öffnet er sich:

Ich bin ein Bildhauer, und in meiner, stillen, nur vom Schlag des Meißels durchtönten Werkstatt ist mir oft so wohl, daß ich in der friedlichen Gesellschaft meiner Bilder alle, auch die wildesten, Triebe des Herzens beruhigt fühle, daß ich aus der kunstgeweihten Einsamkeit nie mehr herausgehn möchte in die stürmisch bewegte Welt, daß ich wünsche, so bei meinem Marmor und Stein das Leben verträumen zu können, während draußen fern von mir Elend und Gefahr, Lust und eitles Glück der Menschen vorüberrauscht! (Ebd.: 82)

Die Kunstsphäre ist separiert von der Außenwelt und stellt in Form der Werkstatt gar einen topografischen Rückzugsort dar. Kunst dient aber zudem auch als therapeutisches Mittel eines gestörten, seiner Leidenschaften regelrecht ausgelieferten Künstlersubjekts (>wildeste Triebe $<$ ). Narziß fährt fort:

Dann aber beginnt mich auch plötzlich wieder vor dieser meiner Abgeschiedenheit zu grausen, mich friert vor der Kälte meiner leblosen Statuen, meiner stummen Gefährten, die in ihrem glatten, menschenähnlichen schönen Leibe keine Empfindungen, 
keine Leidenschaften bergen; des Künstlers Stillleben verliert seine Weihe und der Mensch lockt mich hinaus zum reizenden, freien Erdengenuß, in die wärmere Zone der Sinnlichkeit, der schäumenden, lachenden üppigen Freudenfülle des Lebens! (Ebd.: 82 f.)

Das Subjekt ist unausgeglichen, in seinen Ansichten schwankend - und ebendies macht den Kern aus, von dem aus Zerrissenheit motiviert ist. Denn zeitweise ist es die Kunst, die in ihrer Leblosigkeit negativ erfahren wird, während >Welt< und $>$ Gesellschaft $<$ mit $>$ Freude $<$ und $>$ Leben $<$ umschrieben werden. Narziß diagnostiziert, dass die eigene persönliche Verfasstheit gefährdet sei und allein durch die Legitimierung der Liebe zu Rosalie gefestigt werden könne:

So war auch ich fast rettungslos in diesen Künstlerzwiespalt zweier Extreme des Göttlichen und Irdischen versunken, und mein Naturell, meine Erziehung, meine Verhältnisse, ein bedeutendes Vermögen, das ich von dem früh gestorbenen Vater ererbt und das eine zärtliche, willenlose Mutter mir ganz für den Genuß des Lebens überließ, Alles trug dazu bei, mich nach zwei mit einander streitenden Richtungen in die Irre zu führen, so daß ich weder in meiner stillbegrenzten Kunst die alleinige Befriedigung des Lebens, noch im Leben die wahre Grenze des Genusses finden kann. Da erblickte ich zum ersten Mal das mild lächelnde, unaussprechlich gütige Antlitz Ihrer geliebten Tochter, und es war mir, als sähe ich den Tugendengel plötzlich vor mir erscheinen, der mir zuwinkte und mir zuflüsterte, daß ich nur in ihrem Besitz Frieden und Versöhnung für mein zerrissenes, verworrenes Streben finden würde! (Ebd.: $83 \mathrm{f}$; Hervorhebungen von mir, S. B.)

Liebe, Kunst und Leben sind miteinander verschränkt. Narziß befindet sich im »Zwiespalt zwischen Romanticismus und Classicismus der Liebe und des Lebens« (ebd.: 109). Der Text geht dabei noch weiter und baut seinen reflexiven Verhandlungsbereich über einen im Zentrum stehenden Künstler hinaus aus: Denn zum einen werden $>$ Klassik $<$ und $>$ Romantik $<$ ebenfalls auf politische Ideologiebereiche bezogen, zum anderen wird >Romantik< skaliert; unter anderem ist >Romantik auch ein sogenannter »neuer Romantizismus « eingeschrieben, dessen Repräsentant Dubois ist: Eine »Durchgangsstufe zu einer freieren und geistreicheren Wiedergeburt der vaterländischen Poesie« (ebd.: 13). Gesetzt wird vom Text von vornherein die Korrelation von $>$ Kunst $<$ und $>$ Politik $<$ und damit eine zeitreflexive Linie eingezogen:

[D]ie ästhetischen Parteien der neuesten Poesie in Frankreich, die sich als Klassiker und Romantiker in einem feindlichen Gegensatz gegenüberstanden, [hatten] bekanntlich auch in der Politik eine entsprechende Stellung gegen einander eingenommen, so daß im Durchschnitt die Royalisten eben so sehr für Anhänger des Romanticismus galten, als die Liberalen es gewöhnlich mit der Partei der Klassiker hielten und in den 
Gegnern dieser Dichtergilde auch die Gegner ihrer Ansichten über Staat und Regierung verfolgten und haßten. (Ebd.: $6 \mathrm{f}$.)

Diesen Gedanken führt Dubois an anderer Stelle gegenüber dem >altklassischen< Marquis differenzierend aus. Jener spricht von einer »armseligen Gegenwart« mit ihrem »neumodischen Bombast« (beide ebd.: 69; Hervorhebung von mir, S. B.) und lobpreist dagegen das »goldene Zeitalter« der Vergangenheit (ebd.: 68). Dubois hingegen deklariert die alte Zeit für vergangen (»würdige Leichenrede«; ebd.: 70), bestärkt den politischen Auftrag der $>$ Romantik $<$ mit revolutionärem Freiheitsbestreben und trennt eine ursprüngliche $>$ Romantik<von Ausformungen »neuester Zeit« (ebd.: 74; vgl. auch: 76 u. 149): Gemäßigte auf der einen und Radikale auf der anderen Seite. Er selbst plädiert schließlich für eine Loslösung der Kunst von der Politik sowie für ihre Autonomisierung.

Insgesamt ist demnach ein breites Raster diachron aufeinander folgender und synchron voneinander abgegrenzter Ästhetiken anzunehmen, deren Existenz im Text aufs Stärkste den Bruch zwischen Vergangenheit und Gegenwart wie auch die Heterogenität der Gegenwart betont. Narziß ist seinerseits ein Künstler mit Sonderstatus, der als Bildhauer von den Poeten abgegrenzt wird (»was seid ihr doch eigentlich für sonderbare Leute mit euerm Klassicismus und Romanticismus«; »[i]hr Poeten«; ebd.: 8). Er steht folglich gleich in mehreren Hinsichten zwischen den Stühlen, seine Unentschlossenheit ist sein prägendes Signum. Zu folgern wäre: Kunst formiert ein hochgradig heterogenes Feld mit Einzelpositionen, Feindifferenzen, Gegenpositionen, Aktualitätsgraden - Narziß als Repräsentant dieses Feldes dient daher als zentrales Zeichen für ihren (gesellschaftlichen und zukünftigen) Status. Seine Kunstproduktion steht in Zusammenhang mit Liebe und gerät zum Mittel zum Zweck (Madelons Statue und Major Eichens Büste), sein Handeln unterbindet das eigene Fortleben wie auch das Madelons und hinterlässt damit den Kollegen und Freund Dubois, der als Partneroption für Madelon in Frage kommt, mit leeren Händen. Man ist geneigt zu behaupten, dass Dubois als Künstler zwar teilweise zu überzeugen vermag - obwohl er mit seiner Simson-Tragödie auf einen alttestamentarischen Stoff zurückgreift und eben nicht Neues schafft -, allerdings als Mensch und in seinem Handlungsziel, Madelon für sich zu gewinnen, vollends versagt. So wie das Weltgeschehen, das metonymisch in der als äußerst dynamisch gezeichneten »Hauptstadt der neuern Weltgeschichte « (ebd.: 3) Paris in Form revolutionärer Unruhen Einzug nimmt und in Person des »Bürgerkönig[s] « Philipp (ebd.: 148) zu einem zukunftsträchtigen Ende kommt, so trägt sich auch auf Individualebene ein Geschehen zu, das, wenn nicht sogar eine katastrophale, so doch eine resignative und fragwürdige Zukunft nach sich zieht. 
Alles in allem liegt mit Madelon oder Die Romantiker von Paris ein Text vor, der Zerrissenheit im Subjekt verankert, die Lexik des Zerrissenen aber zudem auf den Zustand der dargestellten Welt überträgt (»Zerrissenheit [des] äußeren politischen Lebens«; ebd.: 75) und beides dadurch homolog setzt. Ferner findet sich Zerrissenheit als Handlungskonsequenz wieder (>zerrissene Lebensfäden<). Oberflächlich besehen handelt es sich bei der verzweifelt-unentschlossenen Partnersuche um den hauptsächlichen Motivationsfaktor für die vorliegende Variante. Allerdings fördert eine nähere Betrachtung Gesichtspunkte zutage, die Anlass dazu geben, auch von einem kunst- und zeitreflexiven Verhandlungskomplex sprechen zu können: Aufgerufen und spezifisch semantisiert werden $>$ Romantik $<$ und $>$ Klassik $<$ und in einen Zusammenhang gebracht mit dem naheliegenden Problemfeld $>$ Liebe< sowie außerdem mit der dargestellten politischen Ereignisgeschichte. Narziß ist zwar nicht alleiniger Held - die Erzählinstanz wechselt fortwährend zwischen fokussierten Figuren -, aber er stellt denjenigen Part dar, der sich selbst als unzulänglich erlebt und dadurch zum Mörder wird. Entscheidend ist dies für den Umgang des Textes mit Zeit in doppelter Hinsicht: Erstens ist die Konfrontation mit der Vergangenheit in der erzählten Gegenwart ausschlaggebend für die Modellierung einer stagnierenden Zukunft auf Figurenebene. Madelon vermag nach Einsichtnahme in die Vergangenheit nicht, sich von dieser zu lösen und ihre Zukunft zu gestalten; Narziß gelangt zu der Erkenntnis des eigenen Ungenügens und handelt fatal. Beides hat auch Einfluss auf Cidevant und Dubois sowie auf Eichen und Rosalie. Zweitens wird nicht allein eine Dynamik des Weltgeschehens und der Figurenhandlung vorgeführt, sondern beides ebenfalls metatextuell und kunstreflexiv codiert: Es geht auch um die Klärung des Status von $>$ Kunst<, die Bedingungen ihrer Produktion, um die Bedingtheit und Abgrenzung gegenwärtiger Ästhetik von vergangener und um die Möglichkeiten zeitaktueller Kunstformen. Dahingehend zieht der Text ein resignatives Fazit. Kunst ist hauptsächlich eines: regressiv orientiert, und diese Ausrichtung wird von allen Beteiligten problematisch empfunden. Dass Kunst in allen Fällen zweckgebunden (zur Huldigung einer Frau) vorliegt, mit dem Ergebnis misslingender Paarbildungen, kann auch auf Textebene als Plädoyer gegen Zweckgebundenheit und Regression verstanden werden. Das Hauptproblem des Textes ist mithin die Bindung an die Vergangenheit (Kunst und Figuren), die einer fortschreitenden Zeit der Welt entgegensteht und die Zukunftsfähigkeit von Kunst unterbindet.

Wir können sagen: Zerrissenheit der Zwischenphase ist stets semiotische Manifestation einer krisenhaften Gegenwart - metonymisch repräsentiert in der Figur -, und dies in markanter Form mit entschiedenem Einfluss auf die Modellierung von $>$ Zukunft $<$. Das Signum der Krisenhaftigkeit resultiert dabei aus einer 
>belastenden< Vergangenheit, deren ungelöste Probleme in die Handlungsgegenwart hineinstrahlen, sowie aus offensichtlich überfordernden Handlungsaufgaben, Optionenentscheidungen, Gemütslagen. Die Konzeption von $>$ Zukunft< gerät so ins Schwanken, ihre Modellierung steht im Zeichen der Kappung. Dabei wird Zerrissenheit auf verschiedenen Wegen motiviert. Ausschlaggebend sind vornehmlich die Problemfelder >Figur und Welt $<$ und >Figur und Familie < - beide Beispiele sind in diese Richtungen analysierbar. Was also für den Zerrissenen akut ist, ist auch für die dargestellte Welt akut: Inkonsistenz, Heterogenität, Imponderabilität, Insuffizienz und Defizienz. Diese Eigenschaften, so wollen wir annehmen, stehen im Zusammenhang sowohl mit den motivierenden Problemfeldern als auch mit >Regression $<$ und >Progression $<$. Das heißt, Zerrissene formieren figürliche Kulminationen der vom Literatursystem als problematisch erachteten Reziprozität von temporal-ontologisch zirkulärer und linearer Weltfundierung sowie von vergangenheitsorientierter und zukunftsorientierter Weltgestaltung.

\subsection{Discours-Phänomene}

Die Untersuchung war bislang vornehmlich auf die Ebene des Dargestellten bezogen: Welten, Räume, Figuren und ihr Verhältnis zueinander. Die Strukturmuster der >Regression < und >Progression < sind jedoch nicht ausschließlich in der histoire verankert, sondern können ebenso im Erzählakt konkretisiert sein. Das heißt, es geht Texten nicht allein darum zu zeigen, dass ihre Gegenstände mit reflexiven Zeitstrukturen verknüpft sind - das, was sie narrativ darstellen, zeitreflexiv von Bedeutung ist -, sondern sie beziehen auch die Art und Weise ihrer Darstellung ein - also, wie sie erzählen: Reflexive Zeitstrukturen auf beiden Ebenen deuten auf das Selbstverständnis einer `Zwischenphaseく hin, den Status zwischen dem Vorgängersystem der Goethezeit und einem noch unbekannten Nachfolgersystem. Abgebildet wird dieser als problematisch erachtete Status in der Reziprozität von $>$ Regression $<$ und >Progression $<-$ in der Überlagerung von Strukturmengen, die temporal zurückdeuten, und solchen, die temporal vorausdeuten. Zeitmodellierend schlägt sich dies in der Kombination von Zirkularität und Linearität nieder, die im Zusammenhang mit der Dynamik oder Statik der dargestellten Welt steht. Strukturgebend auf Ebene des discours sind nun zwei Erzählstrategien: (1) die Funktionalisierung von Textelementen in lyrischer Diskursivierung und (2) die narrative Retrospektive. Beide Strategien sind für das vorliegende Textkorpus signifikant.

Dem liegt die Hypothese zugrunde, dass auch das Erzählen selbst - nicht allein das Erzählte - aus literaturhistorischer Sicht den Status eines Interims abbildet, 
insoweit es auf die Goethezeit zurückweist und den Realismus vorwegnimmt. Allein: Erzählen und Erzähltes hängen insofern zusammen und fügen sich in den gegebenen Kontext dieses Kapitels, als beide Strategien mit der Konzeption von >Person< wie auch mit der Modellierung von >Zeit< - vornehmlich mit der Gestaltung von $>$ Zukunft $<-$ korrelieren. Daher verspricht ihre Analyse, über weitere Strukturformen von $>$ Regression $<$ und $>$ Progression $<$ Aufschluss zu geben.

\section{Postromantisches Erzählen: Die Funktionalisierung von Lyrik im narrativen Kontext}

Ein breitflächig anzutreffendes Merkmal seit den 1820er-Jahren ist das der steten Prosaisierung. Man denke nur an die Werke etwa von Zschokke, Gaudy, Hauff und Mundt, an die von Dronke, Mügge und Hebbel und auch an die von Auerbach und Stifter - nicht zuletzt ebenso an unseren Ausgangstext Ottos Die Lehnspflichten. Alle genannten Autoren verzichten in der Regel auf den Einsatz von Lyrik. Konnten noch in den verschiedenen Phasen der Goethezeit entweder das Drama oder die Lyrik als die dominierenden Gattungen gelten, so erfährt die Prosa in Form des Romans und insbesondere der Novelle im Abflauen der Goethezeit zunehmende, schließlich sogar starke Präsenz, während erstere zwar nicht gänzlich verschwinden, aber gegenüber dem Vorgängersystem eine vergleichsweise kleine Rolle spielen. Diese Entwicklung ist dem Literatursystem durchaus bewusst und kann an Texten selbst abgelesen werden. Daher finden sich in Erzähltexten der 1820er- und auch der 30er-Jahre - weniger dann in den 1840er-Jahren - allenthalben lyrische Formen wieder, die zwar in Prosakontexte eingebettet sind, dort allerdings wichtige Funktionen einnehmen. Zum einen steht Lyrik in Korrelation mit Figuren und der Konzeption von >Person< (die, wie zu sehen war, gegenüber der Goethezeit fundamentale Änderungen erfährt), zum anderen markieren lyrische Einsprengsel in metatextueller Hinsicht dezidiert postromantisches Erzählen, denen das Literatursystem insgesamt folgt. Das wird kein Zufall sein. Auch ist es nicht als schlichte Fortführung von goethezeitlichen Erzähltraditionen zu werten, dass Lyrik in Prosatexten auftritt - sondern muss als intentionales Textmerkmal und metatextuelle Regulation der Zwischenphase begriffen werden, die dadurch ihre Stellung zur Goethezeit zum Ausdruck bringt.

Die Problemkonstellation in Fontanes Geschwisterliebe hatten wir bereits angerissen; wir wollen die Analyse vertiefen. Zu konstatieren war bis hierher, dass Geschwisterliebe das Prinzip der anthropologischen Reduktion flexibilisiert, indem er die radikale und die relative Teilregulation miteinander kombiniert: Die dargestellte Anthropologie, so wurde gesagt, ist angesichts der eklatanten 
Fehlleistungen der Figuren untragbar und zugleich doch auch unverzichtbar; so defektiv sie der Text kennzeichnet, so zwangsläufig ist ihre Defizienz innerhalb einer literarischen Diskursivierung. Diesen Widerspruch baut der Text auf, indem er sämtliche Figuren des fokussierten Teilraums durch Tod tilgt, sie damit jedoch in ein der Welt eingeschriebenes Jenseits überführt. >Zukunft< in diesem Fall ist jenseitig zeitenthoben und wird im Diesseits negiert.

Entscheidend ist die Handlungsdynamik, durch die dieser Endzustand herbeigeführt wird. Denn in der Erzählung ist die Verzahnung regressiven und progressiven Handelns und Denkens signifikant: Nach der Paarbildung zwischen Clara und Eisenhardt wird die regressive Tendenz Rudolphs offensichtlich; zuvor erfährt Clara mit der Einsicht ihrer Liebe zu einem fremden Mann die Markierung eines progressiv orientierten Textelementes. Textlogisch ist eine regressive Ausrichtung jedoch unabdingbar, die Rückkehr in einen Vergangenheitsraum gar existenziell notwendig. Denn Clara wird mit der Trennung von ihrem Bruder in einen Leidenszustand versetzt und gesteht sich den schadhaften Verlust der geschwisterlichen Vereinigung ein. Progressives Handeln in der vorliegenden Form jedoch wird gleichfalls als >normal $<$ markiert, folgt Clara mit ihrer Hinwendung an Eisenhardt doch lediglich demjenigen Modell, das die Goethezeit für die Adoleszenz und zum Erreichen gesellschaftlicher Mündigkeit als anzustrebendes vorgesehen hatte. Die Sachverhalte, dass sich dieses Geschehen in einem quasiinsularen, mit >Alter< und >christlicher Religion< attribuierten Teilraum abspielt, dass alle Figuren sterben und doch im Jenseits miteinander vereint werden, und schließlich, dass die Handlungsträger offensichtlich dem Spannungsfeld zwischen Vorwärtsgewandtheit und Rückwärtsstreben ausgesetzt sind und daran scheitern, sind maßgebliche Kennzeichen der offensichtlichen anthropologischen Störung, die der Text verhandelt und die in direkter Beziehung zur vorliegenden Zeitmodellierung steht. Die regressiv-progressive Reziprozität, wie sie uns in diversen Ausformungen in diesem Kapitel begegnet ist, hat auch hier Zukunftsnegation zur Folge. Im Gegenwartssegment ist die dargestellte Welt heterogen angelegt; Störfaktor und zugleich zentrierter Handlungsraum ist ein deutlich als >Vergangenheitsraum< semantisierter Teilraum innerhalb einer »der ältesten Städte der Mark Brandenburg « (Fontane 1975 [1839]: 9). Das Thema der Ablösung von der Herkunftsfamilie und die resultierende Dreiecksgeschichte mit tödlichem Ausgang stehen im unmittelbaren Kontext der Problematisierung von >Vergangenheit< sowie im übergeordneten Kontext der Problematisierung von >Gegenwart<, wobei diese im Kontrast zwischen Innenraum der Handlung und säkularem, bürgerlichem, modernisiertem Außenraum verhaftet ist. Die dargestellte Welt ist - auch über das Textende hinaus - temporalsemantisch polysem. 
Mikrostrukturell manifestiert sich die anthropologische Störung, um die es hier geht, bereits in der Figurenkommunikation. Und hier kommt - jedoch nicht ausschließlich - die Lyrik ins Spiel. Fundamentale, aktuell-gegenwärtig entstehende zwischenmenschliche Probleme nämlich werden mittelbar in lyrischer Form zum Ausdruck gebracht ebenso wie sie unmittelbar im gemeinsamen Gespräch kommuniziert werden. Ganz offensichtlich teilen also zumindest die Hauptfiguren Rudolph und Clara die Eigenschaft, in der spontanen Produktion von Liedern etwas auszudrücken, das ihnen in der gegenseitigen Kommunikation versagt bleibt und es ihnen unmöglich macht, >einfach gesagt< zu werden. Da nun beide Figuren dem besagten, als >alt< gekennzeichneten Teilraum angehören und da Eisenhardt nicht singt, muss gefolgert werden, dass der Text diese Eigenschaft ebenfalls als >alte< Kommunikationsform ausstellt - und dies teilt er im Übrigen mit anderen Texten der Korpora A, B und C, die mehr oder weniger alle die innertextuelle Produktion von Lyrik durch die Figuren mit der > Vergangenheit<korrelieren. Die Eigenschaft zu singen und Lyrik zu produzieren, entspricht einer antiquierten Anthropologie oder einer Anthropologie der Regressivität. ${ }^{20}$

Fontanes Text weist vier Lieder auf, die durch die Handlung motiviert und entsprechend innerdiegetisch integriert sind (nicht also etwa als bloße Mottos zu Kapitelanfängen fungieren). Alle haben gemein, dass sie einer psychischen Problemlage entspringen, die die Figur als solche erkennt und nicht anders als in Liedform zu verarbeiten weiß. Ferner finden sich in allen Texten Entsprechungen von Personen der fiktiven Realität wieder: Rudolph singt über Clara, Clara über Rudolph. Lyrik verarbeitet folglich Realität und entwickelt im Zuge dessen alternative Welt-, Figuren- und Zukunftsentwürfe. Die Funktion der Lieder ist demnach offensichtlich: Sie dienen der selbsttherapeutischen Kompensation zwischenmenschlicher Problemlagen im künstlerischen Ausdruck. Bezeugt wird dies etwa durch die Einbindung des Motivs der Harfe: Sobald Rudolph »seines entsetzlichen Unglücks bewußt « (ebd.: 11) wird, greift er »von wildem Schmerze gefoltert, wild in die Saiten «; er entlockt dem Instrument Disharmonien, »um zu ermessen, ob irgendein Ton auf der Erde unharmonischer zu klingen [vermag] wie eine Saite in seinem Herzen«. Hauptsächlicher Produzent ist denn auch mit drei Liedern Rudolph; zumindest eines der Lieder stammt von Clara.

\footnotetext{
${ }^{20}$ Man denke beispielsweise auch an die Venezianischen Novellen Gaudys. Lyrik findet sich nur an zwei Stellen. In Liebeszauber ist sie explizit verbunden mit einer alten Hexe, die den Liebeszauber vollzieht. Mit ihrer Hinrichtung am Ende tilgt der Text sein wunderbares Element und damit Lyrik und unternimmt zugleich die Abkehr von romantischen Regulationsmechanismen im Umgang mit Problemen der dargestellten Welt. In Schloß Pizzighetone verzichtet die Erzählinstanz auf die Wiedergabe eines Liedes, das die Sängerin lediglich improvisiert und wohl mehr schlecht als recht umsetzt - auch dies ist als Prosaisierungsstrategie zu deuten.
} 
In dem letzteren (Lied II) wird Claras Wunsch offenbar, sich von der Herkunftsfamilie zu lösen und einen neuen Lebensabschnitt anzusteuern. Sie ist an dieser Stelle klar progressiv ausgerichtet. Zutage tritt auch das aus ihrer Sicht zentrale Problem, das sie an ihrer Loslösung hindert: Die Blindheit des Bruders und seine Bedürftigkeit.

Welch ein Wunder! Ist es Täuschung?

Nein, es kann nur Wahrheit sein,

Um das Haupt des blinden Bruders

Leuchtet mild ein Heil'genschein.

Um Verzeihung will ich beten

Vor dem Engelsangesicht,

$\mathrm{Da} \beta$ im wilden Herzenskampfe

Liebe siegte über Pflicht.

Ach, so soll ich ihn verlassen!

Oh, mein Gott, er ist ja blind,

Schwester, Mutter, Liebe - alles

Fehlte dann dem blinden Kind.

Himmel! Wie so engelsmilde

Er so plötzlich auf mich blickt;

Doch es waren wohl nur Grüße,

Die der Mond mir zugeschickt.

Aber nein, in seinem Auge

Glänzt das wunderbare Licht,

Segensvoller, freudereicher

Strahlt mir selbst die Sonne nicht.

Gott, wie groß doch deine Werke

An mir schlichtem Mädchen sind,

Ach, nun steht die Welt mir offen,

Rudolph ist ja nicht mehr blind. (Ebd.: 18) 
Getragen von einem christlich-religiösen Duktus und in gleichmäßig vierhebigem Trochäus sind hier bemerkenswerte Relationierungsmaßnahmen zu beobachten. Clara versieht Rudolph mit Insignien eines Heiligen und Überirdischen. Damit überhöht sie einerseits ihren Bruder ins Übermenschliche, sie zeigt damit andererseits die hohe Notwendigkeit der eigenen Fürsorge an und hebt auf ihr Hauptproblem ab, das im Vers »Liebe siegte über Pflicht« aufgeht: Liebe und Pflicht sind unvereinbar; sie stehen in oppositioneller Relation. Die Pflicht bindet sie an den Bruder, Liebe allerdings erfordert deren Auflösung und das Verlassen des Bruders. Clara befindet sich also in der Konfliktlage, dem Wunsch auf Liebeserfüllung nachgehen zu wollen und zugleich über ihre Verpflichtung gegenüber dem Bruder bewusst zu sein. Aufgelöst werden kann diese Inkonsistenz nur durch die Tilgung der selbstauferlegten Pflicht, was gottgelenkt mit der Transformation vom Blinden zum Nicht-Blinden vollzogen wird. Im Lied erübrigt sich Claras Problem, ihrem Wunsch auf Öffnung der Welt und Liebeserfüllung wird entsprochen.

Allein: Die Erzählinstanz relativiert das Gesagte und klassifiziert es als bloßen Wunschtraum der Figur ohne Wahrheitsgehalt in der Wirklichkeit: »Ihre überreizte Phantasie machte sie glauben, der heißeste ihrer Wünsche sei in Erfüllung gegangen, und von der Überzeugung beseelt [...] umschlang sie jetzt in geistiger Trunkenheit - oh, arme Clara - den noch immer blinden Rudolph « (ebd.). Claras Äußerung ist mithin realitätsbezogen, zugleich aber realitätsinkompatibel. Die getätigten Propositionen haben nur teilweise Entsprechungen in der dargestellten Wirklichkeit, insbesondere aber nicht in den für das geschwisterliche Verhältnis und zur Lösung des Figurenkonflikts entscheidenden Punkten.

Rudolphs Texte sind ähnlich konstituiert, jedoch mit anderer intentionaler Ausrichtung und anderem Status in Bezug auf die Wirklichkeit. In seinem ersten Lied (I) etabliert er die für ihn wichtige Dichotomie von Ich und Welt, im zweiten (III) baut er diese Dichotomie aus und überträgt sie auf das figurative Dreiecksverhältnis, im dritten (IV) besingt er seine Todessehnsucht. Zunächst vergleichbar sind die Texte I und III: Beide drehen sich thematisch um die eigene Situation und die Schwester. Lied I ist wie auch Claras Text durch vierhebige Trochäen strukturiert; die Geschwister singen im Gleichmaß.

Selbst die dunkelste der Nächte

Sieht am Morgen wieder Licht,

Nur der düstren Nacht des Blinden

Harrt das Licht des Tages nicht. 
Menschenleer war's noch auf Erden,

Gott, da schufst du schon das Licht,

Und du lässest Blinde werden!

Höhnt das deine Weisheit nicht?

Laß mich einmal nur erschauen

Deiner Augen Sternenlicht,

Und ich will dir ganz vertrauen,

Länger zweifeln will ich nicht.

Laß mich in Claras Herz mich lesen,

Zeige mir ihr Angesicht,

Ja, du bist ein höchstes Wesen,

Einen Zweifel gibt es nicht. (Ebd.: 16)

Die Dichotomie von $>$ Ich $<$ und $>$ Welt $<$ macht die Sprechinstanz am Gedanken der Theodizee fest: Wie kann es sein, dass in der besten aller Welten Blinde existieren, wenn doch Gott gerade mit seiner ersten Handlung in der Genesis Licht erschuf, das der Blinde nicht wahrzunehmen imstande ist? Der christliche Grundzug ist demnach wie bei Clara vorhanden, gleichwohl in anderer Funktionalisierung. Denn Rudolph belässt es nicht bei seinem Zweifel, sondern knüpft an den Beweis der Existenz Gottes die Forderung nach Einblick in Claras Innenleben, genauer: die Forderung, »in Claras Herz [zu] lesen«. Die Fähigkeit des Lesens impliziert den Vorgang der Decodierung von Zeichen; das Herz ist im kulturellen Wissen als Symbol für die Liebe und Topos des Gefühls abgespeichert. ${ }^{21}$ Wenn also Rudolph fordert, in Claras Herzen lesen zu dürfen, dann deutet das auf eine tiefe Verunsicherung in Bezug auf Clara hin wie auch auf den Kontrollzwang, dem Rudolph unterliegt. Er möchte sich über die Gefühle seiner Schwester Klarheit verschaffen, als ob ihm schwante, dass die geschwisterliche Verbindung auf der Kippe steht. Clara jedenfalls lauscht dem Lied Rudolphs und erstarrt. Sie wird an dieser Textstelle erstmals mit >Tod $<$ in Verbindung gebracht $(»[\mathrm{~s}]$ tarr und regungslos«; ebd.:

\footnotetext{
${ }^{21}$ Vgl. etwa den Eintrag im Damen Conversations Lexikon (1835: 273): »Herz, die Oppositionsseite gegen den Verstand, in seiner Thätigkeit Gefühl gegen Klugheit, Gemüth gegen Ueberzeugung. Wie das Gehirn die Werkstätte der Gedanken, ist das Herz die der Empfindungen, die geläutert durch den hineinfallenden Sonnenstrahl der Vernunft, zu Gefühlen sich steigern. - Weibliches Herz s. Gemüth.«
} 
17). Ihr Geheimnis zeigt an, dass dem Verhältnis tatsächlich eine Veränderung bevorsteht.

Lied III singt Rudolph nach Offenbarung der Liebe Claras zu Eisenhardt. Es baut sich erneut über den Gegensatz von Ich und Welt auf, wobei besonderes Augenmerk auf der Hochzeit und der Tragfähigkeit der Ehe liegt. Die Sprechinstanz nimmt dabei zunächst nur eine Beobachterposition ein, ist dann jedoch selbst involviert - und verfährt nunmehr in jambischem Versmaß.

Der Lerche Lieder tönen

So voller Freud' und Lust,

Als wollten sie verhöhnen

Den Schmerz in meiner Brust.

Sie kann gar fröhlich singen,

Weil ihr das Leben lacht,

Mir wird es nie gelingen

Nach einer solchen Nacht.

Es tönten Orgelklänge

Mit feierlichem Laut,

Da schritten durchs Gedränge

Der Bräut'gam und die Braut.

Ich suchte ihre Herzen,

Doch ach, sie hatten keins,

Nicht Liebeslust, noch Schmerzen; -

Da schlug die Glocke eins.

Und sieh, am Hochzeitslager

Erblickt' ich jetzt die Braut,

Der Bräut'gam, blaß und hager

War schon ihr angetraut.

Er hielt sie fest umschlungen, 
Dann hört' ich einen Schrei,

Der mir das Herz durchdrungen; -

Da schlug die Glocke zwei.

Und durch des Tores Pforte

Zog jetzt ein Trauerzug

Der still zum Friedensorte

Die tote Braut nun trug.

Ich fragte herzzerrissen:

Wo denn der Gatte sei?

Doch wollt' es keiner wissen; -

Da schlug die Glocke drei.

Und ehe neue Bilder

Mir Leib und Seel' erschreckt,

Die wild und immer wilder

Den Wahnsinn wohl geweckt,

Enfloh ich meinem Lager,

Doch nicht der Angst und Not,

Mir folgte, blaß und hager,

Ihr Gatte jetzt - der Tod. (Ebd.: 23 f.)

Angesichts der nun für ihn und seine Schwester neuen Situation entwirft Rudolph eine dystopische Zukunftsvision, die durch den Tod geprägt ist. Bemerkenswert daran ist zweierlei: Erstens generalisiert er die Sachlage vermittels Verwendung der Lexeme >Braut< und >Bräutigam $<$; zweitens ist die allgemeine Bedrohung, die von der Vereinigung von Mann und Frau in der Ehe ausgeht, auch temporal codiert (»Glocke«). Dabei wird die Problematik als massiv gefährdend markiert und zeitlich ausdifferenziert: $\mathrm{Zu}$ einem Zeitpunkt t1 geht es noch feierlich zu, wenngleich die Sprechinstanz - die nun hier interessanterweise imstande ist, in die Herzen zu blicken - den Brautleuten jedwedes Gefühl abspricht. In t2 
offenbart sich eine besondere Semantik des Bräutigams (»blaß und hager«); die Braut erleidet den Tod durch seine Hand. In $\mathrm{t} 3$ wird die tote Braut zum Friedhof gebracht, der Gatte ist verschwunden, die Sprechinstanz wird in den Zustand der Zerrissenheit (»herzzerrissen«) versetzt und - noch vor Ausbruch des Wahnsinns - ebenfalls vom Gatten $(\approx>$ Tod $<)$ verfolgt.

Rudolphs lyrisches Zukunftskonzept sieht demnach Negation durch Tod vor und beruht auf der Gefahr sexueller Liebe ausgehend vom Mann, die - sofern man diese Übertragung vornimmt - gleichermaßen Clara und Rudolph in existenzieller Hinsicht betrifft. Sein Konzept steht demjenigen Konzept Claras und Eisenhardts gegenüber, die jenes nicht lyrisch kommunizieren, sondern im direkten Gespräch mit Rudolph zu klären suchen, indem sie für die Neukonstellation bestehend aus Ehepaar und Bruder plädieren. Wenn Clara mit ihrem Ablösungsversuch wie auch dem Versuch der Realisierung ihrer Liebe zu Eisenhardt zumindest zwischenzeitlich ein anthropologisches Konzept der Goethezeit ansteuert, so muss - das wird an dieser Stelle deutlich - für Rudolph ein neues anthropologisches Konzept angenommen werden, das dem der Goethezeit entgegensteht und die Familie als ranghöchsten Wert definiert. Und ebendieses Konzept klassifiziert der Text als gültiges. Denn während Claras künstlerisch getätigte Aussagen zwar realitätsbezogen, aber realitätsinkompatibel sind, so referieren Rudolphs Aussagen nicht nur ebenfalls auf die Wirklichkeit der Figuren, sondern formieren zugleich eine zukunftsgewisse Prolepse - gleichwohl im hyperbolischen Sprachmodus. Rudolphs Text ist realitätsbezogen und realitätskompatibel. Seine Prophezeiung tritt im Kern tatsächlich ein.

Bestätigt wird dies im letzten Lied. Lied IV folgt als Reaktion auf den Verlust der Schwester: Das Leben erscheint nicht mehr lebenswert; mit dem Tod ersehnt er Glück und `Erwachen<. Den erneuten Situationswechsel zeigt der Text durch eine dominant daktylische Struktur mit lose jambischem Einschlag an.

Wie ist mein ewiges Leben,

Dies Leben voll Kummer und Not?

Es ist wohl die Parze gestorben,

Und tot ist wohl endlich der Tod!

Ach, Vater im Himmel - ich flehte

Vergeblich noch immer zu dir,

Die letzte Bitte - zu sterben, 
Versagst du auch diese noch mir?

Du drücktest doch, wie einem Toten,

Die Augen auf ewig mir zu,

So übe nun endlich Erbarmen

Und gönne dem Toten die Ruh.

Dann kämen die lachenden Erben

Und scharrten gar hurtig mich ein,

Und schmausten im Trauerhause

Bei Leichenkuchen und Wein.

Verteilten zuerst meine Habe,

Zuletzt gedächten sie mein,

Und weinten - vor Freude, und sprächen:

>Der Gute wird glücklich sein.く

Dann aber erwacht' ich im Grabe

Und lachte und jubelte laut,

Weil ich mit erblindeten Augen

Das menschliche Herz noch durchschaut. (Ebd.: $31 \mathrm{f}$.)

Abermals geht es um die richtige Einschätzung des Gefühlslebens durch den Blick in das menschliche Herz. Und setzt man die Anthropologie, die dieser Text Rudolphs entwirft, in Verbindung mit den Mechanismen der dargestellten Welt in Geschwisterliebe, so soll die Figur auch hier Recht behalten. Tatsächlich heißt es ja in der Schlusswendung: »Dort oben haben sie endlich die stets und treu Geliebte wiedergefunden, ihr heißes Sehnen gestillt und jeden Trennungsschmerz in der seligen Vereinigung mit ihrem Clärchen vergessen.« (Ebd.: 39) Ebenso also wie Rudolphs Text Leben mit >Tod und Tod mit 〉Leben « verschränkt, verfährt auch Fontanes Text zuerst mit der schon im Leben stoten<Clara und 
mit der abschließenden Installation des topologisch >oben< situierten Jenseits und der Harmonisierung der Figuren. Das Leiden im Diesseits wird durch Seligkeit und Sehnsuchtsstillung substituiert. Die von Rudolph proklamierte Verfassung des Menschen ist dabei durchaus ambivalent, handelt es sich doch - das letzte Lied unterstreicht dies eindrücklich - um eine betont pessimistische Anthropologie, die als gültige gesetzt wird. Zwar erweist sich seine Einschätzung der Lage als richtig, sein Denken, Handeln und Fühlen erweisen sich als die für den Text insgesamt repräsentativen Formen - allerdings kann dies keinen Bestand im Diesseits der Welt haben und wird ebenfalls getilgt.

Führen wir die Überlegungen zusammen: Das Geschwisterpaar ist Brennpunkt der Problemverhandlung im Text. Besonderer Beachtung bedarf Rudolph, der als Figur mehrfachcodiert auftritt: Zum einen ist er - wie seine Schwester auch - dem semantisierten Raum des $>$ Alten $<$ in einem modernisierten Umfeld zugeordnet und folglich temporalsemantisch als >alt< gekennzeichnet. Zum anderen aber vertritt er in seinem Verhalten teils eine nicht alte - das heißt: bekannte, verinnerlichte oder konventionalisierte - Anthropologie, sondern vielmehr eine neue, die, sobald Veränderungen auftreten, massiv regressiv ausgerichtet ist und als Zukunftskonzept die Re-Installation des Ausgangszustandes fordert. Darüber hinaus scheint die Produktion von Lyrik einerseits allein dem Teilraum, dem Rudolph und Clara angehören, eigen zu sein und mithin ebenfalls ein altes Kommunikationsmittel darzustellen, andererseits aber vermag es Rudolph mit seinem Zukunftskonzept die Zukunftsmodellierung, wie sie Fontanes Text vornimmt, zu antizipieren ungeachtet der Tatsache, dass er, wie auch die beiden anderen Figuren, dennoch scheitert.

Die Verwendung von Lyrik wird also von der semantischen Tiefenstruktur aus als unzeitgemäße Kommunikationsform ausgewiesen, denn sie vermag es nicht, zwischenmenschliche Probleme zu lösen, noch ihre therapeutische Funktion zu erfüllen, die ihr die Figuren zuschreiben. Dennoch steht sie grundsätzlich in einem Wechselverhältnis zur Realität, die sie künstlerisch verarbeitet. >Regression< und >Progression < sind beide an das >Alte < gekoppelt und gehen im Problem der Paarbildung auf. >Regression< ist die dominante Struktur im Text; sie weist Gültigkeit auf, während progressives Handeln sanktioniert und als nicht zukunftsweisend ausgewiesen wird. Lyrik dient dabei grundsätzlich dazu, Wünsche zu äußern und eine Zukunft zu imaginieren. Mit den Wünschen der Figuren wird die reziproke Anlage von >Regression< und >Progression< deutlich, die im gemeinsam bewohnten topografischen Innenraum (des Alten) verankert ist, denn Clara strebt einen neuen Lebensentwurf an, Rudolph möchte in den alten zurückkehren. Allein die Unzulänglichkeit des Rückwärtsgewandten wird dadurch angezeigt, dass ihm 
zwar im Abgleich mit der Realität Gültigkeit zugeschrieben wird, es zugleich aber für das Diesseits keinen Fortbestand erzeugt, sondern gleichfalls stirbt.

Die Zukunft, die der Text modelliert, ist polysem - und doch auch diesseitig gekappt. Tragischerweise sind alle offerierten Zukunftskonzepte mit der Modellierung von >Zukunft< vereinbar - jedoch nur nach Abzügen oder in Form raumsemantischer Verlagerungen. Rudolph sieht den Tod nach der Aufgabe des geschwisterlichen Idylls voraus. Sein Wunschkonzept aber besteht ja in der erneuten Vereinigung mit der Schwester, die der Text ihm schließlich doch noch gewährt. Clara konzipiert ein nicht realisierbares Dreiecksverhältnis, das denn ebenfalls doch - allerdings im Jenseits - zustande kommt. Wir sehen: Der Umgang mit Veränderungen in der Gegenwart, die Modellierung von >Vergangenheit< und auch die Gestaltung von >Zukunft< ist - gleichwohl hier die Oberfläche trügen mag - höchst problematisch. Und diese Problematik formiert ein Kernelement derjenigen Zeitstruktur, die um >Regression< und >Progression< aufgebaut ist.

Weiten wir den Blick über das Einzelbeispiel hinaus aus, dann lässt sich erkennen, dass das Textkorpus noch dankbarere, da eindeutigere Fälle liefert zum Beispiel die Texte Tiecks. Sind etwa die Erzählungen des Phantasus in der Regel noch durch teils umfangreiche Gedichteinlagen bespickt (zum Beispiel in Der Runenberg und Liebeszauber), weisen hingegen Texte der 1820er- und 1830er-Jahre - Die Reisenden, Der fünfzehnte November, Die Ahnenprobe, Die Klausenburg - zum großen Teil gar keine lyrischen Passagen mehr auf. Vielmehr gilt auch hier: Wenn Lyrik zum Einsatz kommt, dann ist sie mehrheitlich zur Darstellung regressiven oder gar goethezeitlich-codierten Handelns, Fühlens, Denkens und Sprechens funktionalisiert, wie in Der Mondsüchtige, Waldeinsamkeit oder Des Lebens Überfluß. In Waldeinsamkeit haben wir es mit einer an der Romantik orientierten, folglich mit einer regressiv konzipierten Figur zu tun, die durch ihre von außen forcierte Versetzung in eine >romantische Situation< einen Einstellungswandel vollzieht und im Endzustand eine quasiromantische Lebenssicht mit konventionellem Eheleben versöhnt. Zuvor wird der Protagonist Ferdinand als Schwärmer semantisiert und als nicht heiratsfähig, das >Romantik< in der (eindeutig nachromantischen) Gegenwart der Textwelt mit Krankheit korreliert, als antiquiert gedacht und verlacht. Die Regressivität der Figur zeigt sich auch darin, dass Ferdinand während seines Aufenthaltes in der einsamen Waldhütte Lyrik gleichsam nur zu reproduzieren vermag: Er überträgt lediglich die »Gläsernen Gedichte« in ein Buch, die ein anderer in die Fensterscheibe geritzt hatte - nicht aber dichtet er selbst. Der rekurrent explizite Verweis auf den Ausdruck >Waldeinsamkeit< wie auch die Zitation des Gedichtes unterstreichen die notwendige Bezüglichkeit des nachgoethezeitlichen Literatursystems 
auf die Romantik, die deutlich als Rückbezug markiert ist und die Modifikation des Romantischen ebenfalls als notwendiges Merkmal ausstellt. Nicht nur konfiguriert das Gedicht in komprimierter Form und durch den Einbezug in den Handlungskontext die Reziprozität von >Regression < und >Progression $<$, auch zeigt es von Beginn an die Rückwärtsgewandtheit ebenfalls von Sidonie an, die folgerichtig den Anteil des >Romantischen $<$ in ihrer Beziehung zu Ferdinand am Ende zu akzeptieren bereit ist - während hingegen der falsche Freund Helmfried von Beginn an eine skeptische Haltung zur Romantik einnimmt, ihre Mechanismen und Kennzeichen aber sosehr verinnerlicht hat, dass seine Intrige zunächst aufzugehen scheint und er durch Umfunktionalisierung des Romantischen beinahe zu triumphieren vermag. Er zitiert das Gedicht von der Waldeinsamkeit, um Ferdinand zu provozieren, und offenbart zugleich diese für den weiteren Handlungsverlauf wichtige Kenntnis.

Wiederum bei Eichendorff halten sich lyrische Formen innerhalb seiner Novellen durchgängig bis in die 40er-Jahre. Sie finden sich im goethezeitlichen Text Das Marmorbild ebenso wie in nachromantischen Texten wie Das Schlo $\beta$ Dürande, Die Entführung, Eine Meerfahrt und in seiner letzten Novelle Die Glücksritter. Insgesamt geht Eichendorff, dies lässt sich unter anderem an dieser Beobachtung ablesen, weniger offensiv mit dem Strukturwandel um als im anderen Fall Tieck. Doch aufschlussreich ist die Verwendung von Lyrik auch bei ihm. In Das Schloß Dürande greifen vornehmlich diejenigen Figuren auf lyrische Gesangseinlagen zurück, die temporalsemantisch als >goethezeitlich< oder >alt< semantisiert sind: Gabriele figuriert eine goethezeitliche Anthropologie, ihr Handeln ist mit dem Modell der Initiationsgeschichte fassbar - sie singt daher auch allenthalben über kecke Liebe, über die Loslösung von ihrer Familie, über ihre Sehnsucht zum Geliebten, über ihre Einswerdung mit der Natur. Auch die Nonnen, bei denen Gabriele zwischenzeitlich untergebracht ist, singen; sie werden als >altmodisch< bezeichnet, der Teilraum des Klosters wird im Zuge des revolutionären Ordnungsumsturzes ja dann auch getilgt. Renald singt seinerseits überhaupt erst im Zustand massiver Zerrissenheit und mit dem expliziten Beweggrund eines Wunsches auf Rückkehr in die »alte[] unschuldige[] Zeit« (Eichendoff 1993 [1837]: 461) - wobei ihm allerdings klar ist, dass die Vergangenheit vergangen und die Gegenwart hoffnungslos ist. Tatsächlich erhält er kurz nach seinem Lied Gewissheit über seine fatale Handlung und über den Tod seiner Schwester. Renald also bringt Lyrik hervor, sich selbst seiner Regressivität eingestehend; Gabriele und die Nonnen singen aufgrund ihrer Zugehörigkeit zum semantischen Raum >Vergangenheit $<$. Zwar wird im Text im Gegensatz zu Tiecks Waldeinsamkeit nicht explizit über die Romantik verhandelt, aber codiert und strukturell eingebunden wird dort Lyrik auf gleiche Weise. 
Angesichts der erörterten Sachlage wollen wir im Rahmen dieser Studie von einem Teilaspekt postromantischen Erzählens sprechen. Dieser Begriff meint Erzähllogiken, die einen metatextuellen Rekurs zur Romantik herstellen und romantische Verfahren, Muster und Modelle abrufen und diese durch die Kombination mit anderen Mustern als bereits konventionalisierte Formen inszenieren. Postromantisches Erzählen beschränkt sich nicht auf narrative Formen, die zeitlich nach der Romantik - seit den 1820er-Jahren - stehen, sondern umfasst primär Formen, die rückbezüglich sind und die Romantik auf einer nichtromantischen Folie als $>$ Romantik $<$ ausstellen, ihre Merkmale und Regularien verhandeln und als untragbar klassifizieren. Postromantisches Erzählen ist gleichbedeutend mit 〉Entromantisierung ‘. Der Einsatz von Lyrik zählt zu diesen Formen. Oberflächenstrukturell stellt sie einen Bruch im Erzählen dar: Prosa wechselt zu Lyrik; die in der Regel übergeordnet-nichtdiegetische Erzählinstanz wechselt über in einen dramatischen Modus der direkten Redewiedergabe. Tiefensemantisch ist Lyrik gebunden an die Anthropologie der Figuren. Zwei Modelle stechen mit Blick darauf ins Auge: (1) Figuren, die Lyrik produzieren, verhalten sich wie >Romantiker , sie werden in der dargestellten Welt als markiert goethezeitlich Handelnde gesetzt, die von ihrem Handlungsumfeld allerdings unverstanden bleiben. Weniger häufig und weniger offensichtlich sind auch solche Figuren mit Lyrik korreliert, die mit >alt< (oder Äquivalenten wie >altmodisch $<$ ) attribuiert sind. (2) Figuren, die Lyrik produzieren, applizieren lediglich (Zeichen-)Inventare der Romantik, sind aber bei genauerer Betrachtung nicht romantisch, sondern allein regressiv semantisiert: Sie streben in die Vergangenheit, wollen Vergangenheitszustände wiederherstellen, jede Form der Veränderung und des Fortschritts vermeiden und die Zukunft wie die Vergangenheit gestalten.

Für das rekonstruierte Gesamtmodell lässt sich konstatieren:

Lyrik in der Novellistik der Zwischenphase ist Bestandteil der Temporalsemantik der Figuren und semantisiert sie als goethezeitlich-romantisch und/oder sie ist ihrerseits postromantisch codiert und verweist auf die (latente oder offene) regressive Ausrichtung der Figuren im Konflikt mit progressiven Strukturen in gegebenen Textwelten. Lyrik kann daher als Oberflächenstrukturelement postromantischen Erzählens klassifiziert werden, insofern es auf discours-Ebene anzeigt, wie Texte mit der Romantik - die ihnen als Literatursubsystem bewusst ist - umgehen und sie in den eigenen Bedeutungsaufbau einbinden. 


\section{,Prärealistisches، Erzählen: Die narrative Retrospektive}

Ein weiteres discours-Phänomen ist augenfällig: die narrative Retrospektive, die Permutation der chronologischen Reihenfolge des ordo naturalis im Akt des Erzählens, wobei der Endzustand des Geschehens zu Beginn der Erzählung vorausgeschickt wird und die ursächlichen Zusammenhänge erst infolgedessen analeptisch nachgeliefert werden. Diese Form der literarischen Diskursivierung findet sich seit den 1830er-Jahren, in zunehmendem Maße dann in den 1840er-Jahren. Es lässt sich daran zweierlei erkennen: die Korrelation der Narrationsstruktur mit der regressiv-progressiven Verschränkungsstruktur und ihre entsprechende Funktionalisierung sowie die Antizipation und Vorwegnahme eines Denk- und Erzählmodells des Realismus. Angesichts der letzteren Annahme wollen wir von >prärealistischem< Erzählen sprechen, einem Erzählen, das aus Sicht der Literaturgeschichtsschreibung - neben anderen Aspekten (wie der Herausbildung der Dorfgeschichte, dem aufkommenden ethnologischen Interesse am $>$ Volk $<$ und der Ausbildung einer Sozialpsychologie) - in Relation zum Realismus steht, ohne selbst diesem Literatursystem anzugehören. ${ }^{22}$ Setzt man dies wiederum in Bezug zum erstgenannten Aspekt, so wird ein weiteres Spezifikum der Zwischenphase ersichtlich, das bereits mehrfach Erwähnung fand, nämlich, dass sich das Literatursystem der Zwischenphase selbst als >Phase des Übergangs< zu begreifen tendiert.

Auf unterschiedliche Varianten retrospektiven Erzählens und seinen Zusammenhang zur Reziprozität von >Regression< und >Progression< gehen wir im Folgenden ein. Das unverkennbare Charakteristikum des narratorial vorangestellten temporalen Teilelementes ist dabei zunächst:

\footnotetext{
${ }^{22}$ Der Begriff des >Prärealistischen < ist nicht unproblematisch und bedarf daher einer Erläuterung. Gemeint ist eine aus literaturhistoriografischer Sicht nachvollziehbare »Hinleitung zum Realismus, ohne daß [die betroffenen Autoren] selbst bereits - zumindest mit ihrer Produktion der vierziger Jahre - als vollgültige Realisten apostrophierbar wären.« (Lukas 1998b: 271) $>$ Prärealistisch< hebt damit auf ein Antizipationsmoment ab, auf Vorläuferstrukturen der sich in den 1850er-Jahren dann zusehends abzeichnenden Konstituierungsphase des Literatursystems >Realismus $<$. Jedoch ist für den vorliegenden Zusammenhang Folgendes hervorzuheben. Es geht um die Installation einer Vergleichsebene, nicht darum, Zwischenbereiche der Literaturgeschichte künstlich zu verwässern: >Prärealistische<Strukturen, wie hier behandelt, zeigen auf, dass semiotisch similare Einheiten funktional unterschiedlich aktualisiert sind. Bei aller Ähnlichkeit ist eben >prärealistisch $<$ ungleich $>$ realistisch $<$; die Vorläufer verhalten sich anders. Wir wollen meinen, dass sich so produktive Analysemomente mit Blick auf den Übergang zwischen beiden Literatursystemen herstellen lassen, die wir hier allerdings nur anzudeuten vermögen.
} 
Der Endzustand und damit die Zukunft des Erzählten wird durch seine exponierte Stellung zu Beginn des Textes relevant gesetzt. Mithin ist das Resultat der verschränkten Strukturprinzipien >Regression< und >Progression<von Wichtigkeit, das als Negation oder Negativierung von >Zukunft< semantisiert und ausgestellt ist.

Das Literatursystem liefert eine ganze Reihe an Beispielen. Bemerkenswert ist die besondere Ausprägung des Phänomens bei bestimmten Autoren, während andere hingegen gänzlich darauf verzichten. Für den letzteren Fall zu nennen wäre etwa Hebbel, dessen Texte sowohl der 30er- als auch der 40er- Jahre keine Entsprechungen aufweisen. Auf der anderen Seite sind die Texte Auerbachs und Stifters relativ häufig durch diese Strukturanlage geprägt. Auch bereits behandelte Texte reihen sich ein. Das Schloß Dürande etwa setzt wie folgt ein:

In der schönen Provence liegt ein Tal zwischen waldigen Bergen, die Trümmer des alten Schlosses Dürande sehen über die Wipfel in die Einsamkeit hinein; von der anderen Seite erblickt man weit unten die Türme der Stadt Marseille; wenn die Luft von Mittag kommt, klingen bei klarem Wetter die Glocken herüber, sonst hört man nichts von der Welt. In diesem Tale stand ehemals ein kleines Jägerhaus, man sah's vor Blüten kaum, so überwaldet war's und weinumrankt bis an das Hirschgeweih über dem Eingang; in stillen Nächten, wenn der Mond hell schien, kam das Wild oft weidend, bis auf die Waldeswiese vor der Tür. Dort wohnte dazumal der Jäger Renald, im Dienst des alten Grafen Dürande, mit seiner jungen Schwester Gabriele ganz allein, denn Vater und Mutter waren lange gestorben. (Eichendorff 1993 [1837]: 423)

Dieser erste Textabsatz ist deshalb aufschlussreich, da er nicht nur wesentliche Informationen über die Temporalsemantik ( $>$ Alt $<v s$. $>J u n g<$ ) und die Defizienz der Familie enthält, sondern schon mit Erzählbeginn einen Teil des diegetischen Ordnungswechsels vorwegnimmt: die Aufgabe nämlich des Feudalsystems. Mit dem Textende schließt sich der Rahmen: »Das sind die Trümmer des alten Schlosses Dürande, die weinumrankt in schönen Frühlingstagen von den waldigen Bergen schauen. - Du aber hüte dich, das wilde Tier zu wecken in der Brust, daß es nicht plötzlich ausbricht und dich selbst zerreißt.« (Ebd.: 465) Auch hier liefert der Text Bekanntes: Erneut weisen die Trümmer auf einen nicht zu behebenden Schaden, den die Geschehnisse hervorgebracht haben. Zugleich aber deutet die temporale Situierung der Erzählgegenwart im Frühling auf einen Neuanfang hin, mit dem das >Alte $<$ zurückgelassen wird. Bemerkenswert schließlich ist auch die Schlussformel, die geradezu programmatisch für die literarische Anthropologie der 40er-Jahre ist, indem sie die Unterdrückung der > wilden Natur $<$ im Menschen beziehungsweise dessen >Zähmung < fordert. 
Stifters Der Hochwald wiederum baut ein komplexes Zeitmodell auf (vgl. Abschn. 3.2) und verbindet seine zeitliche Erzählanlage mit der Differenzierung des Raums:

An der Mitternachtsseite des Ländchens Oesterreich zieht ein Wald an die dreißig Meilen lang seinen Dämmerstreifen westwärts, beginnend an den Quellen des Flusses Thaia, und fortstrebend bis zu jenem Gränzknoten, wo das böhmische Land mit Oesterreich und Baiern zusammenstößt. (Stifter 1980b [1842/44]: 211)

Eingeführt wird demnach also ein Grenzraum zwischen drei Ländern und ihm zugeordnet werden die Figuren der Geschichte, die die Erzählinstanz zu erzählen ankündigt (»wo die Personen dieser Geschichte lebten und handelten«; ebd.). Es folgt eine narratoriale >Durchwanderung des Gebietes; beschrieben wird unter anderem der See, der beim Rückzug der Schwestern eine Rolle spielen wird. Die Erzählinstanz offenbart sich als diegetische und kommt auf eine »zerfallene Ritterburg « zu sprechen:

Der Punkt, von dem aus man fast so weit als es hier beschrieben, den Lauf dieser Waldestochter übersehen kann, ist eine zerfalle Ritterburg, von dem Thale aus wie ein luftblauer Würfel anzusehen, der am obersten Rande eines breiten Waldbandes schwebet. Friedbergs Fenster sehen gegen Südwesten auf die Ruine, und dessen Bewohner nennen sie den Thomasgipfel oder Thomasthurm, oder schlechthin St. Thoma, und sagen, es sein ein uraltes Herrenschloß, auf dem einst grausame Ritter wohnten, weßhalb es jetzt verzaubert sei und in tausend Jahren nicht zusammenfallen könne, ob auch Wetter und Sonnenschein daran arbeite. Oft saß ich in vergangenen Tagen in dem alten Mauerwerke, ein liebgewordenes Buch lesend, oder bloß den lieben aufkeimenden Jugendgefühlen horchend [...]. (Ebd.: 215)

Wie schon in Eichendorffs Text ist die Rede von Ruinen, von Attributen des Alten und Uralten, von einer Burg oder einem Schloss, das in der Gegenwart, in der bezeichnenderweise ein jugendlicher Erzähler agiert, wie ein romantisierter Fremdkörper (»verzaubert«), als Überbleibsel einer >grausamenく Vergangenheit und eine Art Mahnmal behandelt wird. Der Erzähler wechselt vom Raum über in die Zeit:

Und nun, lieber Wanderer, wenn du dich satt gesehen hast, so gehe jetzt mit mir zwei Jahrhunderte zurück, denke weg aus dem Gemäuer die blauen Glocken, und die Maslieben und den Löwenzahn, und die andern tausend Kräuter; streue dafür weißen Sand bis an die Vormauer, setze ein tüchtig Buchenthor in den Eingang und ein sturmgerechtes Dach auf den Thurm, spiegelnde Fenster in die Mauern, theile die Gemächer, und ziere sie mit all dem lieben Hausrath und Flitter der Wohnlichkeit - dann, wenn Alles ist wie in den Tagen des Glückes, blank, wie aus dem Gusse des 
Goldschmiedes kommend -- dann geh' mit mir die mittlere Treppe hinauf in das erste Stockwerk, die Thüren fliegen auf - - - Gefällt dir das holde Paar? (Ebd.: 217)

Mit der weiteren Information, es handele sich um die »Zeit des dreißigjährigen Krieges« (ebd.), von der erzählt wird, lässt sich rückfolgern, dass das ErzählerIch in der ersten Hälfte des 19. Jahrhunderts situiert sein muss. Durch dessen Relationierung zum Erzählten wiederum muss angenommen werden, dass das mit dem erzählten Geschehen Implizierte ebenfalls in Beziehung zur unmittelbaren Gegenwart steht, in der der Text Der Hochwald verfasst worden ist. Auch hier also fungiert die Voranstellung der Zukunft des Erzählten - das seinerseits die Gegenwart des Erzählens formiert - nicht der bloßen fiktiven Ausschmückung der lokalen Dimension der erzählten Welt, sondern ist als Erzählstrategie mit Funktionspotenzial zu verstehen. Und zwar werden die Folgen, die die Geschichte nach sich zieht, in Form temporaler Zeichen in räumlichen Elementen anschaulich gemacht und implizit als Warnsignal ausgestellt, das auf die Gefahren der in der Binnenhandlung angelegten Anthropologie hinweist: Exogame Liebe wird angestrebt, aber getilgt, Endogamie hingegen als Wert gesetzt, zugleich aber als nicht nachhaltig gekennzeichnet.

Im wieder anderen Fall von Gutzkows Imagina Unruh heißt es:

Wer in Italiens gegenwärtigen Kunstzuständen heimisch ist, wird Gelegenheit gehabt haben, daselbst dem unbestrittenen Ruhm einer deutschen Malerin, der Gräfin Imagina von Wartenberg, zu begegnen. [...] Ihre Erfindungen sind allgemein gewürdigt. [...] In Blätterwerk, Arabesken, phantastischen Gruppirungen hat diese zarte weibliche Hand so viel Liebliches hervorgebracht, daß man nur die sonderbare Scheu und Aengstlichkeit beklagen muß, mit welcher die deutsche Künstlerin ihre Arbeiten der Welt verschließt und nur selten, nur vor ihr vertraut gewordenen Personen zu bewegen ist, ihre reichen, künftiger Bewunderung vorbehaltenen Mappen zu öffnen.

Gibt schon dieser Reiz des Geheimnißvollen der jungen und schönen Frau einen doppelten Zauber, so steigert sich dieser vollends zum Märchenhaften, wenn man mit der Lebensgeschichte einer noch so jungen Existenz vertraut wird. Wenigen nur mag diese Gunst des Zufalls zu Theil geworden sein. Daß Imagina von ihrem Gatten, dem Grafen von Wartenberg, geschieden ist, weiß alle Welt. Wegen einer an ihm begangenen Untreue behaupten Einige, wegen eines Misverständnisses Andere. Das wahre Sachverhältniß ist aber ein völlig anderes, wie die nachfolgenden Blätter beweisen werden. [...] (Gutzkow 1999 ff. [1847]: 3 f.)

Der Textausschnitt ist in dreierlei Hinsicht für unsere Überlegungen bemerkenswert. Erstens exponiert der Einstieg sein titelgebendes Subjekt, indem dieses direkt in den Fokus gerät und als exzeptionelles Künstlersubjekt vorgestellt wird. 
Zweitens rückt der Text dadurch auch $>$ Kunst $<$ als thematischen Komplex an zentrale Position und entfaltet selbstreflexives Potenzial. Drittens spielt auch dieser Text mit Zeit und Zeitlichkeit, denn vorweggenommen wird der Endzustand einer Figur mit ambigem Status. Als Künstlerin ist sie mit leichten Abstrichen zur Meisterin arriviert und als solche angesehen - als soziales Wesen, so wird deutlich, ist sie gescheitert. Daraus folgt mit Blick auf die modifiziert-romantische Künstlerfigur: >Zukunft< ist auch hier nur reduziert realisierbar; wobei der Text so funktioniert, wie seine Hauptfigur künstlerisch agiert: nämlich retrospektiv und regressiv - er etikettiert dies zugleich als literaturästhetisches Problem (vgl. Kap. 4).

Alle zitierten Texte rekonstruieren im Erzählakt >Vergangenheit<, die dadurch einen besonderen Stellenwert erhält. Ganz offensichtlich ist die dargestellte Gegenwart, von der aus erzählt wird, ohne die Vergangenheit nicht denkbar, zumindest aber ist sie erklärungsbedürftig: Es bedarf eines Rückblicks. Stets mehr oder minder stark ausgeprägt in dieser Hinsicht ist die Negativität der Gegenwart, die ja ihrerseits die Zukunft des Erzählten temporalstrukturell formiert. In Der Hochwald sind es die Ruinen des Schlosses, die einerseits als Ruderalfläche die Absenz eines ehemaligen Adelsgeschlechts anzeigen, andererseits verkommen sie zum Topos romantisierender Schwärmerei, der das Erzählersubjekt anheimfällt. Beides apostrophiert der Text als problematisch: In dem einen Fall wird `Zukunft< gar negativiert, da die Familie mit den beiden Schwestern gänzlich ausstirbt; in dem anderen ist es allein die ereignislose Statik von >Welt $<$ sowie die ausgeprägte Neigung des Erzählers, die Vergangenheit zu rekonstruieren. Letzteres unternimmt der Erzähler zumindest auch darstellerisch, indem er Gegenwärtiges sukzessive durch Vergangenes substituiert (»denke weg [...]; streue dafür [...], setze [...], theile $[\ldots]-$ dann, wenn Alles ist wie in den Tagen des Glückes $[\ldots]--$ dann geh' mit mir die mittlere Treppe hinauf in das erste Stockwerk, die Thüren fliegen auf - - - Gefällt dir das holde Paar?«; Stifter 1980b [1842/1844]: 217). Auch in Das Schloß Dürande signalisieren die Trümmer einen unglücklichen Geschehensverlauf, sie indizieren in diesem besonderen Fall zudem aber vornehmlich ein mit der Figurenhandlung einhergegangenes Metaereignis. Und schließlich führt ebenfalls Gutzkows Text eine reduzierte Form des Endzustands vor - obgleich einen nur verhältnismäßig reduzierten, keinen radikal reduzierten wie dies die Texte von Stifter und Eichendorff tun (Abb. 3.6).

Abermals haben wir es mit einer Skalierung, mit einer Auffächerung des Zukunftshorizontes zu tun. Hebbels Die Kuh ist zwar kein Beispiel für retrospektives Erzählen, der Text versinnbildlicht aber eindrücklich einen maximal reduzierten Endzustand des Erzählten und eine Extremform der Zukunftsnegation. Das Schloß Dürande und Der Hochwald negieren Zukunft ebenfalls, unterscheiden 


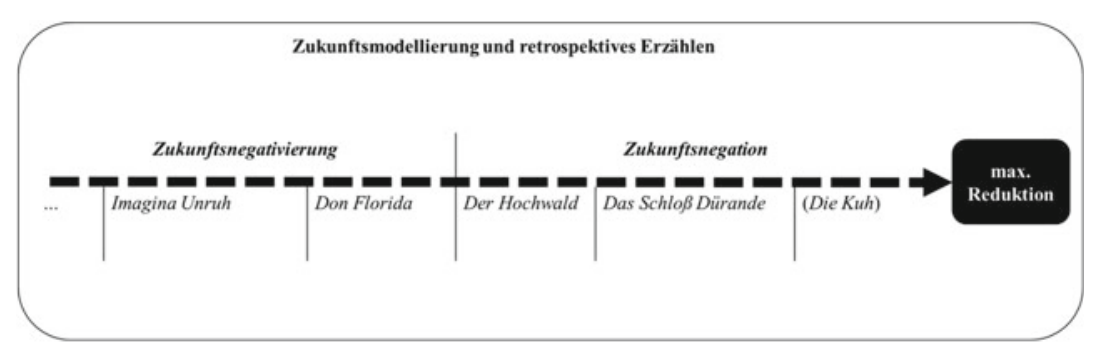

Abbildung 3.6 Negativität des Endzustands und retrospektives Erzählen

sich von Hebbels Text aber dadurch, dass sie überhaupt noch Leben thematisieren; beide wiederum trennt die Tatsache, dass die Erzählgegenwart in Der Hochwald >belebter< ist als es der nur kurze Blick der Erzählinstanz auf einen de-kultivierten (oder renaturierten) Raum in Das Schloß Dürande nahezulegen vermag. Jedoch tilgen auch sie die Figuren in einem ihrer Teilräume und attribuieren diesen mit dem Merkmal >vergangen< - ähnlich im Übrigen wie Auerbachs Des Schloßbauers Vesele, bei dem die gesamte Familie stirbt und die Hauptfigur - wahrscheinlich auch gestorben - verschwindet, oder wie Grillparzers Der arme Spielmann. Imagina Unruh und Don Florida wiederum negativieren Zukunft lediglich; die Hauptfiguren dürfen weiterleben. Sie müssen indessen Rückschläge hinnehmen. Vom Erzähler in Don Florida wird dies deutlich negativ erfahren der Tod seiner Geliebten stellt für ihn einen nachhaltigen Verlust dar, der bis in die Gegenwart nachwirkt - er erzählt daher die »Geschichte seines Unglücks« (Waiblinger 1981 [1828]: 230). Über Imaginas Gemütszustand im Endzustand erfährt der Leser nichts. Ausgehend vom letzten Zusammentreffen mit Otto von Sudberg aber ist davon auszugehen, dass sie mit sich im Reinen ist und ihr Dasein selbst nicht negativ wertet, gleichwohl sie natürlich vom gesellschaftlichen Leben ausgeschlossen ist. Zukunftsnegativierend (bei retrospektiver Erzählanlage) funktionieren weiterhin stärker Waiblingers Das Blumenfest und Grillparzers Das Kloster bei Sendomir, schwächer Immermanns Der Karneval und die Somnambule und Auerbachs Der Tolpatsch.

Der Unterschied zwischen Zukunftsnegation und -negativierung besteht demnach in der Attribuierung des Endzustands: in dem einen Fall als >ein Ende markierendく, in dem anderen als >über das Ende des Erzählverlaufs fortbestehend $<$; in dem einen Fall wird die Zukunft tatsächlich >gekappt $<$, in dem anderen lediglich >beschnitten<; in beiden Fällen ist sie ausgehend von der Figurenhandlung nicht oder nur mit Einschränkungen umsetzbar. Die Grenzen zwischen 
Negation und Negativierung gestaltet das Literatursystem fließend. Zukunftsmodellierung tritt skaliert auf - ganz im Gegensatz zur Goethezeit, wo das Literatursystem diesbezüglich durch Polarität gekennzeichnet ist: Scheitern wird als Scheitern inszeniert, Glücken eindeutig als Glücken.

Wenn demnach im Fall retrospektiven Erzählens stets eine Zukunft impliziert ist, die einem reduzierten Zustand äquivalent ist, dann ist damit auch ein weiteres Merkmal der spezifischen Ausformung von Zeitreflexion eruiert: Denn Texte dieser Menge setzen die Rekonstruktion von Vergangenheit um. Da sie dies deutlich exponieren, verfahren sie selbst - nicht nur ihre Figuren - regressiv und bilden damit eines ihrer tragenden Strukturmerkmale semiotisch ab: Die discours-Ebene verhält sich homolog mit der histoire-Ebene, der Signifikant homolog mit seinem Signifikat.

Texte der Zwischenphase, die durch retrospektives Erzählen gekennzeichnet sind, setzen auf discours-Ebene die Orientierung an der Vergangenheit relevant. Retrospektives Erzählen entspricht der Vergegenwärtigung einer Vergangenheit, die einer Krisenzeit äquivalent ist. ,Vergangenheit< wird dadurch zur dargestellten Gegenwart transformiert und als solche fokussiert. Dessen ungeachtet überlagert wiederum dieses Zeitsegment abermals eine dominante (Vor-)Vergangenheit, die zur ,Störung von Zeit< führt. >Prärealistisch ist diese Struktur deshalb zu nennen, da sie im Literatursystem des Realismus zu einer dominanten Form avanciert.

Von Ausnahmen wie Die schwarze Spinne oder auch Der tote Gast einmal abgesehen, tendiert das Literatursystem dazu, den Rahmen und damit die Rückblicksituation zu reduzieren und auf ein Minimum zu beschränken. Einerseits wird damit der Zustand syntagmatisch ausgestellt, der für die projizierte Zukunft ausschlaggebend ist. Andererseits wird dadurch diejenige Problemlage simuliert, die uns nur allzu bekannt ist: die Krisenhaftigkeit der Gegenwart, zu der die im Erzählen aufgerufene Vergangenheit umgestaltet wird. Entweder tun Texte dies ausgehend und primär geltend für die diegetische Erzählinstanz, deren persönlicher Antrieb es ist, >zurückzublicken< und die Vergangenheit narrativ zu rekonstruieren. Oder eine nichtdiegetische Erzählinstanz agiert retrospektiv, wobei $>$ Regression< allgemeingültig als Norm gesetzt ist. Verfahrenstechnisch unterscheiden sich also Der Hochwald, Die Mappe meines Urgroßvaters, Brigitta, Der arme Spielmann, Das Kloster bei Sendomir, Die schwarze Spinne und Don Florida mit diegetischer Erzählerfigur von solchen wie Das Blumenfest, Des Schloßbauers Vesele, Imagina Unruh und Das Schloß Dürande mit nichtdiegetischer Erzählinstanz. Die unterschiedliche Gestaltung mit diegetischer oder nichtdiegetischer Erzählinstanz allerdings ist indessen nur oberflächlich bedeutsam. Denn zwei Grundlinien sind allen Texten mit narrativer Retrospektive eingeschrieben: 
Texte (mit narrativer Retrospektive) folgen erstens dem Modell der Dominantsetzung von >Regression< und sie erheben >Regression<zweitens zu einem Richtwert, an dem der Aufbau und die Regularien der erzählten Welt ausgerichtet sind.

Fließende Übergänge zum Nachfolgersystem >Realismus< lassen sich mit einem kursorischen Blick auf Storms Immensee verdeutlichen. Oberflächlich sind die Textstrukturen, die wir bislang in den Blick genommen haben, von denen, die Immensee aufweist, nicht zu unterscheiden: Auch dieser Text erzählt retrospektiv und versieht sogar seine Hauptfigur zusätzlich mit der Eigenschaft, Lyrik hervorzubringen. Wir werden sehen: Unterschiede bestehen in anders gearteten Funktionalisierungen dieser Strukturen und liegen im Detail - dies macht denn aber auch plausibel, in unserem Zusammenhang durchaus von prärealistischen Ausformungen sprechen zu können.

Immensee ist neben anderen Texten - etwa Storms Posthuma (1851), Kellers Die Leute von Seldwyla (1856), Ludwigs Zwischen Himmel und Erde (1856), Raabes Chronik der Sperlingsgasse (1856) und Ein Frühling (1857) - als konstituierend für den Realismus anzusehen (vgl. Titzmann 2002b; Decker 2005a u. Nies 2007). Dabei ist das Zusammenspiel mehrerer Aspekte ausschlaggebend: Eine Problematik resultierend aus der Unterdrückung von Liebe und Erotik durch das männliche Subjekt bei gleichzeitiger Setzung von partnerschaftlichgeschlechtlicher Liebe als Sinnstiftungsmodell, zusätzlich auch die Verräumlichung innersubjektiver $>$ Räume $<$ und $>$ Grenzen $<$ (Bewusstsein vs. Unbewusstsein $)$, deren Überschreiten angedeutet wird, nicht aber vollzogen werden kann, und schließlich die Korrelation derjenigen Figuren mit Semantiken des Todes, deren Liebe nicht realisiert wird. Immensee verhandelt zentral die scheiternde Liebe zwischen Reinhardt und Elisabeth. In syntagmatisch chronologisch geordneten, aus unterschiedlichen Lebensabschnitten gewählten Zeiträumen wird dieses Scheitern oberflächlich zwar an eine soziale Motivation gebunden - Elisabeths Mutter, die auf eine alternative Partnerwahl mit Erich drängt -, zusätzlich aber wird es psychologisch motiviert: Reinhardt ist nicht fähig, Elisabeth seine Liebe zu gestehen: Er »konnte [...] sich des erlösenden Wortes nicht bewußt werden « (Storm 1987 [1850]: 312). Er scheitert infolge seines unbewussten Umgangs mit >Natur<, hauptsächlich an seiner Sexualität, die er mit zunehmendem Alter verdrängt und kulturell überformt. Das männliche Subjekt ist narrativer Fixpunkt und wesentlicher Problemherd zugleich. Denn gegenläufig zum bewusst motivierten Handlungsgang setzt der Text eine unbewusste Motivation, der Reinhardt nicht gewachsen ist:»Hier und anderswo definiert sich [...] das Subjekt der realistischen Literatur über sein Bewußtsein, das sich nach außen gegen die Umwelt, 
nach innen gegen ein Nicht-Bewußtes abgrenzt, um sich in totaler Affektkontrolle Autonomie und Autarkie zu beanspruchen« (Decker/Schwarz/Wünsch 1999: 35). Das Unbewusste hindert den Protagonisten daran, das zu realisieren, das er bewusst ansteuert - und ebendies erhebt Immensee zum Problem, insofern der Text nicht allein Bewusstes und Unbewusstes zeichenhaft abbildet - im titelgebenden See samt Wasserlilie -, sondern zudem die gescheiterte Figur im einsamen Alter mit >Tod< attribuiert.

Entscheidend zur Bestimmung einer Demarkationslinie zwischen Realismus (am Beispiel von Immensee) und der Zwischenphase ist der Umgang mit Liebe: Für den Realismus ist die Verdrängung, ja die Angst vor Sexualität signifikant, für die Zwischenphase die Äquivalenz unterschiedlich gearteter Liebe - die Gleichsetzung etwa von geschwisterlicher und partnerschaftlicher Liebe; für den Realismus der doppelläufige Problemkomplex bestehend aus der Unmöglichkeit geschlechtlicher Liebe und der Essenz der Paarbildung zur Gewährleistung persönlichen Glücks (oder zumindest des eigenen Fortbestehens), für die Zwischenphase der Kollaps individuellen Daseins aufgrund divergenter Werte- und Normensysteme, die das Handeln der Figuren in unterschiedliche Richtungen lenken. Semiotisch manifest werden diese Aspekte in den Struktureinheiten der Lyrikeinlagen sowie der narrativen Retrospektive.

$\mathrm{Zu}$ Immensee: Gedichte und Lieder spielen bereits in der Kindheit der Figuren eine Rolle, dann in Reinhardts Studentenzeit, schließlich auch beim letzten Zusammentreffen zwischen ihm und Elisabeth. Sie alle verhandeln das Verhältnis zwischen männlicher und weiblicher Figur und indizieren insbesondere Reinhardts Einstellung zu >Natur $<$. Das erste Gedicht, das er nach einer gemeinsamen Erdbeersuche anschließt, wird wie folgt eingeleitet: »Reinhardt hatte aber doch etwas gefunden; waren es keine Erdbeeren, so war es doch auch im Walde gewachsen « (Storm 1987 [1850]: 303 f.). Im Gedichttext selbst heißt es im letzten strophischen Abschnitt:

Der Kuckuck lacht von ferne,

Es geht mir durch den Sinn:

Sie hat die goldnen Augen

Der Waldeskönigin. (Ebd.: 304)

Reinhardt bindet Elisabeth in seinen Text - den er im Übrigen im Gegensatz zu den Figuren in Geschwisterliebe retrospektiv und nicht spontan hervorbringt und den er aufschreibt und nicht singt - ein, er transponiert sie in das rekurrent auftretende Zeichen »sie«. Des Weiteren belegt er »sie« mit »Natur - einerseits durch 
ihre Lokalsituierung im Naturraum, andererseits in der Korrelation mit der »Waldeskönigin «. Ein erster wesentlicher Aspekt hier wäre also die Funktionalisierung von Lyrik zwecks >Kultivierung von Natur . Gedichtet wird, um die menschliche Natur fassbar zu machen. Das 〉Etwas<, für das er in der zwischenmenschlichen Interaktion keine Worte findet, wird im lyrischen Text überformt und gelangt dort zum Ausdruck. Zuvor schon hatte Reinhardt ein Gedicht verfasst: »[D]arin verglich er sich selbst mit einem jungen Adler, den Schulmeister mit einer grauen Krähe, Elisabeth war die weiße Taube« (ebd.: 299). >Kultur« - hier: das Schulwesen - gilt als etwas Gegebenes und Dominierendes, >Natur $<$ - die Kinderliebe zwischen den Hauptfiguren - ist ebenfalls gegeben, bedarf aber eines gesonderten Kommunikationskanals. Das bestätigt von anderer Seite aus auch das Zigeunermädchen, das mit Hilfe eines Liedes Reinhardt auf die Momenthaftigkeit und Vergänglichkeit seiner Leidenschaft hinweisen muss: »Nur diese Stunde/Bist du noch mein« (ebd.: 305). Die vorherige Kommunikation zwischen beiden läuft dagegen fehl - das heißt, sobald >etwas zwischen Mann und Frau tritt, misslingt auch der verbale Austausch und man muss auf lyrische Rückgriffe ausweichen. Ist das Verhältnis hingegen quasigeschwisterlich - wie im Fall Erichs und Elisabeths (»schwesterliche[] Augen«; ebd.: 318) - gibt es folgerichtig kein derartiges Problem.

Mit diesem Aspekt verbindet sich die implizite Proposition des Textes, dass $>$ Kultur< und >Natur $<$ im Subjekt disjunkte Teilräume bilden, die miteinander zwar in Konflikt stehen, jedoch allenfalls im übertragenen Sinn einander gegenübergestellt werden können, sei es durch lyrische Texte, die die Figuren hervorbringen, sei es auf primärer Textebene durch den See, die Wasserlilie und die Ranken in der Tiefe des Wassers. Träger ist hier die Opposition Kultur vs. Natur, ${ }^{23}$ die auch an einem weiteren Umgang des Textes mit Lyrik deutlich wird: Einerseits sammelt Reinhardt im Erwachsenenalter Volkslieder - eine kulturelle Handlung -, andererseits semantisiert er Lieder als >natürliche Gewächse< und bedient sich dazu romantischer Topoi: »S Sie werden gar nicht gemacht; sie wachsen, fallen aus der Luft, sie fliegen über Land wie Mariengarn, hierin und dorthin« (ebd.: 320). Und: » Das sind Urtöne [...], sie schlafen in Waldesgründen« (ebd.: 321).

Der zweite Aspekt besteht in der Funktionalisierung von Lyrik als Ausweichstrategie. Während Storms Text Lyrik (wie auch das Erzählen; vgl. ebd.: 297 f.) in der Kindheit als Bindeglied zwischen Reinhardt und Elisabeth setzt, wird das im Text zuletzt zitierte Gedicht zum Keil, den Reinhardt zwischen sich selbst und

${ }^{23}$ Zur Ausgestaltung des Komplexes in Kellers Romeo und Julia auf dem Dorfe vgl. Titzmann (2002a). 
Elisabeth treibt. »Meine Mutter hat's gewollt« kann im gegebenen Handlungsrahmen als perfid eingesetzter Text gewertet werden - nicht allein, dass (implizit) Elisabeth als Sprechinstanz gesetzt und damit vermeintlich ihre Perspektive eingenommen wird; Reinhardt lenkt mit der Rezitation des Volksliedes zugleich vom eigenen Problem ab und betont überdeutlich die soziale Dimension der gescheiterten Paarbeziehung. Damit weicht er aber auch einer Auseinandersetzung mit der eigenen Fehlleistung aus und marginalisiert das eigentliche Problem. Ihm ist bewusst, dass er Elisabeth begehrt, nicht bewusst ist ihm, warum die Paarbildung scheitert. Im Unbewussten ist die Liebe zu Elisabeth allerdings durchaus vorhanden - daher produziert er - unbewusst gesteuert - Lyrik, um einerseits an die gemeinsame Verbindung in der Kindheit anzuschließen und um andererseits von der eigenen misslichen Persönlichkeitskonstitution abzulenken.

In beiden Aspekten unterscheidet sich Storms Text demnach von Texten der Zwischenphase. Erstens findet Lyrik in unserem Zeitraum nicht als Ausweichstrategie Anwendung, sondern wird katalysatorisch eingesetzt: Die Figuren bringen ihre eigene Situation zum Ausdruck und bezwecken damit die Realisierung einer Zukunft nach ihren Vorstellungen - ganz gleich, ob die Figur goethezeitlich semantisiert ist wie Gabriele in Das Schloß Dürande oder Wilhelm in Cordelia oder lediglich regressiv wie Rudolph in Geschwisterliebe oder Ronald in Der Hochwald oder gar >biedermeierlich wie Theobald in Cordelia; unabhängig auch von der Frage, ob die Figur damit Erfolg hat oder nicht. Zweitens geht es der Zwischenphase nicht vornehmlich um die Oppositionsbildung zwischen Natur und Kultur, ${ }^{24}$ sondern um die Semantisierung der Rückbezüglichkeit auf die Goethezeit. Das mag grosso modo auch noch für den Realismus (etwa bei Spielhagen und Fontane) zutreffen. Wenn Lyrik hier allerdings auftaucht, dann wird sie zwar wie dort zwecks Thematisierung einer Problemlage zwischen Frau/Jungfrau und Mann/Jüngling gebraucht, sie erhält darüber hinaus aber ein dezidiert metatextuelles Funktionspotenzial und steht im Kontext des Selbstverständnisses des Literatursystems als `Zwischenphase «. Lyrik wird in der Regel als unzeitgemäße Kommunikationsform semantisiert.

Retrospektives Erzählen in Immensee korreliert wie auch in der Zwischenphase Zeitreflexion und läuft wie auch dort auf die Modellierung einer negativierten Zukunft hinaus, eingeführt aber werden zudem zentrale Paradigmen, die für den Realismus insgesamt bezeichnend sind: die alte, solitäre männliche Figur, Erinnerung und der Tod. Mit Erzähleinsatz situiert der Text ein ereignisloses Geschehen

\footnotetext{
${ }^{24}$ Vgl. auch Titzmann (2017: 138), der die häufige Gestaltung von Grenzräumen zwischen $>$ Natur $<$ und $>$ Kultur $<$ postuliert.
} 
an einem »Spätherbstnachmittage« (Storm 1972: 295). Dann ist von »Abendsonnendufte« die Rede, schließlich davon, dass »es allmählich dunkler« wird und ein »Mondstrahl durch die Fensterscheiben« fällt; Reinhard erscheint als »alter« Mann mit »dunklen Augen« und »schneeweißen Haaren«, trägt Kleidung einer »vorübergegangenen Mode«, seine »verlorene Jugend« wird korreliert mit den Augen der Figur, dann mit Elisabeths kleinem Bild:

Wie er so saß, wurde es allmählich dunkler; endlich fiel ein Mondstrahl durch die Fensterscheiben auf die Gemälde an der Wand, und wie der helle Streif langsam weiter rückte, folgten die Augen des Mannes unwillkürlich. Nun trat er über ein kleines Bild in schlichtem schwarzem Rahmen. >Elisabeth!< sagte der Alte leise; und wie er das Wort gesprochen, war die Zeit verwandelt; er war in seiner Jugend. (Ebd.: 296)

Im abschließenden Rahmen scheint der Mond nicht mehr, die Szenerie ist noch dunkler und wird mit dem semantisierten Raum des Sees und der Wasserlilie in Verbindung gebracht, dessen Verschwinden in einer imaginierten Ferne im übertragenen Sinn den Erinnerungsverlust und den Verlust der Vergangenheit konfiguriert:

Allmählich verzog sich vor seinen Augen die schwarze Dämmerung um ihn her zu einem breiten dunklen See; ein schwarzes Gewässer legte sich hinter das andere, immer tiefer und ferner, und auf dem letzten, so fern, daß die Augen des Alten sie kaum erreichten, schwamm einsam zwischen breiten Blättern eine weiße Wasserlilie. (Ebd.: 328)

Im Zentrum des Erzählens steht also eine Verlustgeschichte. Unverkennbar sind die vielen Temporalzeichen, die die Figur als alten Menschen kennzeichnen, der nach der Einbuße seiner Liebe ebenso mit Zeichen des >Todes « versehen wird. Figuren, von denen aus das Erzählen motiviert ist, sind in der Regel nicht nur $>$ reduzierte< Existenzen, sie sind im Realismus sogar so sehr reduziert, dass sie buchstäblich mehr tot als lebendig erscheinen.

Immensee bringt demzufolge eine Reihe von Merkmalen in Anschlag, die für das literarische Erzählen im Realismus insgesamt von Bedeutung sind: die Bedeutsamkeit von >Vergangenheit< als rekonstruierte >Realität<, die Todesnähe und Sinnkrise des rückblickenden, alternden und solitären Subjekts, die Installation von Ehe und Familie als sinnstiftende Werte sowie die Erinnerung als Vorgang der Vermittlung zwischen Sinnstiftung und Sinnverlust (vgl. Decker 2005a; Blödorn 2019: 116-119 u. Blödorn 2020: 71 f.). Zeitreflexives Potenzial 
entfaltet der Text in seiner Relationierung von vorgelagerter Realität und literarischer Repräsentation; ${ }^{25}$ zentral ist die Erinnerung und das Erinnern - und damit retrospektives Erzählen - für die Konzeption der >Person< im Realismus (Abb. 3.7).

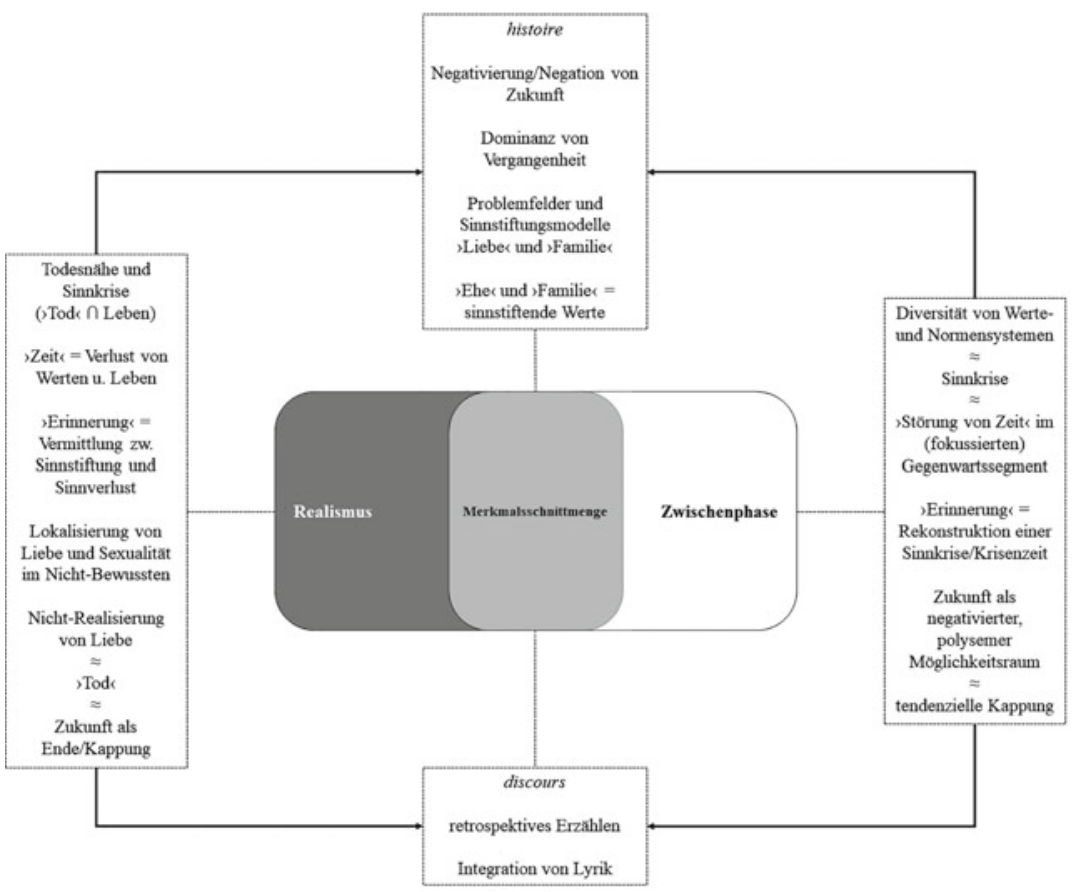

Abbildung 3.7 Realismus und Zwischenphase: Merkmalsgleichheit und Merkmalsunterschiede mit Blick auf retrospektives Erzählen

Während also die Merkmalsschnittmenge interepochale Gemeinsamkeiten (auf histoire- und discours-Ebene) aufzeigt, liegen Differenzen in zeitreflexiven Gestaltungsweisen: Erstens denkt der Realismus vom >Alten< ausgehend, insbesondere vom gealterten Subjekt - die Zwischenphase bis in die dreißiger Jahre hinein hingegen ausgehend vom jungen Subjekt; teilweise noch in den 1840er-Jahren

${ }^{25} \mathrm{Zu}$ einem mutmaßlich kardinalen Zeitreflexionskomplex im Realismus - in Form von >ZeitOasen< und Erzählstrategien der Verlangsamung - vgl. Rast (2018). 
(Auerbach), wo dann aber ebenso die Gegenüberstellung von jungen und alten Figuren (Der Hagestolz) salonfähig wird. ${ }^{26}$ Zweitens reduziert der Realismus sein Konzept von >Zukunft< - pointiert gesprochen - auf die Modellierung eines Endes und hebt zugleich im >lebenden Toten <, im »Tod als Zielpunkt des Lebens « (Blödorn 2020: 89), die Feindifferenz zwischen Negativierung und Negation auf. In der Zwischenphase hingegen dominiert ein breiter Zukunftshorizont: >Zukunft< ist durchaus noch denkbar, muss jedoch angesichts unterschiedlicher Wahloptionen, die zukunftsentscheidend sind, ausgehandelt werden. Insofern ließe sich der Realismus als Verschärfung bereits bestehender Modelle der Zwischenphase auffassen, der Übergang vom Realismus zur Zwischenphase in zeitsemiotischer Hinsicht als Verengung des Zukunftshorizontes. Hält man jedoch die jeweiligen Varianten retrospektiven Erzählens gegeneinander, so wird auch deutlich, dass die Zwischenphase mit ihrer Zukunftsnegation teils zu resoluteren Ergebnissen tendiert: Trümmer alter Gebäude und die Absenz des Figurenpersonals sind dahingehend vielsagend. Im Realismus betrifft das Ende zumeist nur Einzelne, nicht ganze (Teil-)Welten. Drittens ist retrospektives Erzählen der Zwischenphase an die Rekonstruktion einer Krisenzeit gekoppelt, im Realismus hingegen ist die Sinnkrise im Ausgangspunkt des Erzählens, dem alternden Subjekt verankert. Wenn >Zukunft< in der Zwischenphase negativierend gestaltet ist oder gänzlich negiert wird, so ist dies das Resultat einer Störung von >Zeit<, wie oben erläutert; die Sinnkrise im Realismus beruht im Gegensatz dazu auf der problematischen Konstitution der Figur, die das sinnstiftende Moment von Liebe und Familie zwar anerkennt, nicht aber Liebe verwirklichen kann.

\subsection{Reflexive Zeitstruktur II: Die reziproke, dynamisierende Koppelung von Regression und Progression}

Die zweite Zeitstruktur, die für die Zwischenphase von Bedeutung ist, fundiert im Kern in der Koppelung von $>$ Regression< und >Progression<, wobei der Zusammenstoß beider im (fokussierten) Gegenwartssegment akut wird und beide jeweils für die Zukunft Unterschiedliches vorsehen: Die Strukturmenge, die wir $>$ Regression< nennen, repräsentiert die Orientierung an der Vergangenheit, die Strukturmenge der >Progression $<$ die Loslösung von allen mit der Vergangenheit verbundenen Werten, Normen und Institutionen. Die Mengen sind reziprok.

\footnotetext{
${ }^{26}$ Aufgrund eben dieser Tatsache lässt sich Der Hagestolz eben auch als realistischer Text lesen und deuten (vgl. Blödorn 2020: $86 \mathrm{f}$.)
} 
Und diese Eigenschaft der gegenseitigen Bezüglichkeit erscheint als kardinales Signum des Literatursystems: Weil es vergangenheitsbezogene Tendenzen in Texten gibt, gibt es auch vergangenheitsverneinende Tendenzen und vice versa. Hauptsächlicher Verhandlungsgegenstand ist der Nexus temporaldeiktisch diametraler Vektoren.

Zeitstruktur II basiert - wie schon Zeitstruktur I - auf mehreren Teilkomponenten, deren Brennpunkt (Komponente 2) zwar den zentralen, jedoch nicht den einzigen Baustein ausmacht. Für ihre theoretische Fassung und heuristische Ausrichtung gelten dieselben Aussagen, wie sie für die Zeitstruktur I formuliert worden sind: Das rekonstruierte Teilmodell ist taxonomisch, nicht typologisch ausgerichtet; seine Komponenten sollen nicht typologisch-terminologische Fixierpunkte darstellen, sondern dienen dem Taxieren, der analytischen Abstraktion und heuristischen Auswertung; sie treten nicht isoliert, sondern gebündelt-komplementär auf (Abb. 3.8).

\begin{tabular}{|c|c|c|}
\hline \multirow{3}{*}{ Komponente 1} & a & Temporale Teilwelten \\
\hline & $\mathrm{b}$ & 〉Zeitstörung`, Krisenstatus des Gegenwartssegments \\
\hline & $\mathrm{c}$ & Konfrontation mit der Vergangenheit \\
\hline \multirow{2}{*}{ Komponente 2} & $\mathrm{a}$ & Regression vs. Progression \\
\hline & $\mathrm{b}$ & Dynamisierung der Leitsemantik \\
\hline \multicolumn{2}{|l|}{ Komponente 3} & Überlagerung zirkulärer und linearer Zeit \\
\hline \multicolumn{2}{|l|}{ Komponente 4} & Inkompatibilität von etischer, emischer und subjektiver Zeit \\
\hline \multirow{2}{*}{ Komponente 5} & $\mathrm{a}$ & Postromantisches Erzählen: Die Integration von Lyrik \\
\hline & $\mathrm{b}$ & Prärealistisches Erzählen: Die narrative Retrospektive \\
\hline
\end{tabular}

Abbildung 3.8 Übersicht über die Komponenten der reflexiven Zeitstruktur II

Ausgangspunkt dieses Kapitels war ein zweifacher: Erstens die Frage nach der Dynamisierung unserer Leitsemantik $>$ Alt $<v$ s. $>J u n g</>N e u<;$ zweitens die Frage nach Spielarten der konkreten Semiotisierung von >Regression $<$ und >Progression $<$.

Ausgegangen sind wir von dem Gedanken, dass $>$ Alt $<$ und $>$ Jung $</>\mathrm{Neu}<\mathrm{zwar}$ ein raumsemantisches Setting bilden, dieses Setting aber durchaus in Bewegung gesetzt und auf seine Tragfähigkeit hin abgewogen wird - ganz offensichtlich gemäß einem grundsätzlichen Prinzip des Erzählens insgesamt: dem Konsistenzprinzip ${ }^{27}$, der Tendenz, gegebene Inkonsistenzen aufzulösen. >Regression< und >Progression< stellen Dynamisierungsvorgänge dar, um einen inkonsistenten Zustand dar, wie er in Gegenwartssegmenten vorherrscht, in einen konsistenten

${ }^{27}$ Zur Erweiterung des Lotman'schen Modells und zum Konsistenzprinzip vgl. Renner (2004: $367 \mathrm{ff}$.). 
Endzustand zu überführen. Die erzählte Gegenwart ist der Zeitraum der Bewegung, des Schlagabtauschs zwischen >regressiven< und >progressiven< Struktureinheiten und daher mit einem Krisenstatus versehen. Dynamik entsteht ausgehend von drei Logiken, denen Texte der Zwischenphase generell folgen: (1) dem Aufbau temporaler Teilweltenmodelle (Komponente 1a), (2) der Semantisierung von Zeit als >Störung < (Komponente 1b), (3) der Auseinandersetzung mit der Vergangenheit (Komponente 1c). Hier offenbaren sich ostensive Schnittstellen zur reflexiven Zeitstruktur I: Die Krisenhaftigkeit des Gegenwartssegments und die Konfrontation mit der Vergangenheit betreffen das Literatursystem insgesamt und reichen über Texte, die die Initiationsgeschichte realisieren, hinaus. Ein besonderes Gewicht auf die Vergangenheit zu legen und die Protagonisten mit Überbleibseln, Relikten dieser Vergangenheit in der Gegenwart zu konfrontieren, ist daher einzeltextübergreifendes und signifikantes Merkmal - es wird sich auch noch in Zeitstruktur III wiederfinden lassen. $\mathrm{Neu}$ an Zeitstruktur II ist der Dynamisierungsaspekt (Komponente 2): Ob sich Altes und Tradiertes bewähren kann oder zugunsten alternativer Modelle fallengelassen wird, das wird im Rahmen der narrativen Ereignisstruktur ausgehandelt und mittels Umsemantisierung entsprechender Elemente (die mit >jung $<$, >neu $<$ oder >alt< attribuiert sind) >in Bewegung gesetzt $<$. Nicht die Leitsemantik >Alt<vs. >Jung < allein ist ausschlaggebend (die Ontologie der dargestellten Welt), sondern zusätzlich ihre Wertung vonseiten verschiedener Textinstanzen (die Figurenwahrnehmung und die Textideologie).

$\mathrm{Zu}$ ersehen sind Strukturmuster der >Regression $<$ und der >Progression $<$ in ihrer Projektion auf die Modellierung der Aktzeit und nicht zuletzt im Auseinanderdriften der Zeitdimensionen einer natürlichen Zeit, ihrer kulturellen Ausdeutung und dem subjektiven Zeiterleben (Komponenten 3 u. 4). Der Zug der >Regression< - und damit die gesonderte Untermauerung der Dominanz von $>$ Vergangenheit< - ist zusätzlich erkennbar im Einsatz von Lyrik und im retrospektiven Erzählen (Komponente 5). Auf Figurenebene lassen sich >regressive < und >progressive< Ausrichtungen in vier Feldern ausfindig machen - politisch-sozial, anthropologisch, sozialökonomisch und ästhetisch-kunstreflexiv -, alle diese paradigmatischen Alternativen überführen Texte stets in die Korrelation von Linearität und Zirkularität und erheben jene zum Problem: Das Zeitmodell der Linearität verläuft - unabhängig davon, ob sich Diskontinuitäten einstellen oder nicht (vgl. Zeitstruktur I) - gradlinig in die Zukunft. Figuren, die sich daran ausrichten, denken an eine Neuausrichtung der Zukunft und wollen sich von der Vergangenheit lösen. Das Zeitmodell der Zirkularität ist kreisförmig strukturiert: Die Vergangenheit ist derart dominant, dass für die Zukunft lediglich ihre Re-Installation vorgesehen ist. Der Krisenzustand der Gegenwart besteht darin, das eine oder das andere durchzusetzen - sei dies gewaltsam-forciert, kommunikativ-vermittelnd 
oder justiziabel-bestimmt. In jedem Fall streben Bewohner erzählter Welten in Texten der Zwischenphase die Auflösung der Überlagerung von >Regression< und >Progression< an, was eine Demarkierung des Zeitmodells zur Folge hätte.

Motiviert wird dies alles auch durch die Inkompatibilität der drei Zeitdimensionen, die Texte durchgehend aufrufen. Auffallend allein ist, wie häufig Zeit als Zeit thematisiert wird: Von Figuren, denen sie zu schnell oder zu langsam vergeht, von solchen, die jegliches Zeitgefühl verlieren, von wieder anderen, die die Gegenwart als >krank < oder die Vergangenheit als prosperierend bezeichnen und dabei immer wieder die Zukunft ins Auge fassen; oder auch auf übergeordneter Textebene, wenn von kulturellen Umbruchszeiten die Rede ist, von sich ständig wiederholenden Strukturen et cetera. Das Problem besteht darin, dass emische, etische und subjektive Zeit aus dem Gleichgewicht geraten, und sie tun dies aufgrund des klaren Einbruchs der Gegenwart gegenüber der Vergangenheit und äußern sich in >regressiven< und >progressiven< Vektoren, die zwecks Regulierung ausgefahren werden.

Lyrik dient stets der Figurensemantisierung. Eine Figur, die Lyrik spontan produziert, kommuniziert im goethezeitlichen Modus oder doch zumindest vergangenheitsorientiert und antiquiert. Teils agieren Figuren so, weil sie einen Zustand der Vergangenheit wiederherzustellen anstreben, teils weil sie Denk- und Handlungsmustern der Goethezeit folgen. Markiert wird lyrisches Sprechen in der Zwischenphase in jedem Fall als antiquiertes Sprechen - ohne, dass deshalb darauf verzichtet würde. Mit retrospektivem Erzählen weist das Literatursystem auf ein dominantes Verfahren des Realismus hin; es steht derweil aber ganz im Dienst der spezifischen Reflexion von Zeit, wie sie der Zwischenphase eigen ist. Denn neben der Orientierung an der Vergangenheit richtet es vorzugsweise den Blick auf das Zukunftssegment: Das Resultat regressiv-progressiver Kollision ist im Fall retrospektiven Erzählen ein negativierter oder gar negierter Zukunftszustand. Nehmen wir hinsichtlich dessen das Reduktionsprinzip, die >Tendenz zur Mitte<, den zukunftsbildenden Parameter der Liebe hinzu, so deutet sich im polysemen Zukunftskonzept, das für die Zwischenphase gleichfalls zentral ist, bereits auch schon die reflexive Zeitstruktur IV an - die Relationierung von Zukunftskonzept und Zukunftsmodell. 
Open Access Dieses Kapitel wird unter der Creative Commons Namensnennung 4.0 International Lizenz (http://creativecommons.org/licenses/by/4.0/deed.de) veröffentlicht, welche die Nutzung, Vervielfältigung, Bearbeitung, Verbreitung und Wiedergabe in jeglichem Medium und Format erlaubt, sofern Sie den/die ursprünglichen Autor(en) und die Quelle ordnungsgemäß nennen, einen Link zur Creative Commons Lizenz beifügen und angeben, ob Änderungen vorgenommen wurden.

Die in diesem Kapitel enthaltenen Bilder und sonstiges Drittmaterial unterliegen ebenfalls der genannten Creative Commons Lizenz, sofern sich aus der Abbildungslegende nichts anderes ergibt. Sofern das betreffende Material nicht unter der genannten Creative Commons Lizenz steht und die betreffende Handlung nicht nach gesetzlichen Vorschriften erlaubt ist, ist für die oben aufgeführten Weiterverwendungen des Materials die Einwilligung des jeweiligen Rechteinhabers einzuholen. 